Andrews University

Digital Commons @ Andrews University

\title{
Job Satisfaction as a Function of the Five Factor Model of Personality in the Community Mental Health Center Environment of Northern Indiana
}

Robert Ryan

Andrews University, ryanr@andrews.edu

Follow this and additional works at: https://digitalcommons.andrews.edu/dissertations

Part of the Community Psychology Commons, Counseling Psychology Commons, and the Personality and Social Contexts Commons

\section{Recommended Citation}

Ryan, Robert, "Job Satisfaction as a Function of the Five Factor Model of Personality in the Community Mental Health Center Environment of Northern Indiana" (2020). Dissertations. 1726.

https://digitalcommons.andrews.edu/dissertations/1726

https://dx.doi.org/10.32597/dissertations/1726

This Dissertation is brought to you for free and open access by the Graduate Research at Digital Commons @ Andrews University. It has been accepted for inclusion in Dissertations by an authorized administrator of Digital Commons @ Andrews University. For more information, please contact repository@andrews.edu. 


\section{ABSTRACT}

JOB SATISFACTION AS A FUNCTION OF THE FIVE

FACTOR MODEL OF PERSONALITY IN THE COMMUNITY MENTAL HEALTH CENTER ENVIRONMENT

OF NORTHERN INDIANA

by

Robert Ryan

Chair: Dennis Waite 


\title{
ABSTRACT OF GRADUATE STUDENT RESEARCH
}

\author{
Dissertation
}

Andrews University

School of Education

\section{Title: JOB SATISFACTION AS A FUNCTION OF THE FIVE FACTORS MODEL OF PERSONALITY IN THE COMMUNITY MENTAL HEALTH CENTER ENVIRONMENT OF NORTHERN INDIANA}

Name of researcher: Robert Ryan

Name and degree of faculty chair: Dennis Waite

Date completed: June 2020

\section{Problem}

The purpose of this study was to examine the relationship between the Big Five personality type indicators and job satisfaction in the community mental health setting. The focus of this study was to gain a better understanding of whether a not-for-profit can benefit from the use of a brief personality instrument to recruit and retain individuals with the highest probability of job satisfaction. This research complements previous research which has revealed a positive correlation between certain Big Five personality traits and job satisfaction in several sectors. The research population for this study consisted of 
community mental health employees working in the outpatient setting at the Bowen Center. The Big Five Indicator (BFI), a 44-item instrument with five scales, and the Job Satisfaction Survey (JSS), a 36-item instrument with nine scales, was used to measure the relationship between personality and job satisfaction while controlling for demographic variables.

\section{Method}

The Bowen Center is a community mental health center based in Warsaw, Indiana. The Bowen Center employs 482 employees ranging from psychiatrists to administrative support staff. The Center provides the full continuum of mental health services ranging from adult inpatient to outpatient therapy. The study focused on the clinical and support staff in only the outpatient offices in all 10 counties Bowen Center have physical locations. These offices are located in Marshall, Kosciusko, Wabash, Huntington, Whitley, Lagrange, Steuben, Dekalb, Noble, and Allen counties. The population included 93 master's-level clinicians, 257 bachelor's-level community-based clinicians, and 37 client services staff.

The population was asked to complete a demographics form, The Big Five Indicator, and the Job Satisfaction Survey: Version 44. The sample was made up of those who completed the forms.

Demographics Form: The participants were asked to identify personal characteristics including their age category, level of education, gender, ethnicity, and marital status. Occupational characteristics were also collected including years in current role, years in the company, job classification, and occupational area. 
Big Five Indicator: The Big Five Inventory (BFI): Version 44 (V44) was created by John, Donahue, and Kentle from the University of California, Berkeley. It is a brief although complete measure of the five-factor model of personality. John et al. touted the BFI as an instrument that "allows efficient and flexible assessment of the five dimensions when there is no need for more differentiated measure of individual facets."

Job Satisfaction Survey: The Job Satisfaction Survey (JSS) was used because it is a multidimensional instrument that was originally used in the social services sector but proven statistically sound in all organizations. The JSS measures nine facets of work: Pay, Promotion, Supervision, Fringe Benefits, Contingent Rewards, Operating Procedures, Coworkers, Nature of Work, and Communication. Total Job Satisfaction was selected as the primary dependent variable (Spector, 1985).

This study is quantitative in nature, cross-sectional, predictive and nonexperimental. This design provides for a high degree of external validity based on realworld setting and participants. Inferences about the relation between variables are discussed, but the causal inferences among variables cannot be determined as this is a correlational research project. Multiple independent variables were used, including the Big Five personality traits, gender, age, education, marital status, ethnicity, years with the company, and years in occupation. The dependent variable is Total Job Satisfaction as presented by the general Job Satisfaction Survey.

The analysis of the data focused on the relationship between job satisfaction and the above-mentioned demographic variables and their ability to predict Total Job Satisfaction. The correlations are presented across and within the sub-groups as defined by Big Five personality traits and demographic variables. An analysis of covariate was 
also utilized to examine job satisfaction with the demographic variables used as independent categorical variables and the big five traits included as covariates. There was little evidence that ordered variables would be necessary or beneficial based on the research design.

\section{Results}

After reviewing the descriptive nature of the demographics, Big Five personality responses and responses from the Job Satisfaction Survey a review of the relationship between variables was sought.

There was a significant positive relationship found between agreeableness and Total Job Satisfaction. This was similar to previous research in other fields. There was a negative relationship between Neuroticism and Total Job Satisfaction. These results suggested that a person with high Agreeableness and low Neuroticism would report high Total Job Satisfaction as an employee at the Bowen Center. Null hypothesis Ho1 was tested and was rejected by the analysis of this data.

Further analysis looked at the relationship between Total Job Satisfaction and Big Five personality traits when controlling for demographics. Here it was found that a single demographic characteristic, job classification had a slight positive correlation with Total Job Satisfaction. With regard to Big Five personality traits a positive predictive relationship was found between Agreeableness and a significant negative relationship with Neuroticism. Null hypothesis Ho2 was tested and was rejected by this analysis of data. 


\section{Conclusions}

Seeking high job satisfaction for their employees is at the core of the Community Mental Health Centers because it ensures higher quality service delivery and lower costs. This study investigated the job satisfaction as a function of the five-factor model of personality by examining the relationship of the Big Five personality traits with job satisfaction.

The research findings offer more understanding into the degree to which the Big Five personality traits relate to job satisfaction in the Community Mental Health Centers. The study suggests the following practical implications:

1. The study's findings can be helpful to the managers of Community Mental Health Centers by focusing their attention on hiring candidates with high Agreeableness as a personality trait. Employees with higher Agreeableness were found to have a positive relationship with job satisfaction.

2. The study's findings can be helpful to the managers of Community Mental Health Centers by focusing their attention on hiring candidates with low Neuroticism as a personality trait. Employees with lower Neuroticism were found to have a higher job satisfaction.

The study findings add a body of knowledge to existing literature regarding the job satisfaction as a function of the five-factor model of personality, as well as the relationship between the Big Five personality traits and job satisfaction when controlling for common demographic characteristics. The study has expounded on the relationship between the Big Five personality traits and job satisfaction; hence, the study findings can 
be used to precisely change the Community Mental Health Center environment work setting and hiring practices. 
Andrews University

School of Education

\title{
THE JOB SATISFACTION AS A FUNCTION OF THE FIVE FACTOR MODEL OF PERSONALITY IN THE COMMUNITY MENTAL HEALTH CENTER ENVIRONMENT OF NORTHERN INDIANA
}

\author{
A Dissertation \\ Presented in Partial Fulfillment \\ of the Requirements for the Degree \\ Doctor of Philosophy
}

by

Robert Ryan

June 2020 
CCopyright by Robert Ryan 2020 All Rights Reserved 


\title{
THE JOB SATISFACTION AS A FUNCTION OF THE FIVE FACTOR MODEL OF PERSONALITY IN THE COMMUNITY MENTAL HEALTH CENTER ENVIRONMENT OF NORTHERN INDIANA
}

\author{
A dissertation \\ presented in partial fulfillment \\ of the requirements for the degree \\ Doctor of Philosophy
}

by

Robert Ryan

APPROVAL BY THE COMMITTEE:

Chair: Dr. Dennis Waite

Dean, School of Education:

Alayne Thorpe

Member: Dr. Carole Woolford-Hunt

Member: Dr. Tevni Grajales

External: Dr. Lionel Matthews

Date approved 
TABLE OF CONTENTS

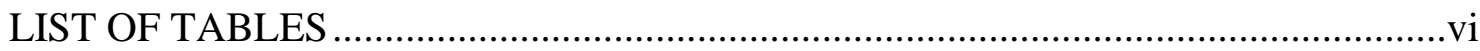

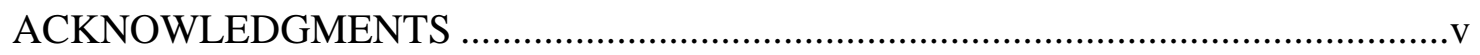

Chapter

1. INTRODUCTION AND PROBLEM STATEMENT

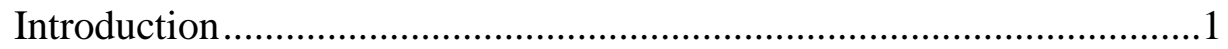

Background to the Study .....................................................................

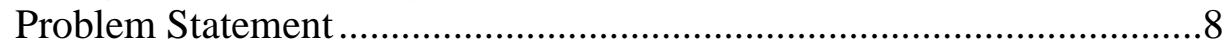

Purpose of the Dissertation ..................................................................10

2. REVIEW OF LITERATURE ................................................................11

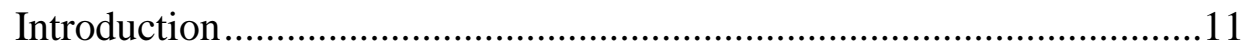

Job Satisfaction Research ...............................................................11

Job Satisfaction ....................................................................12

Factors Affecting Job Satisfaction ............................................12

Work-Related Stress and Job Satisfaction ..................................13

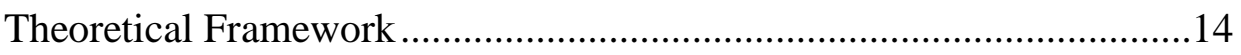

Parsons' Goodness of Fit Theory …………………....................14

Equity Theory of Motivation .......................................................15

Herzberg Two-Factor Theory ....................................................17

Dispositional Theory.................................................................19

Relevance of the Theories to This Dissertation .............................20

The Big Five Model of Personality....................................................22

Job Satisfaction and the Five-Factor Model ...........................................23

Effects of the Big Five Personality Traits on Job Satisfaction .................25

Relationships Between Five-Factor Model of Personality (Big Five Traits) and Job Satisfaction and Hypothesis

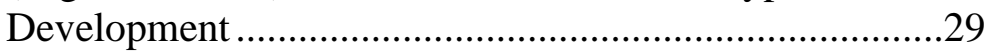

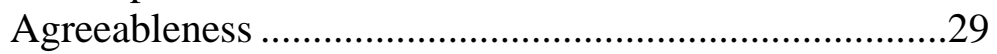

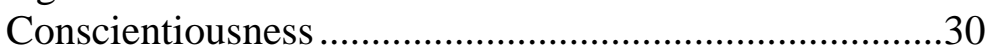

Openness to Experience ………………………………......30

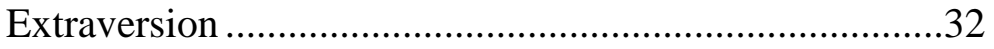

Neuroticism.....................................................................3 
Job Satisfaction and Demographic Factors.................................................33

Socio-demographic Factors as Determinants of Job Satisfaction..............34

Development of the Community Mental Health Center: From the Signing

of the Mental Health Act of 1965 Through Today ........................36

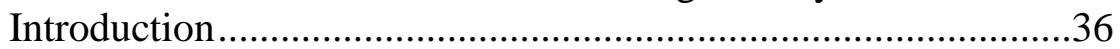

The Emerging Roles of Community Mental Health Centers........39

Mental Health Services and Policy in the United States and Prior to the Community Mental Health Center Act of 1963 .........49

Development and Expansion of Community Mental Health Center Facilities and Responsibilities, 1963-1981

The Omnibus Budget Reconciliation Act of 1981: The Return of

Authority to the States

Community Mental Health Centers Enter the $21^{\text {st }}$ Century ..........49

Systematic Analysis of the Existing Literature...............................50

History of Bowen Center From 1960 to 2017 ............................52

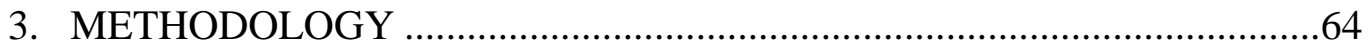

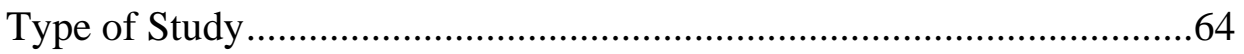

Population and Sample ....................................................................65

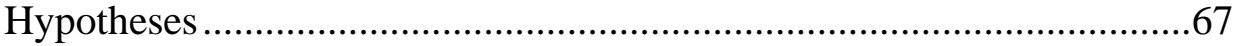

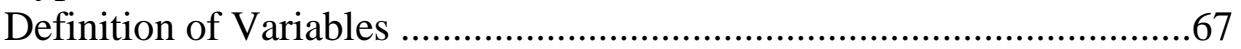

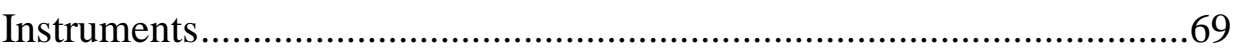

Demographics Form.................................................................69

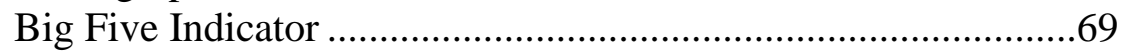

Job Satisfaction Survey ………………....................................

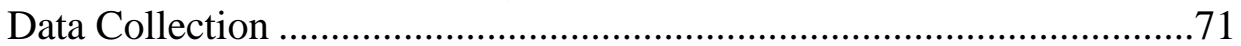

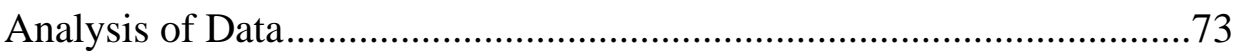

Treatment of Missing Data .........................................................

Descriptive Analysis .................................................................

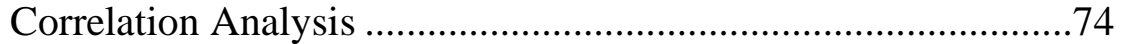

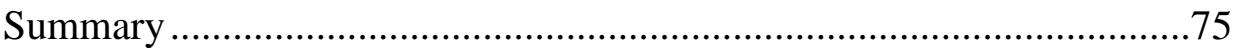

4. RESULTS, DATA ANALYSIS, AND DISCUSSION .................................76

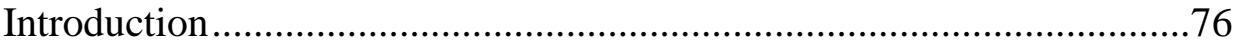

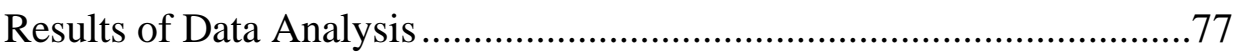

Demographic Characteristics \& Descriptive Statistics ..............................77

Demographic Characteristics ........................................................77

Descriptive Statistics of Big Five Type Indicator Participants'

Characteristics...................................................................

Descriptive Statistics of Participants' Opinions about Job

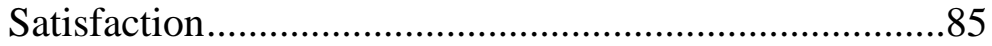

Correlational Analysis \& Hypotheses Testing.........................................8

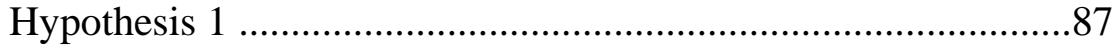

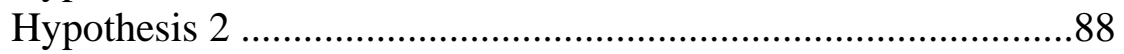


Discussion of the Study Findings

Job Satisfaction as a Function of the Five-Factor Model of Personality

5. CONCLUSION, RECOMMENDATIONS, AND AREAS FOR FUTURE STUDY

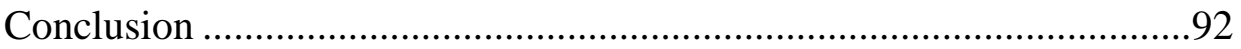

Job Satisfaction as a Function of the Big Five Personality Traits ...........94

Demographics and Big Five Scores of Personality Traits That Best Predict

Job Satisfaction ......................................................................94

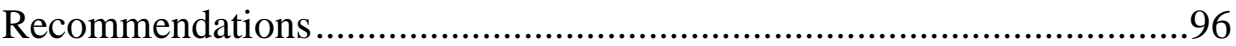

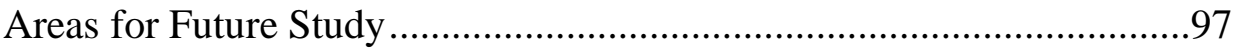

Appendix

A. DEMOGRAPHICS \& JOB SATISFACTION SURVEY ...............................99

B. HOW I AM IN GENERAL - BIG FIVE TYPE INDICATOR......................102

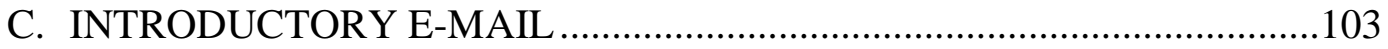

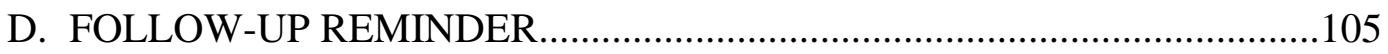

E. RESEARCH PROTOCOL.....................................................................106

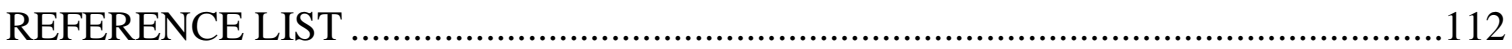




\section{LIST OF TABLES}

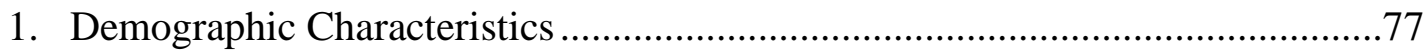

2. Descriptive Statistics of the Big Five Type Indicator Participants' Characteristics

3. Descriptive Statistics of Participants' Opinion About Job Satisfaction...............85

4. Correlations Between Big Five Traits and Total Job Satisfaction .......................88

5. Correlations Between Big Five Traits and Total Job Satisfaction Controlling for

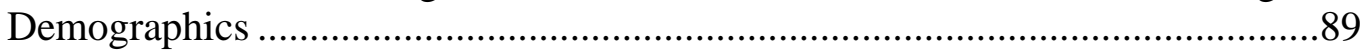




\section{ACKNOWLEDGMENTS}

I would like to thank the following people, without whom I would not have been able to complete this dissertation!

Dr. Dennis Waite, whose knowledge \& worldview have helped to shape me in my clinical and personal life. Thank-you to Dr. Jerome Thayer and Dr. Bruce Wrenn who helped in the development of my dissertation. Thanks to my current dissertation members of Dr. Carole Woolford-Hunt and Dr. Tevni Grajales who were so gracious to step in and help me across the finish line. Thanks to Bonnie Proctor for her help editing and showing me the way to be a better writer.

To The Bowen Center, where I completed my internship, helped me grow as a professional and finish my dissertation, thank-you. Specifically, to Dr. Richard Ruhrold a mentor and someone I look up to as a person and as a clinician. A special thanks to Kurt Carlson who has guided this organization from a small struggling agency to what we are now. He has been the defining influence in my professional life, and I will be forever indebted for his kindness and opportunity he has given me.

And my biggest thanks to my family for all the support you have shown me through this process. My daughters Victoria and Taylor, my parents who taught me how to love unconditionally and have always been my support, and my sister and her family who I have so much love, pride and respect for. To my inspiration, Tracy, my best friend and wife, thanks for all your support, without which I would have stopped these studies a long time ago. You have been amazing and know that I am equally committed to helping you achieve your dreams! 


\title{
CHAPTER 1
}

\section{INTRODUCTION AND PROBLEM STATEMENT}

\author{
Every man's work, whether it be literature, \\ or music or pictures or architecture \\ or anything else, is always a \\ portrait of himself. \\ --Samuel Butler
}

\section{Introduction}

Currently, many organizations are significantly considering how to hire and retain top talent or highly skillful employees, and this has led to increased competitiveness in today's job market. Government agencies and non-profit organizations also loom over hiring and are very selective in their hiring these days. Knowing the likelihood of a hiring candidate's job satisfaction before hiring would be a valuable advantage. Job satisfaction has been shown to have many qualities not-for-profit companies' value. Job satisfaction can be identified by the willingness of employees to assume more responsibilities (Cranny, Smith, \& Stone, 1992; Bakotic, 2016). Job satisfaction is closely related to employee turnover intention and absenteeism (Saeed, Waseem, Sikander, \& Rizwan, 2014), organizational commitment (Leite, Rodrigues, \& Albuquerque, 2014; Tnay, Othman, Siong, \& Lim, 2013), employee performance and motivation (KuranchieMensah \& Amponsah-Tawiah, 2016), as well as job performance (Platisa, Reklitisb, \& Zimerasc, 2015). Masindi (2015) concluded that organizational commitment and job 
satisfaction have a greater influence on employees' turnover intentions. Personality and job satisfaction go hand in hand when it comes to an organization's success and achievements. In relation to this matter, a satisfied employee tends to work more efficiently and therefore help to achieve the organizational goals and objectives.

Salyers, Rollins, Kelly, Lysaker, and Williams (2013) stated that burnout is very common among community mental health centers (CMHC) workforce and mental health administrators. Burnout is characterized by a reduced sense of personal achievement in the workplace, depersonalization, and higher levels of emotional exhaustion. Burnout affects job satisfaction (Salyers et al., 2013). Problems such as failure to retain qualified and trained professionals, low productivity, and high absenteeism also negatively affect job satisfaction (Platisa et al., 2015; Saeed et al., 2014).

According to Bakotic (2016), positive correlation exists between factors affecting workers' satisfaction and the level of the organization's performance. There are also individual studies that indicate a strong correlation between higher employee reimbursements to the firm commitment to the team.

Deckert and Statz-Hill (2016) stated that job dissatisfaction and lower workforce morale can result in increased workforce absenteeism, high employee turnover, and employee conflicts. Hong (2009) argued that even though there are numerous complex economic factors that influence a high employee turnover rate, job satisfaction level within community mental health centers generally makes an important contribution.

Job satisfaction influences service delivery in community mental health centers since it has significant impact on employee hiring and retention. Currently, the country's mental health system is multifaceted and complex and is comprised of numerous diverse 
institutional sections that compete for the professional resources that are currently available (Salyers et al., 2013). Community mental health centers should compete for workforce with other numerous types of institutions and agencies, which includes private practice, state hospitals, private clinics, and universities, as well as various non-mental health settings that are progressively employing mental health professionals for mental health-associated tasks or modules of their programs. However, the number of highly skilled and well-trained employees is still inadequate for all the community mental health centers. These most effective and highly skilled mental health workforces also tend to look for jobs in the community mental health system segments that have the most favorable working conditions and better pay (Deckert \& Statz-Hill, 2016).

Van Vuuren (2017) in his research on how work affects mental health and family described work as both a salvation and a curse. For humans, the work environment can provide valuable experiences, such as meaning and personal growth or negative experiences, such as alienation and mental health issues. Modern work has evolved from being almost exclusively a necessity for survival to becoming a life event from which one can gain personal satisfaction and self-actualization.

When an individual finds an equally beneficial occupation-employee relationship, the resulting job satisfaction has been found to increase the individual's longevity, mood, and personal relationships. Their company also benefits from this successful union through improvements in retention rates, motivation, group participation, and company commitment and loyalty (Crawford, LePine, \& Rich, 2010).

Kappagoda (2012) stated that dispositional factors are significant antecedents of job satisfaction. Personality motives, preferences, attitudes, requirements and 
characteristics that result in a propensity to react to conditions in a preset way are the dispositional factors. Understanding the personality of an individual is significant to the managers because this knowledge will be used when placing persons or employees into jobs. It also gives the managers or administrators clues about how that individual (employee) will feel and act in various situations in the workplace (Kappagoda, 2012).

Kumar and Bakhshi (2010) stated that dispositional factors usually refer to the five-factor model of personality, which are openness to experience, neuroticism, conscientiousness, agreeableness, and extraversion. Dispositional features that affect job satisfaction have recently focused on negative affectivity (Baker, 2011). Denollet (2013) stated that negative affectivity refers to the predisposition to experience various or numerous upsetting and negative emotions and equated negative affectivity with neuroticism, which is one of the key areas in the five-factor model of personality. In their study, Zhai, Smyth, Nielsen, and Luan (2009) found that negative affectivity was significantly related to low job satisfaction. Zhai et al.'s study findings show that high neuroticism scores predict lower ratings of job satisfaction. These researchers concluded that job satisfaction partially mediates the association between life or job satisfaction and affectivity. They also concluded that job satisfaction tends to be associated with various personality traits or characteristics. However, this single approach neglects the complete range of personality since it can influence job satisfaction.

Even though the job satisfaction as a function of the five-factor model has been studied by various authors (i.e., Judge, Heller, \& Mount, 2002; Kappagoda, 2012), the indepth analysis of the job satisfaction and five-factor model in a not-for-profit CMHC has yet to be studied. Some past researchers have studied the parts of job satisfaction and the 
five-factor model. For instance, Farhadi, Fatimah, Nasir, and Wan Shahrazad (2012) conducted a study to examine conscientiousness and agreeableness. They found that conscientiousness was associated with negativity which affects job satisfaction, but agreeableness was found to positively associate with complete job satisfaction (Farhadi et al., 2012). The authors concluded that workforces with fewer agreeableness and conscientiousness characteristics engage in deviant behavior more often compared to the employees with more conscientiousness and agreeableness. Therefore, personality traits (conscientiousness and agreeableness) contribute to the prediction of deviant behavior in the workplace.

On the other hand, neuroticism is negatively related to job satisfaction whereas extraversion is negatively related to only a few dimensions of job satisfaction (Judge, Heller, \& Mount, 2002; Kappagoda, 2012; Schmitt, 2012).

Kappagoda (2012) argued that in relation to the individual variations on the fivefactor model of personality with job satisfaction for various areas of occupation or job classifications, it is anticipated that the personality factors/dimensions that predict job satisfaction vary as a function of areas of occupation or job classifications.

Therefore, the purpose of this study is an in-depth examination of job satisfaction as a function of the five-factor model of personality in the community mental health center.

\section{Background to the Study}

Community mental health centers serve higher-need populations and play a significant role in the primary care delivery system (Shin \& Mauery, 2013). In spite of their importance, community mental health centers face unique challenges in recruiting 
and retaining a well-qualified workforce, including high productivity expectations, low pay, difficult working environments related to serving a high percentage of chronically mentally and mixed settings (rural and urban). Community mental health centers are considered as vital safety-net providers. Community mental health centers provide important and quality health care services to lower income individuals, both an uninsured and underinsured population (Shin \& Mauery, 2013). With an increase in health care reforms and federal efforts to redesign the delivery of mental healthcare, community mental health centers are struggling to stay profitable and meet these new demands. It is important to solve these new challenges because without community mental health centers large amount of need would go unmet (Data Report, 2017).

The CMHC Workforce Report (Data Report, 2017) indicated that new staff members can take 4-5 months before they achieve their full productivity. According to the same report, some community mental health centers cannot bill other insurers or Medicaid for the period spent on other non-direct service tasks/activities or in training; hence, this will negatively impact the community mental health centers' income to support their workforce.

The CMHC Workforce Report (Data Report, 2017) recommended that seasoned staff need to cover for workforce who leave while new staff are trained. Therefore, more experienced staff should frequently take on the higher risk cases and more complex cases; this will create substantial stress among the seasoned workforce.

Buche, Beck, Page, Singer, and Casemore (2016) cited an aging workforce, recruitment and retention of workforce, and a shortage of qualified workforces as the key problems faced by community mental health centers. Employee retention and recruitment 
efforts in CMHCs are hindered by inadequate compensation, high productivity, and high expectations, which discourage various individuals from remaining, working, or entering in the community mental health centers. However, even with these factors faced by community mental health centers, there are some clinicians who thrive in these conditions in community mental health centers. Outcomes monitoring and performance improvement programs or techniques should be adopted in community mental health centers to improve the chances a potential employee will be successful in a not-for-profit CMHC environment (Center for Substance Abuse Treatment, 2006).

The Substance Abuse and Mental Health Services Administration (SAMSHA, 2012) found that the key factors that impact CMHC employees include inadequate compensation, recruitment, an aging workforce, staff shortages, higher turnover, as well as distribution and retention of the staff.

Despite the significance job satisfaction in the human services, there has been scant or limited research studies conducted in this area, and none of the existing research studies (literature) have been conducted to examine personality and job satisfaction specifically within community mental health centers. Therefore, the aim of this study was to examine personality and job satisfaction across job classifications, particularly in community mental health centers. The study also examined the issues currently faced by community mental health centers, which are heavily dependent on Medicaid reimbursement, a very specific and highly employed (low unemployment) workforce, highly regulated, and low-profit industry. 
Lastly, this dissertation documents the history on the CMHC development from President John F. Kennedy enacting the Mental Health Act, to today. This is included in the literature review section (chapter 2).

\section{Problem Statement}

The general problem addressed by this study was to assess whether an employee's Five personality traits correlate with an employee's reported job satisfaction on the Job Satisfaction Survey. Further, the study assesses whether the Big Five personality traits of employees correlates differently when controlling for personal demographics and occupational characteristics. See Figure 1.

These correlations should be understood as one of three kinds:

1. Increase in job satisfaction: Certain personality characteristics or combinations of personality characteristics will have a positive relationship with job satisfaction. It has been argued by some (Barak, Librowsky, \& Shiloh, 1989; Chartrand, 1991; Gottfredson \& Holland, 1990; Gronholdt, 2001; Jiang, 2000; Tanoff, 1999; Wiggins, Lederer, Salkowe, \& Rys, 1983) that there are discernible variables that correlate with a person's level of reported job satisfaction, both positively and negatively. This dissertation will contribute to the literature by exploring what personality characteristics are related to job satisfaction in the Community Mental Health Centers.

2. Decrease in job satisfaction: Certain personality characteristics may have a negative relationship with job satisfaction. Research has clearly shown that job satisfaction and job dissatisfaction are not opposite ends of the same pole. This dissertation will focus exclusively on job satisfaction. As such, it will attempt to identify personality characteristics that decrease job satisfaction. 
when controlling demographics and occupational characteristics: This dissertation explores personality traits and Total Job Satisfaction controlling for demographics and occupational characteristics. For example, does the Big Five personality trait of Openness significantly increase job satisfaction differently depending on occupational characteristics?

Figure 1. Variable map.

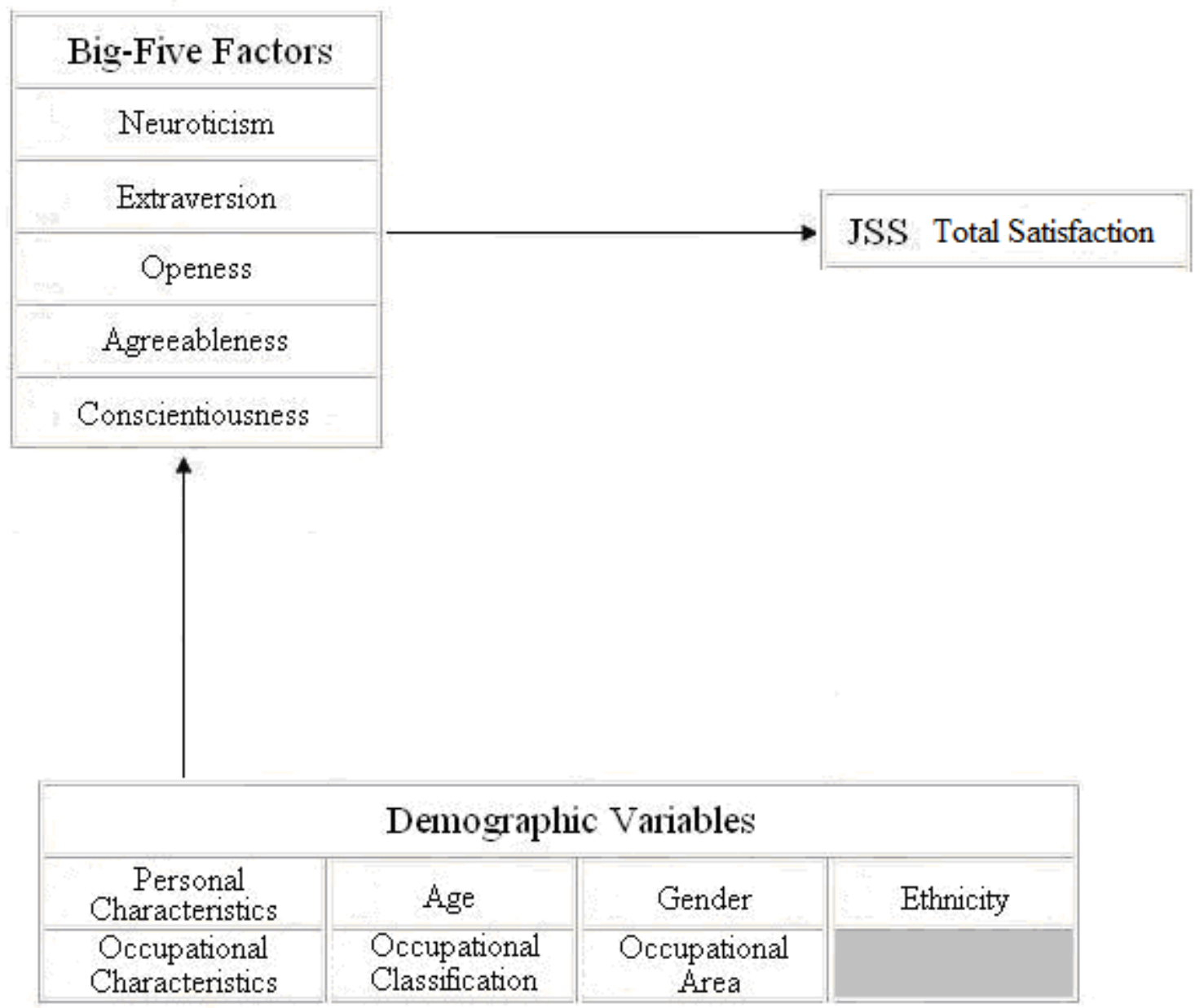




\section{Purpose of the Dissertation}

This dissertation examines personality as a predictor of job satisfaction among CMHC workers employed in outpatient occupations within the community mental health center (Bowen Center) and how this relationship varies when demographic and occupational characteristics are controlled. The purpose is to identify occupational characteristics that best fit an individual's personality characteristics, therefore reaping the known benefits of the resulting job satisfaction (Jones, Hill, \& Henn, 2015).

The purpose of this study is an in-depth examination of personality and job satisfaction across job classifications in a not-for-profit community mental health environment. More specifically, the purposes of the study are:

1. To determine the relationship between Big Five personality traits and job satisfaction in a not-for-profit community mental health environment.

2. To determine the relationship between Big Five personality traits and job satisfaction when controlling for demographic and occupational characteristics. 


\title{
CHAPTER 2
}

\author{
REVIEW OF LITERATURE \\ Scientific research consists in seeing what \\ everyone else has seen, but thinking \\ what no one else has thought. \\ --Anonymous
}

\section{Introduction}

This chapter entails the existing literature review pertinent to this dissertation. It also includes the theoretical and conceptual framework as well as theories related to the study topic. Lastly, this section includes history on the Bowen Center and the greater history of CMHC development from the enactment of the Community Mental Health Act (October 31, 1963) through today.

\section{Job Satisfaction Research}

Research involving job satisfaction has a long history, with modern research stretching from the early 1920s to as recent as 2017. EBSCO.com searches in July 2017 yielded over 5,000 hits for job satisfaction from just the last 10 years. Within these articles and dissertations there are variations regarding the actual definition of job satisfaction (Cranny et al., 1992; Gronholdt, 2001; Jiang, 2000; Lambert, Hogan, \& Barton, 2001; Peiser \& Meir, 1978; Tanoff, 1999); however, the following is proposed and supported in the research. Job satisfaction is the affective interaction which results between a person's desired occupational outcomes and actual outcomes (Cranny et al., 1992). It is important to note that it has long been established that "job satisfaction" is a different construct than "job dissatisfaction” (Porter, Steers, Mowday, \& Boulian, 1974). 
The researcher acknowledges this difference so will not be directly studying the effect that personality characteristics have on job dissatisfaction.

Van der Doef, Mbazzi, and Verhoeven (2012) stated that job satisfaction is an important issue for health-care professionals including CMHC workforce globally. Lu, Barriball, Zhang, and While (2012) found that the organizational features of structures (i.e., hospital or CMHC structure) significantly influence job satisfaction for the healthcare workforce. Organizational features include intention to leave due to low job satisfaction, lack of equipment, and personnel shortages (Liu et al., 2012).

\section{Job Satisfaction}

Armstrong (2010) stated that job satisfaction refers to the feelings and attitudes individuals or employees have about their jobs. For instance, a favorable and positive attitude towards the work indicates job satisfaction, whereas unfavorable and negative attitudes towards one's work or job shows job dissatisfaction (Armstrong, 2010).

Bontis, Richards, and Serenko (2011) stated that job satisfaction can be utilized as an approach of motivating workforces in organizations. Hence, job satisfaction is very important because most people spend a major part of their life at their workplace. Also, satisfied staffs tend to work effectively to meet the organizational goals.

\section{Factors Affecting Job Satisfaction}

According to Wilson (2010), job satisfaction levels are influenced by extrinsic and intrinsic motivation factors, the extent to which a person fails or succeeds in his or her job, the quality of supervision, and social relationships with the work groups.

Discretionary behavior which aids the organization to be successful tends to occur when the job provides the workforces with higher levels of satisfaction, when workforces 
feel committed to the organization, and are properly motivated (Wilson, 2010). Wilson found that the important factors such as work challenges, team, job influences, career opportunities, and personal expectations affect job satisfaction among the employees.

Kahya (2007) examined the definite factors affecting job performance and found that working conditions, education, salary, and experience can have significant effects on employees' performance and job satisfaction. The employee's grade or position in an organization also has positive effects on his or her performance, and ultimately job satisfaction (Kahya, 2007). In addition, Kahya stated that working environment and conditions have both a negative and positive association with employee performance. Kahya also found that highly qualified and educated workforces exhibited dissatisfaction of bad working conditions; hence their performances were negatively impacted. On the contrary, workforces with lower job qualifications, displayed higher performance regardless of the unfavorable working conditions. Kahya found that experience was positively related with performance and satisfaction.

\section{Work-Related Stress and Job Satisfaction}

Job-related stress is considered to be detrimental when emotional and physical responses occur when there is a disparity between job requirements and the employees' needs, resources, and capabilities (Mursali, Basuki, \& Dharmono, 2009). Beheshtifar, Hoseinifar, and Moghadam (2011) found that work-related stress generally influences individual and organizational issues comprising organizational commitment, job satisfaction, performance, and physical, mental, and behavioral outcomes.

Hoboubi, Choobineh, Ghanavati, and Keshavarzi (2017) stated that work-related stress is an important factor to job satisfaction. Work-related stress leads to satisfaction 
and creativity when it functions as a motivator, and subsequently removes mundanity and boredom. However, when functioning as a negative factor, work-related stress results in low job satisfaction and aggression among the workforce (Halkos, 2008).

Hoboubi et al. (2017) argued that job satisfaction can protect workforces from stressors while satisfaction is a regulating factor for stress. Job satisfaction and workrelated stress can have negative impacts on the productivity of the workforce and this could result in increased costs or expenses of an organization.

Vaessen (2010) stated that affective disposition on job satisfaction includes two aspects: (a) negative affectivity and (b) positive affectivity. Negative affectivity is shown by nervousness, unpleasant involvements, and distress, whereas pleasurable involvements, eagerness, and high vigor or enthusiasm show positive affectivity.

\section{Theoretical Framework}

\section{Parsons' Goodness of Fit Theory}

In psychology, goodness of fit defines the compatibility of an individual's personality with the features of their specific work or social milieu (Edwards, 2008; Parsons, 1909). Every environment (e.g., place of work) has particular or unique demands and features (Chartrand, 1991). Goodness of fit refers to a significant element in the emotional adjustment of a person to the surrounding environment (Thomas \& Chess, 1977); for example, emotional adjustment of employees to their organization or workplace.

According to Parson's goodness of fit theory (Edwards, 2008), workforces with the goodness of fit (emotional challenges) is a significant factor in how well the employees will adapt and adjust to diverse conditions in their workplaces or in the 
organization. The goodness of fit concept will be applicable to employees and it will be a significant factor in how the workforce will adjust and adapt to work conditions in order to be more satisfied with their jobs (Langer \& Lietz, 2015); hence, goodness of fit plays a significant role in job satisfaction levels of employees in CMHCs.

In goodness of fit theory, Parsons suggests that the self-knowledge of a person is attached to work knowledge, and the person can make a coherent decision in regard to the best match between the individual knowledge concerning the given job and his/her selfknowledge (Cable \& Judge, 1996; Edwards, 2008; Parsons, 1909). However, the challenge is to effectively describe works and people. An important hypothesis of Parsons' goodness of fit theory is that people will make coherent decisions when provided with good information (i.e., about jobs) (Zunker, 2002).

Parsons (1909) proposed the concept of matching occupations or jobs to personalities, skills, or talents. Based on Parson's Goodness of Fit theory, the use of a correct understanding of a person's job-relevant attributes (i.e., interests, aptitudes, skills) and a comprehensive knowledge of the job market and employment or work will improve job choices (Altmaier \& Hansen, 2012).

\section{Equity Theory of Motivation}

Equity theory states that individuals are more concerned with the precise amount of reward they receive for their activities or accomplishments, and with the correlation of the reward they receive to what other people get (Redmond, 2013). Redmond stated that greater pay levels correspond to greater performance and could motivate workforces to increase their inputs. 
Redmond (2013) stated that equity theory suggests that an individual's motivation is based on what that individual considers to be fair when compared to others. When applied to the workplaces, equity theory focuses on exchange relationships or a worker's work-compensation relationship, and the workforce's attempts to reduce/minimize any sense of inequity that could result in the workplace (Redmond, 2013; see also Disley, 2009).

Developed by Adams (1963), the equity theory of motivation recognizes that motivation could be affected by a person's perception of fair treatment at the workplace or social exchanges (Baxamusa, 2016). When compared to other individuals, people want fair compensation for their contributions (which are the outcomes individuals experience for their inputs) (Redmond, 2013). Redmond (2013) further stated that an individual's beliefs in relation to what is unfair or fair might impact their behaviors, motivation, and attitudes. Equity theory demonstrates that a person's perception is associated with their own reality (Redmond, 2013).

Gogia (2010) stated that equity theory attends to unfairness or fairness and social relationships. Equity theory suggests that when a state of inequity is perceived, a person can experience a state of dissatisfaction or distress and this distressing state will make people take action to restore equity (Gogia, 2010).

Armstrong (2010) stated that equity theory recognizes that people are concerned with the relationship of the extent to what other people get or receive and with the total amount of rewards they get for their work/efforts.

According to an individual input (e.g., competence, education, experience, and effort), a person may compare outcomes (e.g., recognition, salary increase, levels) as well 
as other factors. Tensions can be created when individuals perceive an imbalance in their input-outcome ratio relative to other people. The tension offers the foundation for motivation because individuals will attempt to fight for what they recognize and believe as fairness and equity (Armstrong, 2010; Robbins, 2005).

The main elements of exchange relations in equity theory are outcomes and inputs. In a case where individuals exchange their services for pay, inputs can involve training, efforts on the job or work, education, and past work experience. An outcome refers to the factors resulting from the exchanges. The most significant outcome is considered to be pay with the outcome, for instance, of fringe benefits, work assignments, supervisory treatment as well as job status symbol (Armstrong, 2010).

According to the equity theory, if people are treated equitably, they will be better motivated and become more satisfied as a result, but when people are treated inequitably, they will be dissatisfied and de-motivated (Armstrong, 2010).

\section{Herzberg Two-Factor Theory}

The two-factor model of dissatisfiers and satisfiers was developed by Herzberg, Mausner, and Snyderman (1959) following an investigation into the sources of job dissatisfaction and satisfaction of employees. Armstrong (2010) argued that it was presumed that individuals have the ability to report accurately the conditions which make them feel dissatisfied and satisfied with their work.

Herzberg's (Herzberg et al., 1959) two-factor theory (which is also called dualfactor theory or motivator hygiene theory) explains motivation and satisfaction in the workplaces. Herzberg two-factor theory states that an employee's dissatisfaction and satisfaction are driven by diverse factors, which include motivation and hygiene factors. 
Herzberg (1968) reported that there are factors that lead to satisfaction with an individual's work and there are factors that lead to job dissatisfaction among employees at the workplace based on the two kinds of motivators. Herzberg further pointed out that extrinsic factors are associated with job dissatisfaction, whereas intrinsic factors are associated with job satisfaction.

The Herzberg two-factor theory was based on the enquiry, "What does an individual want from his/her job?" (Harpaz, 1990). From the answers to this question, Herzberg (1968) stated that eliminating dissatisfying features from jobs will not automatically make the work or job satisfying (Armstrong, 2010). In addition, Herzberg (1968) found that hygiene factors and motivators are the key factors in job satisfaction.

Herzberg (1968) also illustrated that the motivators are intrinsic factors allowing psychological development and growth on the job; for example, the actual job/work or job itself, challenges, advancements, responsibility, recognitions, and achievements (Ajila \& Abiola, 2004; Wilson, 2010).

In contrast, Armstrong (2010) argued that hygiene factors are extrinsic. Hygiene factors define the work conditions rather than the job/work itself. According to Bhattacharyya (2009), the hygiene factors consist of interpersonal relations with supervisors and subordinates, supervision, administration, organization or company policy, conditions of the work, salary, and job security. Herzberg (1968) concluded that employers need to be more concerned with the job itself as well as work conditions.

Extrinsic rewards tend to have important impacts on the motivation of workers, whereas intrinsic rewards do not have any important effect on the motivation of the workforce (Chris \& Awonusi, 2004). On the other hand, an inefficient reward system will 
result in demotivation of the employees while an efficient reward system will be an excellent motivator. Thus, it can be concluded that both extrinsic and intrinsic rewards can motivate the worker and can lead to higher job satisfaction level, greater productivity, and improved performance (Reio \& Callahon, 2004; Richard, 2013).

\section{Dispositional Theory}

Dispositional theory is another renowned job satisfaction theory. Dispositional theory generally suggests that individuals have innate dispositions towards a definite level of satisfaction, irrespective of their job (Al-Witri, 2016). This strategy became an important description of job satisfaction in regard to the perspective or notion that job satisfaction becomes more stable over time or more stable in different jobs as well as careers. The Core Self-Evaluations Model is an important model, which narrows the scope of the dispositional theory. This model is suggested by Judge, Locke, Durham, \& Kluger (1998) and Judge, Heller, Mount (2002), where they proposed that there are four principal self-evaluations that determine an individual's disposition toward job satisfaction, and these four main self-evaluations include: neuroticism, locus of control, overall self-efficacy, and self-esteem. The Core Self-Evaluations Model further illustrates that general self-efficacy (the confidence or trust in personal competence) and greater self-esteem (the values people place on themselves) result in higher levels of job satisfaction. People who tend to have internal locus of control (belief that a person has full-control over his/her life) have greater levels of job satisfaction. Lastly, low neuroticism levels result in higher levels of job satisfaction. 


\section{Relevance of the Theories to This Dissertation}

Parsons' goodness of fit theory explains the concept of goodness of fit (emotional challenges) and how it is a significant factor in how well employees will adapt and adjust to diverse conditions in their workplaces or in the organization. Therefore, this theory is used because it gives a theoretical background on how the concept of goodness of fit is applicable to employees and in how the workforce adjusts and adapts to work conditions in order to be more satisfied with their jobs (Langer \& Lietz, 2015); hence, goodness of fit plays a significant role in determining job satisfaction levels of employees in CMHCs.

Herzberg's (1968) two-factor theory provides a theoretical perspective and deeper understanding of the sources of job dissatisfaction and satisfaction of employees, and, thus, it is helpful to this study. Herzberg pointed out that extrinsic factors are associated with job dissatisfaction whereas intrinsic factors are associated with job satisfaction. Herzberg (1968) found that hygiene factors and motivators are the key factors that result in job satisfaction. Thus, both extrinsic and intrinsic rewards can motivate the worker and can lead to higher job satisfaction level. Hence, the Herzberg two-factor theory is important since it gives insights on the factors that affect job satisfaction in the organization, and these factors can be applicable in CMHCs.

Equity theory was used in this study since it gives insights on how employees or a person handles unfairness or fairness in an organization, and how the relationship between their inputs and outputs (rewards) could lead to either a state of job satisfaction or dissatisfaction. Equity theory recognizes that people are concerned with the relationship of the extent to what other people get or receive and with the total amount of rewards they get for their work (Armstrong, 2010) According to an individual inputs, for 
instance, competence, education, experience and efforts, a person may compare outcomes (e.g., recognition, salary increase, levels) as well as other factors in the organization and this could significantly determine job satisfaction. According to the equity theory, if people are treated equitably, they will be better motivated and become more satisfied as a result, but when people are treated inequitably, they will be dissatisfied and de-motivated (Armstrong, 2010). Therefore, equity is pertinent to this study.

The scope of the dispositional theory, which is another renowned job satisfaction theory, is narrowed down to the Core Self-Evaluations Model suggested by Judge, Locke, Durham, and Kluger (1998) and Judge, Heller, Mount (2002), who proposed that there are four principal self-evaluations that determine an individual's disposition toward job satisfaction, and these four main self-evaluations include: neuroticism, locus of control, overall self-efficacy, and self-esteem. Since the main objective of the dissertation is to examine how the Big Five personality traits (agreeableness, conscientiousness, openness to experience, neuroticism, and extraversion) and demographic variables affect job satisfaction in the CMHC environment, dispositional theory plays a key role in providing a theoretical perspective and insights of how neuroticism (which is one of the four principal self-evaluations of the Core Self-Evaluations Model) affects job satisfaction levels. According to the dispositional theory, neuroticism lowers job satisfaction levels.

Therefore, when tied together, these three theories explore the determinants of job satisfaction, which is part of the study objective and also helps to theoretically understand sources or factors of job satisfaction among employees in organizations. 


\section{The Big Five Model of Personality}

The five-factor model formulated by Goldberg, 1993, or "Big Five" as it is often referred to, has been numbered and labeled as: (I) Extraversions; (II) Agreeableness; (III) Conscientiousness (or Will); (IV) Neuroticism (or Emotional Stability); and (V) Openness (or Intellect). The trait "Extraversion" can be seen as a contrast between those who are outgoing versus those who are more reserved. High extraversion is often associated with individuals described as attention-seeking and domineering, whereas individuals with low extraversion can be described as reserved or reflective.

Agreeableness can be seen as a contrast between compassionate/cooperative and those who are suspicious/individualistic. Conscientiousness contrasts those who would be described as efficient/organized versus those who are laissez-faire/spontaneity. Neuroticism can be seen as describing how susceptible a person is to psychological stress. Finally, Openness seeks to describe a person's intellectual curiosity, level of creativity and level of stimulation (Pervin \& John, 1997, p. 260; see also Ijaz \& Khan, 2015; Judge, Heller, \& Mount, 2002; Kappagoda, 2012; Templer, 2012).

The Big Five model of personality is made up of five sub-sections such as agreeableness, conscientiousness, openness to experience, neuroticism, and extraversion (Ijaz \& Khan, 2015; Judge, Heller, \& Mount, 2002; Kappagoda, 2012; Templer, 2012).

Ijaz and Khan (2015) stated that the Big Five model of personality distinguishes the dissimilarities of human nature and offers a general guideline that helps in understanding the individual's present as well as future anticipated activities/actions as well as possible outcomes. This model is also a comprehensive foundation that can be used to understand other dimensions of life and human behaviors (Zhai et al., 2014). 


\section{Job Satisfaction and the Five-Factor Model}

The five-factor model is related to the general job satisfaction levels experienced by staffs or workforces. Generally, satisfied workforces tend to avoid absences and often tend to remain in their positions as compared to the dissatisfied workers (Zhai et al., 2014).

Neuroticism is found to be negatively related to job satisfaction (Kappagoda, 2012), while agreeableness, conscientiousness, and extraversion are positively correlated with job satisfaction (Bowling, 2010; Templer, 2012; Zhai et al., 2014). This can be a result of the social nature of the work setting (Judge, Heller, \& Mount, 2002).

Accomplishment-striving and status-striving are the aspects of motivation that are correlated with conscientiousness and extraversion, respectively. These aspects of motivation result in improved performance, which would then lead to job satisfaction (Judge, Heller, \& Mount, 2002; Yahaya et al., 2011).

Nielsena, Glasøc, and Einarsenb (2017) stated that workplace deviance is associated with the five-factor model of personality. Personal deviance is negatively related to higher levels of agreeableness. Organizational deviance is positively related to higher levels of neuroticism, but it is negatively related to higher levels of conscientiousness. This implies that persons (employees) who are agreeable are less likely to be hostile to their colleagues, whereas conscientious and emotionally stable persons (employees) are less likely to steal or withhold efforts at the workplace (Nielsena et al., 2017).

Extraverted employees are more satisfied at work since the job gives them a chance to experience maximum motivation levels, while introverted employees are 
having lower job satisfaction levels at work because of too much stimulation (Ijaz \& Khan, 2015; Judge, Heller, \& Mount, 2002; Kappagoda, 2012). Zhai et al. (2014) found that conscientiousness is the determining factor in regard to job absence. Cocker, Martin, Scott, Venn, and Sanderson (2013) found that neuroticism, higher educational achievement, and treatment are related to job absence.

Various researchers (i.e., Bowling, 2010; Templer, 2012; Zhai et al., 2014) have found that agreeableness, conscientiousness, and extraversion are associated with job satisfaction and cooperative behavior. Job performance is associated with the five-factor model through increased teamwork among employees, and effective teamwork is important to job satisfaction (Ijaz \& Khan, 2015; Kuranchie-Mensah \& AmponsahTawiah, 2016), and job performance is closely related to job satisfaction (Kappagoda, 2012). Tesdimir et al. (2016) also found that conscientiousness is an important determinant of job performance. Bowling (2010) stated that conscientious employees tend to perform better as employees and they have a better possibility of obtaining satisfying jobs, which results in increased job satisfaction.

Extraversion and conscientiousness are the two traits of the five-factor model that are closely related to positive job satisfaction (Templer, 2012; Zhai et al., 2014), even though conscientiousness is more positively related to job performance (Ijaz \& Khan, 2015). Therefore, the five-factor model of personality is a strong predictor of job satisfaction and performance (Kappagoda, 2012).

Even though the five-factor model has been previously used in studies comparing personality and job satisfaction (Ijaz \& Khan, 2015; Judge, Heller, \& Mount, 2002; 
Kappagoda, 2012; Templer, 2012; Zhai et al., 2014), none of those studies have included all five factors or focused on the CMHC as this study did.

\section{Effects of the Big Five Personality Traits on Job Satisfaction}

Ganu and Kogutu (2014) studied the effects of the Big Five personality traits on organizational commitment and job satisfaction among health care employees, and their study findings revealed that there is an important relationship between the Big Five personality traits with organizational commitment and job satisfaction. Ganu and Kogutu also found that neuroticism and extraversion are positively related to job satisfaction, whereas neuroticism, openness, and conscientiousness were positively related to organizational commitment. In addition, their study results suggested that workforces who exhibit the traits of conscientiousness, extraversion, neuroticism, and openness tend to find higher levels of job satisfaction and a higher sense of commitment to the health care organization (Ganu \& Kogutu, 2014).

However, Ijaz and Khan (2015) stated that the five-factor model is related to the general job satisfaction levels experienced by staffs or workforces. Generally, satisfied workforces tend to avoid absences and often tend to remain in their positions as compared to the dissatisfied workers (Zhai et al., 2014).

Neuroticism is found to be negatively related to job satisfaction (Kappagoda, 2012), while agreeableness, conscientiousness, and extraversion are positively correlated with job satisfaction (Bowling, 2010; Templer, 2012; Zhai et al., 2014). This can be a result of the social nature of the work setting (Judge, Heller, \& Mount, 2002). Accomplishment-striving and status-striving are the aspects of motivation that are correlated with conscientiousness and extraversion, respectively. These aspects of 
motivation result in improved performance, which would then lead to job satisfaction (Judge, Heller, \& Mount, 2002; Yahaya et al., 2011).

Nielsena et al. (2017) stated that workplace deviance is associated with the fivefactor model of personality. Personal deviance is negatively related to higher levels of agreeableness. Organizational deviance is positively related to higher levels of neuroticism, but it is negatively related to higher levels of conscientiousness. This implies that persons (employees) who are agreeable are less likely to be hostile to their colleagues, whereas conscientious and emotionally stable persons (employees) are less likely to steal or withhold efforts at workplace (Nielsena et al., 2017).

Extraverted employees are more satisfied at work since the job gives them a chance to experience maximum arousal levels, while introverted employees are having lower job satisfaction levels at work because of too much stimulation (Ijaz \& Khan, 2015; Judge, Heller, \& Mount, 2002; Kappagoda, 2012). Zhai et al. (2014) found that conscientiousness is the determining factor in regard to job absence. Cocker et al. (2013) found that neuroticism, higher educational achievement, and treatment are related to job absence.

Various researchers (i.e., Bowling, 2010; Templer, 2012; Zhai et al., 2014) have found that agreeableness, conscientiousness, and extraversion are associated with job satisfaction and cooperative behavior. Job performance is associated with the five-factor model through increased teamwork among employees, and effective teamwork is important to job satisfaction (Ijaz \& Khan, 2015; Kuranchie-Mensah \& AmponsahTawiah, 2016), and job performance is closely related to job satisfaction (Kappagoda, 2012). Tesdimir et al. (2016) also found that conscientiousness is an important 
determinant of job performance. Bowling (2010) stated that conscientious employees tend to perform better as employees and they have a better possibility of attaining satisfying job, which results in increased job satisfaction.

Extraversion and conscientiousness are the two traits of the five-factor model which are closely related to positive job satisfaction (Templer, 2012; Zhai et al., 2014), even though conscientiousness is more positively related to job performance (Ijaz \& Khan, 2015). Therefore, the five-factor model of personality is a strong predictor of job satisfaction and performance (Kappagoda, 2012).

Ijaz and Khan (2015) stated that there is relationship between job satisfaction and personality traits. The Big Five model of personality is related to the general job satisfaction levels experienced by workforces (Zhai et al., 2014). Ijaz and Khan (2015) highlighted that five popular personality traits (extraversion, neuroticism, conscientiousness, agreeableness, and openness to experience) have different effects on job satisfaction. In addition, conscientiousness, extraversion, neuroticism, and agreeableness have regular relationships with job satisfaction (Carpenter, Bauer, \& Erdogan, 2010; Judge, Heller, \& Mount, 2002; Templer, 2012).

Carpenter et al. (2010) found that extraversion is positively related to job satisfaction. However, in Hlatywayo et al.'s (2013) study, neuroticism was found to be negatively correlated to satisfaction. Moreover, Kappagoda (2012) found that employees who have higher scores in neuroticism tend to be less satisfied with their salaries, the amount of work, and colleagues. Conversely, workforces with higher scores on extraversion traits tend to be happier, more satisfied, and valuable for the organization 
(Hlatywayo et al., 2013; Zhai et al., 2014). Hlatywayo et al. (2013) found that neuroticism has a stronger negative relationship with job satisfaction.

Bowling (2010) examined the effect of conscientiousness and job satisfaction on extra-role behaviors and found that conscientiousness was the most consistent and dependable predictor of efficacy or efficiency. Tesdimir et al. (2016) found similar results in their study, and concluded that the conscientiousness trait is the main predictor for desirable performance and job satisfaction as rated by managers. However, Zhai et al. (2014) found that the extraversion personality trait is the most effective and reliable facet greatly associated with workforces and managers. Ijaz and Khan (2015) stated that openness to experience is the most effective and tenacious personality trait, and it is a significant predictor.

Eswaran, Islam, and Yusuf (2011) stated that the five-factor model of personality characteristics demonstrates that the personality of an individual includes five selfdetermining traits that offer an important and an all-inclusive catalog for re-evaluating and reassessing the dissimilarities in the traits.

McDougall (2016) classified personality traits largely into five distinct components, which include temperament, temper, character, intellect, and disposition. However, many authors (Ganu \& Kogutu, 2014; Ijaz \& Khan, 2015; Judge, Heller, \& Mount, 2002; Kappagoda, 2012; Ongore, 2014; Templer, 2012; Tesdimir et al., 2016; Zhai et al., 2014) collectively agreed that personality traits are captured by five secondary features, which include openness to experience, neuroticism, conscientious, agreeableness, and extraversion. 
The effect of personality traits on job satisfaction is an ongoing debate in the literature of management and psychology. A number of researchers (e.g., Furnham, Eracleous, \& Chamorro-Premuzic, 2009; Whysall, Foster, \& Harris, 2009; Broadbridge, Maxwell, \& Ogden, 2007) have studied associations between job satisfaction and personality characteristics; however, Furnham et al. (2009) urged the need to conduct further research to clearly understand how job satisfaction is influenced or affected by personality traits. Due to the robustness of big five-factor model of personality and its importance in elucidating personality traits, the following subsections depict the relationship between job satisfaction and the Big Five personality traits such as openness to experience, neuroticism, conscientious, agreeableness, and extraversion.

\section{Relationships Between Five-Factor Model of Personality (Big Five Traits) and Job Satisfaction and Hypothesis Development}

\section{Agreeableness}

Templer (2012) found that agreeableness is associated with happiness because agreeable employees or persons have higher motivation to attain interpersonal relationship/intimacy, and this ultimately results in higher levels of job satisfaction and subjective well-being. Templer also stated that agreeableness is positively associated with life satisfaction. Mihalcea (2013) found that in contrast to workforces with other personality traits, workforces with the agreeableness personality trait tend to attain greater job satisfaction levels.

Ongore (2014) found that agreeableness and openness to experience are important predictors of job engagement. Agreeableness comprises traits, for example, of modesty, trust, tender-mindedness, and altruism. Workforces who possess agreeableness tend to be 
purpose-driven and confident to resolve the conflicts and problems. Hence, agreeable workforces are more engaged to their jobs and perform their work role effectively, ultimately leading to higher job satisfaction. Hence, it can be stated that agreeableness is positively correlated with a high level of job satisfaction.

\section{Conscientiousness}

Bowling (2010) found that conscientiousness is associated with job satisfaction and it represents an overall work-involvement tendency; hence, conscientiousness results in a better possibility of attaining satisfying job/work rewards, both informal (e.g., feelings of personal accomplishment, respect, and recognition) and formal (such as promotions or increased pay). People who possess the conscientiousness personality trait are focused, risk-averters, and these individuals could be simply distinguished based on their cautious and positive thinking towards the risks. Regarding their job, conscientious persons are short-sighted, and these individuals tend to prefer to accomplish the goals of the organization by holding back individual goals (Tesdimir et al., 2016).

Zhai et al. (2014) found that there is a significant association between job satisfaction and conscientiousness. Tesdimir et al. (2016) stated that conscientiousness is a stronger predictor of work performance in occupational employees. Therefore, it can be concluded that there is a significant relationship between the conscientiousness personality trait and a high level of job satisfaction.

\section{Openness to Experience}

Openness to experience is associated with being artistic and creative, politically liberal, an possessing divergent thinking and low religiosity, but none of these psychological states seem to be highly associated with job satisfaction (Judge, Heller, \& 
Mount, 2002). Kerr and McKay (2013) found that individuals with openness to experience have divergent thinking and are habitually reflective, scientific, intellectual, artistic, open-minded and creative.

Mohan and Mulla (2013) studied the moderating effect of conscientiousness and job complexity on the association between work outcomes and openness to experience. They found that openness to experience indicated negative association with performance in lower complexity jobs and a positive association with performance in higher complexity jobs.

Mohan and Mulla (2013) also stated that openness to experience revealed positive association with progression when the employees had low conscientiousness scores and a negative association with progression when the employees had high conscientiousness scores.

However, Kumar and Backshi (2010) stated that openness to experience generally has a double influence on the person's personality because it stimulates people to have an intense bad and good feeling at the same time.

In their study, Eswaran et al. (2011) found that openness to experience has a positive association with job performance and job satisfaction. Furthermore, they asserted that openness to experience is an important valid predictor of job satisfaction and of the training-adeptness criterion across professions as the persons with openness to experience trait are more innovative, insightful, and caring. People who possess the openness to experience personality trait tend to be more optimistic in learning novelties and from the experiences of other people or from their own experiences. 
Ijaz and Khan (2015) found that both openness to experience and extraversion have an important positive relationship with job satisfaction, whereas neuroticism has a strong negative relationship with job satisfaction. In conclusion, Ijaz and Khan stated that various personality traits have important effects on the job satisfaction level of workforces. The Big Five (Personality) traits such as openness to experience and extraversion are positively related to job satisfaction among the employees. Hence, it can be stated that there is a significant relationship between openness to experience personality and a high level of job satisfaction.

\section{Extraversion}

Carpenter et al. (2010) stated that extraversion is the measurement of personality related to search for excitement, dominance, and self-confidence. Extravert traits comprise enjoying being in social situations, being decisive and outgoing, talkativeness, and social poise. Individuals with extraversion traits are generally social, gregarious, energetic, talkative, outgoing, self-confident, companionable, and active. Moreover, McCrae and Allik (2012) found that people who possess the extraversion personality trait are spontaneous, impulsive, and conversational. Extravert individuals also react more affectively. Ashton (2013) found that the extraversion personality feature is deliberated as a result of differences in physiological and neurological mechanisms of people. In contrast to introverts, extravert people react more affectively.

Although neuroticism is associated with the experience of negative life events, Hlatywayo et al. (2013) argued that extraversion is associated with the experience of positive emotions, and that positive emotionality can generalize to job satisfaction (Zhai et al., 2014). Zhai et al. (2014) found that only the association between extraversion and 
subjective well-being is partly mediated by job satisfaction, suggesting that the effects of the Big Five on subjective well-being are primarily direct through job satisfaction. In addition, the study indicated that extraversion is the strongest predictor of job satisfaction and subjective well-being. Therefore, extraversion was found to be one of the most important factors in the Big Five traits that can be used to predict job satisfaction (Zhai et al., 2014). Based on their study findings, Zhai et al. (2014) concluded that only extraversion has a significant effect on job satisfaction, and also suggested that there are cultural differences in the relationships between job satisfaction and the Big Five traits (five-factor model of personality). Therefore, it can be stated that there is a significant relationship between extroversion and a high level of job satisfaction.

\section{Neuroticism}

Because of their essentially negative nature, neurotic persons (or employees) experience more negative life situations than do other people (Kappagoda, 2012), since these individuals select themselves into events/situations that promote a negative affect. The events could result in diminished job satisfaction levels depending on the degree to which such events occur or with respect to the work (Hlatywayo et al., 2013). Neuroticism is the primary source of negative affectivity, and the relationship between job satisfaction and negative affectivity has been examined and documented in Judge, Heller, and Mount's (2002) meta-analysis.

\section{Job Satisfaction and Demographic Factors}

Job satisfaction refers to a pleasurable positive emotional state that results from the appraisals of job or a person's job or experience (Kermani, 2013, p. 104). Job satisfaction depends mostly upon demographic factors; for example, ranks, education, 
tenure, marital status, sex, and age. Various demographic factors are important predictors of job satisfaction (Bashir, Jianqiao, Jun, Ghazanfar, \& Khan, 2011). Hence, demographic variables should be thoroughly understood and considered when determining job dissatisfaction or satisfaction of employees. Herzberg highlighted several attributes of dissatisfied or satisfied workforces (Scott, Swortzel, \& Taylor, 2005).

Scott et al. (2005) stated that a worker's self-esteem or confidence tends to be high when the worker commences a new job; however, the self-esteem or morale of the employee decreases with time to a greater or some extent depending on the work setting or job conditions. In addition, the morale of the employees remains at a comparatively lower level once they work for two to three decades in the same company or organization. However, the level of job satisfaction of the worker after the 30 years working in the same organization or company will start to increase and will endure all through the remaining career of a worker. Workers who begin their careers with higher morale tend to experience an important drop in the first year and this will remain low for subsequent years. However, the level of job satisfaction increases as tenure rises (Scott et al., 2005).

\section{Socio-demographical Factors as Determinants of Job Satisfaction}

Ghinetti (2007) stated that the determinants of job satisfaction frequently used in analyses done within labor economic theory consist of marital status, the rate of unemployment, managerial positions, job tenure, and education. Ghinetti further argued that having a managerial position or leadership role/position and job tenure have a positive relationship with job satisfaction. Moreover, Bryan and Sell (2011) stated that 
the associations between wages, the rate of unemployment, education level, and job satisfaction are convoluted and intertwined.

Bryan and Sell (2011) found that education raises salaries and as a result leads to higher job satisfaction. In addition, education raises the employee's expectations in regard to the scope of work or job responsibilities and hence the possibility of feeling dissatisfied with the job, which would ultimately lead to job dissatisfaction. Bryan and Sell concluded that the level of job satisfaction can rely on the gap between the aspirations and outcomes since the aspiration can be increased by education.

Bryan and Sell (2011) found that wage or salary is a significant factor associated with job satisfaction. According to the authors, the overall assumption is that higher salaries can lead to increased job satisfaction, as increased wages or salaries lead to higher utility. Wage is used as one type of reward along with future job opportunities and recognition at work. Workers are occasionally motivated by expanded responsibilities and promotional opportunities.

Career-oriented individuals have a stronger sense of professional growth, and they tend to experience greater levels of happiness from the work or obtain higher levels of job satisfaction (Kuranchie-Mensah \& Amponsah-Tawiah, 2016; Nabi, 2000). The value congruence between what a company can offer and the skill and desire a workforce possesses to achieve the required outcomes strengthens overall job satisfaction (Ren, 2010). Ren (2010) investigated the impacts of value congruence on organizations or companies and found that value congruence was associated with higher employee autonomy and making decisions as opposed to job satisfaction. 


\title{
Development of the Community Mental Health Center: From the Signing of the Mental Health Act of 1965 Through Today
}

\author{
Introduction
}

Community mental health centers have increasingly played a significant role in provision of mental health services to various individuals (Shin \& Mauery, 2013).

CMHCs were originally established by U.S. Congress in 1963, and since then federal funding facilitated CMHCs to serve every member of the community, irrespective of their ability to pay, and thus, it created a "mental health safety net." Whereas CMHCs were not completely rural, those in rural regions were typically the only providers providing reduced fee payment scales, and these centers were usually the main source of specialty mental health services. Deinstitutionalization and changes in funding forced numerous CMHCs to devote a vast amount of their resources to people defined as members of priority populations, which included SED (severely emotionally disturbed) children as well as adults with severe, persistent mental illness.

The Community Mental Health Centers Construction Act of 1963 (PL 88-164) as well as its succeeding amendments required grantees to offer five fundamental elements of service, which include crisis or emergency interventions, partial hospitalization, education/consultation, and inpatient and outpatient services (Wagenfeld, Murray, Mohatt, \& DeBruyn, 1994). Clear-cut grant subsidy or funds enabled CHMCs to serve every member of the public, irrespective of their capability to pay, and this resulted in the creation of an effective mental health safety net.

As a result of the deinstitutionalization movement, which started in the 1960s, several CMHCs abandoned their roles as numerous service agencies allocated a huge percentage of their resources to the requirements of persons defined by their state mental 
health organizations or centers as members of the priority people/population (Schnapp, Bayles, Raffoul, \& Schnee, 1999). The priority populations identified by the state mental health organizations comprised individuals with severe and persistent mental illness, and these were:

1. Adults with serious and persistent mental illness; for example, manic depressive disorder, major depression, schizophrenia, as well as other severely disabling mental disorders that necessitate treatment and ongoing support or crisis resolution

2. Children and juveniles who are below 18 years with a diagnosis of mental illness displaying social disabilities or severe emotional distress that need continued interventions or are life-threatening (Diamond, Warner, \& Wong, 1998). The Omnibus Budget Reconciliation Act of 1981 (PL 97-35) accelerated the transition of CMHCs away from their safety-net functions through consolidation of federal mental health subsidy or funds into block grants dispersed and managed by the state mental health organizations/agencies. CMHCs have received no direct federal funds for their operations grants since 1981, and certainly, the name "community mental health center" is no longer a formal federal title, even though several mental health hospitals or centers continue to utilize the name CMHC. Professionals in rural mental health stated that the lack of the community mental health centers' response to the farm crisis of the 1980s as well as other similar community problems caused this move away from addressing the mental health requirements of the general public and CMHCs focused on addressing/meeting the requirements of priority populations (Beeson, Johnson, \& Ortega, 1991; Cecil, 1988). 
The latest trend has brought rural CMHCs in certain states back to their initial roles of offering various mental health services to the community. For instance, CMHCs are increasingly becoming the centers of Medicaid-managed behavioral health-care programs in states such as Colorado, Utah, and Oregon (Lambert, Hartley, Bird, Ralph, \& Saucier, 1998). These provisions can increase the necessity for communication and official connections between CMHCs and various community providers including rural health clinics and community health centers. Although such provisions/arrangements do not give funds to serve the underinsured and uninsured, it's likely that states have expanded the emphasis of rural CMHCs beyond the priority people, which have been their primary concern for many years. Beyond the direct cost savings resulting from keeping individuals who have serious mental illness out of inpatient settings as well as in community-based settings, effective/managed care will generate incentives for CMHCs to offer more preventive mental health services to the community. Furthermore, in states with stronger county government participation in the funding and provision of mental health services, the funding mechanisms of managed health care as well as the primary focus offered by the state/county can allow community mental health centers to resume their roles of safety-net providers. 
The Emerging Roles of Community Mental Health Centers

\section{Mental Health Services and Policy in the United States Prior to the Community Mental Health Center Act of 1963}

The National Institute of Mental Health (NIMH) was created by the 1946

National Mental Health Act (PL 79-487). The National Institute of Mental Health was assigned with the following roles:

1. Promoting and conducting mental health research

2. Developing and promoting training for mental health specialists

3. Helping states to develop programs aimed at addressing mental illness; hence, minimizing the requirement for institutional care (Buck, 1984).

To help states develop programs aimed at addressing mental illness, and hence minimize the requirement for institutional care the first of these functions, the National Institute of Mental Health was authorized by the U.S. Congress to administer block funding/grants to the states to develop and expand mental health services, which include community-based preventions, outpatient care, and screening for inpatient care (Buck, 1984).

The National Institute of Mental Health block grant programs had a significant impact on the establishment and growth of outpatient mental health centers/clinics. The quantity of clinics (outpatient mental health centers) increased from 850 to 1,930 between 1947 and 1964 (Buck, 1984). Buck argued that although slight clinic development happened in rural regions during this era, it was rational to assume that certain urban clinics provided services to populations of the adjacent rural communities. 
Even though federal funding for the outpatient mental health clinics grew during the late 1950s as well as early 1960s, this program represented a reducing share of federal funds as well as of full NIMH grants disbursed on community-based mental health services. Conversely, from 1950-1960, state expenditure for community-based mental health services significantly grew from $\$ 5.1$ to $\$ 60.3$ million (Buck, 1984), which was attributed to the increasing concerns about the growing inpatient population in state clinics or health-care facilities as well as the increasing requirement to change to more benevolent community-based health-care models.

The nationwide movement to offer community-based mental health services to an extensive section of United States citizens started after a 1953 symposium on mental health co-sponsored by the American Psychiatric Association and the American Medical Association. The conference initiated a proposal for the research and development of national standards for treatment of people with mental illness. The World Health Organization published its research in 1955, showing the necessity for community-based treatment of individuals with mental illness. Numerous European nations were ahead of the United States in the development of outpatient services and community-based residential care for mentally ill individuals (Chu \& Trotter, 1974). Due to increasing concerns, Congress agreed to sponsor the research endorsed by the American Psychiatric Association and the American Medical Association conference, and on July 28, 1955, the U.S. Congress passed the Mental Health Study Act (PL 84-182). The research was carried out by the Joint Commission on Mental Illness and Health, a non-profit corporation created by the American Psychiatric Association and the American Medical Association with fractional funding from a key pharmaceutical manufacturer (Dorwart \& 
Epstein, 1993). The Joint Commission released its report in 1960, named the "Action for Mental Health," which is almost the time John F. Kennedy assumed office as U.S. President. "The Action for Mental Health" report suggested building on the existing structure that was established by state governments through the use of the National Institute of Mental Health-financed community clinic model (Buck, 1984). This strategy was planned to reinforce the state hospital systems and to retain state control over the clinics.

The "Action for Mental Health" results influenced President Kennedy's address made before the U.S. Congress on February 5, 1963. President Kennedy stressed that poverty is a causal factor in mental illness, and advocated for community prevention efforts explicitly aimed at lower-income individuals. The President also suggested a 50\% decrease in state hospital populations across the nation over the next decade (Dorwart \& Epstein, 1993). He also formed an interagency task force on mental health in response to the report, which was supervised or directed by Anthony Celebrezze, the Secretary of Health, Education, and Welfare. The task force involved representatives from the Council of Economic Advisors, the Department of Labor, Veterans Administration, and the Bureau of the Budget (Chu \& Trotter, 1974). Experts from the National Institute of Mental Health operated the group. In December 1962, The A. Celebrezze Task Force presented its outcomes. The task force proposed a federal definite grant program that could lead to the creation of a national network of community mental health centers. During the succeeding hearings about the recommended Community Mental Health Centers Act, the Kennedy administration and Congress selected to adopt/follow the recommendations of the Celebrezze Task Force instead of the recommendations 
presented in the "Action for Mental Health" study report (Buck, 1984; Grob, 1991). The moral principles of that period, emphasizing the importance of civil and human rights, combined with strongly negative criticisms of state governments as care providers, influenced the selection.

During the period before the Community Mental Health Centers Act implementation, members of the psychiatric profession were divided into two camps with regard to the desired model for organization and delivery of mental health services. One group took a public health model of mental illness that aimed at community care, education, and prevention. The community psychiatry tenets had a lot in common with the evolving anti-poverty movements; therefore, these groups inclined towards a natural alliance (Rochefort, 1984). The remaining group supported the older "medical model" standpoint that aimed at state government control of community-based services and expanding the state hospital system (Chu \& Trotter, 1974). The first camp influenced the Kennedy administration and the Celebrezze Task Force, whereas the second camp influenced the development of the Joint Commission report, with the support of the American Medical Association. Comparing community care to "socialized medicine," the American Medical Association associated itself with state government leaders who opposed the Community Mental Health Centers Act (Rochefort, 1984). The opposing view enthusiastically opposed the Community Mental Health Centers Act because of the recommended change in the control loci as well as subsidy (Chu \& Trotter, 1974). It was justified that the majority of state government administrators reinforced deinstitutionalizations due to philanthropic reasons as well as ways of controlling increasing costs of institutional care. Public-health-model supporters held the state governments 
responsible for failing to institutionalize the mental health system as well as its more publicized neglect and abuse of psychiatric patients. The association of community mental health activists and community psychiatrists effectively characterized state government administrators as individually responsible for the continuous evils of protective care. The persistent bitterness of state mental health program directors toward the psychiatrists running numerous new $\mathrm{CMHCs}$ created an insistent obstacle to cooperation between the two segments of the public mental health systems.

Development and Expansion of Community Mental Health Center Facilities and Responsibilities, 1963-1981

On October 31, 1963, the Mental Retardation Facilities and CMHC Construction Act (PL 88-164) (called the CMHC Act) was signed into law by President John Kennedy (Bloche \& Cournos, 1990). The signing of the CMHC Act signified an important change of control over the community mental health system from the local states to the federal U.S. government. The CMHC Act created a divide in responsibility and authority between the system of community-based mental health care and the state hospital system of institutional care aimed at serving as a way to manage admissions to the state hospital systems (Bloche \& Cournos, 1990; Levine, 1981). The tally of county and state mental hospitals was reduced by approximately $67 \%$ (two-thirds) over the next 15 years, whereas federal funds funded the formation of more than 500 CMHCs (Rochefort, 1984). The National Institute of Mental Health staff stated that $37 \%$ of the CMHCs served in rural regions in 1980, and this report was presented to the U.S. Congress (Foley \& Sharfstein, 1983). 
As a result of the push to pass all-inclusive social legislation in an impulsive political climate, the Community Mental Health Center role defined in the Act was comprehensive as well as open to interpretations. To be entitled for federal funding, CMHCs had to offer these services:

1. Outpatient services: CMHCs offer outpatient services but no specific services and target populations were well-defined.

2. Inpatient services: CMHCs offer inpatient services through referrals or directly by screening patients for hospitalization.

3. Partial hospitalization services: CMHCs offer these services as the precursor to day treatment programs.

4. 24-hour emergency services: These services are available at CMHCs as part of at least one of the outpatient, inpatient, and partial hospitalization services.

5. Education and consultation services, for community and professional agencies. The law also encouraged provision of five extra services (research or assessment and training, diagnosis, rehabilitation, as well as pre-care and aftercare) which authorized a CMHC to utilize the "all-inclusive" description, partially because the CMHC Act unsuccessfully defined priority service populations. Numerous CMHCs did not undertake the role for the aftercare of individuals released/discharged from the state health care facilities/hospitals. Although the population of the CMHC facilities fell significantly in the 1960 s with regard to the objectives of the numerous state legislatures and the Kennedy administration, numerous individuals with severe and persistent mental disease were discharged into the community setting with no follow-up or little care (Chu \& Trotter, 1974; Grob, 1991). Even though the Community Mental Health Center Act 
required centers to serve definite geographic catchment areas, the law similarly encompassed the minimum requirements regarding the provision of services to lowerincome individuals, proposing that CMHCs should offer only an equitable or rational amount of mental health services to the poor population (Chu \& Trotter, 1974). This was unanticipated given the considered association of mental disease with poverty expressed by the community mental health movements and the Kennedy administration. The absence of clear specification in regard to the role of CMHCs in serving lower-income people led to substantial latitudes in CMHC practices and policies. Providing mental health services to lower-income individuals varied considerably from center to center, and this was due to the degree at which CMHC leadership regarded these activities as mission-critical.

With the anticipation that the CMHC facilities could ultimately become independent, the U.S. Congress established a decreasing and time-limited federal support into the Community Mental Health Center Act (Dorwart \& Epstein, 1993). Further, the preliminary funds funded building but not staffing of the facilities. Therefore, the funds that were used to operate $\mathrm{CMHCs}$ became a significant problem from the start of the program (Silverman, 1980). Numerous CMHCs developed serious financial snags after a few years of operation. This problem prompted CMHCs to promote services to persons covered by health insurances at the expense of needier people (Grob, 1991). Other researchers (i.e., Chu \& Trotter, 1974; Dorwart \& Epstein, 1993) stated that the CMHCs underperformed in serving both the lower-income population and individuals with severe and insistent mental disease. A more benevolent opinion is that CMHCs were merely overpowered with the demands for services as well as the variety of requirements of the 
different groups, which comprised the weaker definition of people with mental disease and could not respond sufficiently due to the substantial resource restrictions (Dowell \& Ciarlo, 1983).

Several amendments to the original Act tried to deal with some of these limitations. For instance, following the 1964 Democratic landslide, Congress overcame resistance to the utilization of federal funds to increase the amount of assigned services to 12, as well as to cover CMHC staff, employment, and operations (Levine, 1981). The other provisions were comprised of services to kids, the ageing population, and substance-abuse treatment services as well as aftercare for deinstitutionalized individuals (Schnapp et al., 1999). Other amendments altered the language of other service descriptions to replicate the increasing pressure to offer management of cases as well as care management to individuals discharged from state hospitals (Grob, 1991).

Dependence on the federal government to deal with issues of illness, poverty, and incapacity continued with the passing of the comprehensive policies related to the Greater Society. From the perspective of the CMHCs, the most significant of these were Social Security Disability Insurance (SSDI), Medicaid, and Supplemental Security Income (SSI). Predominantly in its primary years, the Medicaid programs encouraged states to choose psychiatric wards and nursing homes in acute-care health-care facilities as places of care for individuals with severe and persistent mental disease (Gronfein, 1985).

Community-based mental health services expanded throughout the 1960s and 1970s, partly due to the increasing quantity of clinicians setting up private practices (Mechanic, 1994). However, the lack of community-based services for persons with severe mental disease discharged from state hospitals remained a seemingly obstinate 
issue, and the urgent need of community-based services for persons with severe mental illnesses was augmented in numerous states across the U.S. by greatly publicized classaction court cases and subsequent agreement decrees that necessitated state mental health agencies to undertake responsibilities or roles to readdress the concerns of long-term negligence (Bookman \& Carlson, 2013).

Regarding these problems, President Carter appointed a Commission on Mental Health in 1977 to study the necessity for additional changes in the country's mental health system. In 1978, the Commission published its recommendations, which aimed at increased funding of mental health services, mainly for individuals with severe and persistent mental illness as well as for other priority population groups. The Commission's recommendations were categorized in the Mental Health Systems Act (PL 96-398), which was signed into law on October 8, 1980, by President Carter, 30 days before President Carter lost the election to President R. Reagan (Foley \& Sharfstein, 1983).

\section{The Omnibus Budget Reconciliation Act of 1981: The Return of Authority to the States}

Ronald W. Reagan won the presidential election in 1980 and promised to return authority/responsibilities for numerous social programs to the States, and to decrease government waste and regulations. The President's policy was called the New Federalism. The Omnibus Budget Reconciliation Act of 1981 (PL 97-35) was the main base of the New Federalism. The 1981Omnibus Budget Reconciliation Act and its subsequent administrative rules involved numerous provisions that directly affected the 
viability, status, and mission of CMHCs (Dorwart \& Epstein, 1993; Mechanic, 1994). These provisions include:

1. Terminating the terminology "CMHC" to designate a distinctive body or organization

2. Removing the federal requirements concerning Community Mental Health Center usage reporting

3. Reducing overall federal funding for mental health service delivery and reallocating funds to substance-abuse treatment services

4. Returning to the states the main authority to decide or determine how and to whom mental health services must be provided via the block grant mechanisms

5. Removing direct federal categorical funding provision from the Community Mental Health Centers and replacing that direct federal categorical funding/grants with alcohol, drug abuse, and mental health block funding/grants to the states

6. Repealing the Mental Health Systems Act.

The image was beginning to shine brighter during the early 1990s. The state expenditure on mental health services improved by around 2\% from 1987 to 1997, while Federal expenditures increased by approximately 6\% from 1987 to 1997, in large part due to increasing dependence on Medicaid funding for the mental health services (U.S. General Accounting Office, 2000). The community mental health services block grant was created by the 1992 Alcohol, Drug Abuse and Mental Health Administration Reorganization Act (PL 102-321). The block grants were intended or used to support services for adults with severe and persistent mental illnesses and children with severe emotional disturbances (Friedman, Katz-Leavy, Manderscheid, \& Sondheimer, 1996). 


\section{Community Mental Health Centers Enter the 21st Century}

Although numerous CMHCs have survived, the service priorities of CMHCs and

the loci of control over their priorities have improved significantly. The common practice among CMHCs as well as other health-care providers has been to use revenues produced by paying patients combined with support from local, federal, and state government to cover the costs of caring for lower-income individuals who are uninsured. However, some forces have joined collectively to change the practices of government agencies, insurers, and providers, and this left them less willing to pick up a portion of the costs of the safety-net populations (Dorwart \& Epstein, 1993). For instance, some states that have implemented managed behavioral health in the states' Medicaid programs have contracted with CMHCs to offer mental health services to every Medicaid client, even though the focus will continue to be on Medicaid's Supplemental Security Income (SSI) population, as well as the nature of these contracts, which can make it more challenging to subsidize services to the uninsured population.

The Community Mental Health Centers Act of 1963 had two purposes. First, economically disadvantaged groups had greater risks for exacerbation and development of numerous mental health problems; therefore, the legislation sought to make mental health services available to every person who needed these services irrespective of financial means (Foley \& Sharfstein, 1983). Secondly, the legislation sought to organize and incorporate services for individuals with severe and persistent mental disease returning to the community from the states' hospital systems. Although the federal designation of Community Mental Health Centers has changed, the two purposes or 
objectives remain the most reliable foundation that can be used to measure the performance of the publicly funded mental health system in the U.S.

CMHCs remained an important and true choice for mental health treatment for lower-income uninsured individuals; however, the availability of mental health services for lower-income uninsured individuals has gradually declined over the last two decades. These persons frequently sit on CMHC waiting lists for prolonged periods or they are turned away as a result of a lack of money or funding for services other than the individuals directed to the priority populations. Whereas Medicaid offers financial access to mental health services for individuals poor enough to qualify, CMHCs still are fixed between local needs and state priorities with inadequate resources and staff.

\section{Systematic Analysis of the Existing Literature}

There has been a dramatic increase in job satisfaction research over the last 10 years. Researchers have pursued this construct for obvious reasons. One frequently cited motivation is that the more employees are satisfied, the more productive, stable, and committed to the corporation they are (Tanoff, 1999).

Van der Doef et al. (2012) stated that job satisfaction is an important issue for health-care professionals including the CMHC workforce globally. Lu et al. (2012) found that organizational features or structures (i.e., hospital or CMHC structures) significantly influence job satisfaction for the health-care workforce. Organizational features include intention to leave due to low job satisfaction, lack of equipment, and personnel shortages (Liu et al., 2012).

Early research focused on establishing a relationship between job satisfaction and job performance (Jewell \& Siegall, 1990). 
The first place researchers looked was to verify their hunch that work variables as opposed to personal variables were the largest contributor to satisfaction. However, many studies began to find that work variables combined made up barely half of the explained difference (Herzberg, 1959; Sergiovanni, 1966). Ground-breaking studies in the 1970s began to focus beyond the workplace/job satisfaction relationship and study the correlation between general life and job satisfaction (Andrews \& Withey, 1976). This early research spawned a new focus for researchers to investigate that continues to this day.

More recent research also found other interesting factors of job satisfaction. They found that it is rare for a person to report feeling completely satisfied with his/her job. Schultz and Schultz (1994) asserted that those who were fortunate enough to have found work that best suited their abilities, values, and morals, report a sense of personal satisfaction, fulfillment, and a feeling of accomplishment that provide a reward, separate from the income they may earn. Finding this goodness of fit between worker and work environment is critical to many positive factors. The Special Task Force to the Secretary of Health Education and Welfare in Work in America (1973) even proposed that work satisfaction appears to be the best predictor for longevity, even better than medical or genetic factors alone.

With these early findings of the 1970s established, further research uncovered a previously accepted fact to be incorrect. Job satisfaction was previously perceived to be one end of the satisfaction dichotomy, with job dissatisfaction being the other. The research provided evidence that suggested job dissatisfaction was a completely separate factor (Herzburg, 1968). Interestingly enough, they found that even though job 
satisfaction has positive health factors associated with it, job dissatisfaction was found to be associated with negative health factors. Job dissatisfaction was found to be associated with emotional illness and symptoms of emotional disorders, such as loss of appetite or “emotional breakdown" (Wiener, Vardi, \& Muczyk, 1981).

Given the important role that the CMHC system plays in managing the serious mental illness in the United States. Although past research has been able to establish many factors that make up the construct of job satisfaction, little or no research has been focused on the interaction that personality and occupational/personal characteristics play in the CMHC industry. In business, one of the most studied relationships is that of employee and job satisfaction, and, yet, there is a gap in the literature concerning an employee's personality and the impact it may have on job satisfaction in this critical industry. Therefore, in this study, the employee's personality and its impact on job satisfaction is explored in CMHCs.

\section{History of Bowen Center From 1960 to 2017}

On April 25, 1960, a meeting was held to establish the Four County Mental Health Clinic, to offer services to citizens of Whitley, Wabash, Marshall, and Kosciusko counties. The Clinic was integrated as the Four County Mental Health Clinic on May 16, 1960, under the General Not-For-Profit Corporation Act of the State of Indiana. The

board of directors included: Marie Armstrong, secretary; L. H. Carpenter, treasurer; John S. Wilson, vice president; and Mildred Hurford, president.

The board of directors held a second meeting on June 7, 1960, to establish a yearly fiscal plan of approximately $\$ 35,000$ and this paved the way for further fiscal planning and budgeting. On March 1, 1961, the Clinic was opened officially in Warsaw 
and started providing specialized outpatient psychiatric care to citizens of Whitley, Wabash, Marshall, and Kosciusko counties. The Clinic was located at 526 East Winona Avenue. The operating budget for the initial year was $\$ 35,000$, with $50 \%$ of the money offered by the Indiana Mental Health Department and the remaining 50\% provided by patient revenues and the four counties.

The Clinic was relocated to Warsaw's 315 West Center Street in April 1962. Huntington County was included in the service region in March 1966. The Warsaw office was then moved to the Murphy Medical Professional Building located at 422 South Buffalo Street. On April 17, 1969, the board of directors met and officially changed the name of the Clinic to reflect the addition of Huntington County and called it the Five County Mental Health Clinic.

With the expansion of its services, space became insufficient and the Clinic was relocated to 703 South Buffalo Street in Warsaw in 1973. In the same year, Dr. Ben Knott was appointed as an administrator. The first satellite branch of the Clinic opened its doors to the clients in Plymouth in July 1973, but was operated on a weekly basis. The Clinic also opened a new office in Huntington in September 1973 and operated on a weekly basis. Another office was opened in Wabash (at the Wabash Junior High School) in October 1973 and operated once a week. A new office was also opened in the City of Columbia in March 1974 and operated once a week.

The office was moved to 44 East Franklin Street in 1975 and opened until midday on Thursday, but it was open for 24 hours on Tuesdays and Wednesdays. Richard Claussen was appointed as the Director, and the office was situated at 1009 Lincoln-way East in 1976. Within the same year (1976), the office relocated to Room 320 at 48 East 
Franklin Street and the Director was Richard Hite. The clinic was opened until 2100 hours on Tuesday, all day, twice a week (that is, Thursday and Wednesday).

The Health Facilities Review Committee of the Indiana Advisory All-inclusive Health Planning Council in Indianapolis met to review plans for the Five County Mental Health Center in June 1975. The groundbreaking for new inpatient and outpatient office block or clinic was done in August 5, 1976, at 850 North Harrison Street, Warsaw. The proposed building cost was $\$ 1.70 \mathrm{M}$ (Bowen Center, 2018). The local funds from the five contributing counties, state, and federal grants were used to fund the construction. The Wabash office was opened in October 1976 and was located at 280 North Wabash Street, staffed 24 hours on Monday, Wednesday, and Friday, but open until 1900 hours on Tuesdays and Thursdays. Heracleo Matheu, M.D., was appointed as the Director of Clinical Services in November 1976; he was a former superintendent of Logansport State Hospital and a nationwide reputable psychiatrist.

The name of the Clinic was historically changed on June 15, 1977, and named the Otis R. Bowen Center for Human Services Incorporated, in honor of Governor Otis R. Bowen, M.D., who was born in Bremen in Marshall County (the Center's service area). The governor was the main supporter of the CMHC center system in Indiana, and in July 1977, the Bowen Center received official acknowledgment as a mental health center by the Department of Mental Health of the State of Indiana. This recognition opened doors for the Center to receive operations grants from the federal government.

For the first time, partial hospitalization services were offered in March 1978 and inpatient services commenced in the 18-bed Inpatient Unit. Since then, new inpatient and outpatient buildings have become operational. A comprehensive CMHC was officially 
opened in Warsaw on April 28, 1978, by Governor O.R. Bowen and was known as Bowen Center. The C\&E Coordinator Laura Meers, Ph.D., created Orby in 1980.

On May 17, 1980, the Bowen Center was certified or accredited by the Joint Commission on Accreditation of Healthcare Organizations (JCAHO). The Center was given a 2-year accreditation. Between 1980 and 1981, the number of the employees working at the Bowen Center rose to 125 due to an increase of the services. The Bowen Center first opened a transitional house in October 1980 for severely/chronically mentally ill adults at Russell House, located at 423 North Plum Street, Plymouth. William Kurosky was appointed as Acting Executive Director after Dr. B. Knott resigned as Executive Director in September 1981. J.W. "Rusty" McIntosh, Ph.D., was appointed as an Acting Executive Director after his predecessor died in February 1982. After serving as a Director of Community Services of the Indiana Department of Mental Health for 18 years, Daniel D. Steiner was named Executive Director on July 18, 1982. Bowen Center received another accreditation for a period of 3 years from the Joint Commission on Accreditation of Hospitals (JCAH) in July 1982.

The commissioners of Wabash County leased a 5500 square-foot space in the Wabash County Hospital to Bowen Center in July 1987. Bowen Center was reaccredited by the JCAHO and given a 3-year accreditation. Kurt Carlson was appointed as the CEO (Chief Executive Officer) of Bowen Center on $15^{\text {th }}$ June, 1989. The Center opened Life Management Associates, but the Warsaw office was closed in February 1990 during the FY'94, forcing the redeployment of employees to other offices (Bowen Center, 2018). JCAHO also reaccredited the Bowen Center for another 3 years in July 1991. 
A new 10-bed facility was constructed in February 1993 to replace the eight-bed old Rusell building to serve acute/chronic mentally-ill adult patients. The Joint Commission on Accreditation of Healthcare Organizations reaccredited Bowen Center for another 3 years in July 1994. The Castaldi/Wilson Apartments, including a 21-unit apartment facility in Warsaw that was built and funded by HUD section 811 to provide affordable housing for severely mentally ill patients, were dedicated and occupied in October 1995. The facility was renamed for the founding members of the Center, which were: John S. Wilson, M.D., of Whitley County, and Lawrence J. Castaldi of Kosciusko County.

Brief Therapy Institute was established in 1995 to put emphasis on the clinical obligation of the Bowen Center to transitory therapies as well as to establish subdivisions via consultations for fees and rigorous training occasions for medical specialists outside the Center. Through legislation, the Department of Mental Health of the State of Indiana created a mental health managed-care plan called the Hoosier Assurance Plan (HAP), and clienteles were enrolled in this plan from July 1996. This led to an improved managed-care model.

A behavioral health managed-care network was formed in 1996 by a collaboration between designated behavioral health centers. The Affiliated Service Providers of Indiana (ASPIN) was founded by Bowen Center. Bowen Center was reaccredited and commended by JCAHO in July 1997 and given another 3 years of accreditation. Bowen Center offers quality professional mental health services to people in northeast Indiana through its offices in the following counties: Whitley, Wabash, Steuben, Noble, Marshall, LaGrange, Kosciusko, Huntington, DeKalb, and Allen. Bowen Center earned Joint 
Commission on Accreditation of Healthcare Organizations accreditation with an award and special praise for 1994 to 1997 and for a second time for 1997 to 2000. The Fort Wayne office was opened in 1997 to offer partial outpatient services as a way of supporting school-based programs that operate in numerous grade schools in the area.

A larger office was built at 990 Illinois Street, Plymouth, in 1998. The Juvenile Justice Task Force of Kosciusko County combined with the Bowen Center in 1998 and moved the entire operations and facilities of a 10-bed adolescent youth shelter, situated in Warsaw (at 2216 North Pointe Drive), to the Bowen Center. In 1998, 18 acres of land were bought in Huntington, and a professional office park was constructed on the land. Due to higher demand for services, a new and larger office was opened in April 1999, located at 119 West Market Street, City of Columbia. The office aimed at accommodating the expansion in programs and services offered to the increasing population. Another larger office situated at Cass Street, Fort Wayne, was leased in December 1999, and was bought in 2000. Transitional living (cluster homes) was opened in November 1999 for men in Plymouth to serve in-between patients (individuals who do not need a group home or apartment).

The Joint Commission on Accreditation of Healthcare Organizations reaccredited the Bowen Center for a fresh 3 years in July 2000. A new office building situated at 2860 Northpark Avenue, Huntington, was renovated and occupied in April 2001. The equipment, land, physical facilities, workforce, and programs of the Shady Rest Home, which is situated at 10924 Lincoln Highway, was acquired on May 11, 2011, from the Marshall County Commissioners in exchange for one dollar, and was used as a residential care facility for severely mentally-ill adult patients. The Kosciusko County Youth Shelter 
was shut down in August 2001 as a result of decreased demand for services, low census, and a lack of referrals.

As a result of numerous referral sources (such as DFC, probation, and courts) demanding additional services, a new office was opened in Albion, Noble County, in August 2001 to provide parenting, management of anger, home-based, chemical reliance, and outpatient services. After a 1-day tailor-made survey on February 28, 2002, the Joint Commission on Accreditation of Health Care Organizations accredited Shady Rest Home in March 2002. An 11-resident supported-living facility called the Harbours was opened in March 2002 for the aging, offering such services as personalized and housing support to assist the elderly in the region and to improve people's quality of life.

The previous Huntington office building was revamped in May and June 2002 to function as a cluster home for five women. These cluster homes served in-between clienteles (patients who did not require a group home or apartments). In addition, a satellite office was opened in Knox. The facility offered chemical-reliance services to the citizens of Starke County. However, it was shut down 4 months later because the Center was not able to create a base for referrals in Starke County. A building located at 115 South McKinley Street, Warsaw, was bought in July 2002 and renovated by the Bowen Center, called Rainbow's End. The building served as a drop-in center for severely mentally-ill patients. In order to meet the increase in demand for services in Allen County, the Franklin Office facility located in Fort Wayne was acquired in August 2002. The facility is located on Goshen Road. Only half of the building was used by the Center while the rest was leased. The Miami Elementary School building was purchased by the Center in October 2002 to be used by the Center to offer its services to the clients from 
Wabash County. In Wabash, cluster homes were opened after the two homes were rented by the Bowen Center in April and May 2003, and these served severely mentally-ill men patients.

The Bowen Professional Building was opened in Fort Wayne in September 2003. The building is located at 2100 Goshen Road. The Joint Commission on Accreditation of Healthcare Organizations reaccredited the Center for 3 years in October 2003. The Bowen Center agreed to buy the NCI building in December 2003 to offer more space for the Center, which is located at Jefferson Street, Warsaw. The second set of cluster homes for severely mentally-ill women patients was officially opened February 1, 2004. The Rainbow's End facility was relocated on May 5, 2004, to another facility located in Warsaw (2621 East Jefferson Street). On June 4, 2004, the Center's services were discontinued and relocated to the new building situated at Elementary School.

An outpatient office was opened by the Bowen Center in Syracuse, Indiana, in November 2004. In addition, another outpatient office was opened in Goshen, Indiana, in January 2005. The outpatient services offered by the Center office on 803 Chicago Street were discontinued in March 2004 and relocated to a building in Elkhart, Indiana.

The Bowen Center opened the Enchanted Hills Clubhouse, Syracuse, in December 2005, which was a pilot program. The Center also opened a new office called Sus Amigos in Warsaw in May 2006, and this was to serve clienteles who speak Spanish. An outpatient office was opened in South Bend, Indiana, by the Bowen Center in June 2006. In order to provide behavioral and social health-care improvements to the poor people in the Enchanted Hills, a Venture Troop/Sea Scout was co-sponsored by the Bowen Center in September 2006. 
The St. Joseph County and Elkhart County offices were shut down in March 2007 and April 2007, respectively, by the Center because of its inability to fund itself, and also because of changes in state funding. A 16-bed inpatient facility was constructed by the Bowen Center in Provident Drive, Warsaw, Indiana, in July 2007. As a result of the merging of cluster home services and workforce, the Huntington cluster home was closed in September 2007. To offer services to the General Motors Company, the Bowen Center started a new satellite facility in Marion, Indiana, in September 2007. Bowen Center held an Open House in October 2007 in the newly built Enchanted Hills Community Partnership Center with the aim of providing improved behavioral and social health-care changes in the entire region.

A service agreement was signed between the Kosciusko Community Hospital and Bowen Center in October 2007 to provide evaluations as well as counseling services for cancer-treatment patients. This led to the development of the Stress Management and Relaxation Training (SMART) program for individuals diagnosed with cancer.

The growth and expansion of the Bowen Center slowed in October 2007, and the Center reduced its community based employees through attrition to 50, due to the changes in the Medicaid Rehabilitation Opting limits, Medicaid rule changes, and the impacts of the 2005 Federal Budget Reduction Act, which forced the Center to reconfigure its services. As a result of the merging of cluster home services and workforce, the First Light (the cluster home in Wabash) was shut down in November 2007. Due to insufficient referrals, the satellite outpatient unit in Marion, Indiana, was closed in March 2008. A pilot program in Warsaw with Tele-psychiatry with a Nurse was started by Bowen Center in March 2009. 
The Medicaid Rehabilitation Opting Transformation project was successfully started by the Bowen Center in July 2010 to deliver different services to its clients. The Preferred Agreement between CMHCs and Indiana's Department of Child Services (DCS) began also in the same period (July 2010), allowing DCS to refer people to CMHCs, and people paid for the Medicaid Rehabilitation Opting equivalent funds. The Center's Sus Amigos office was closed in August 2010 due to loss of funds to finance the programs. Bowen Center opened a clinic to offer autism services in Warsaw in October 2010. A new office was opened by the Bowen Center in LaGrange County (836 N. Detroit Street) in December 2010.

Bowen Center contracted Netsmart in July 2011 to implement an Electronic Medical Record (EMR) system. Affiliated Service Providers of Indiana received grants in July 2011 that included the Bowen Center as a location to provide Veterans Behavioral Health Services via the Telepsychiatry Association. The Bowen Center opened a clinic to offer autism services in Fort Wayne in January 2012. The Chronic Addiction Care Navigation Program(s) was also started by Bowen Center in March 2012. To meet the demands of the growing number of employees, Bowen Center bought the Umbaugh Building in June 2012. The Division of Mental Health and Addiction gave SOF Grants to the Bowen Center in July 2012.

The Life Plex Pilot Program by Bowen Center in September 2012 soon revealed the efficiency and efficacy of integrating primary health and behavioral health. The Center also used the SOF grant awarded to it by the Comstock House in Warsaw in September 2012. New offices situated at 923 Cardinal Court in Auburn and 200 Hoosier Drive, Angola, were opened by Bowen Center in March 2013. The Office of Medicaid 
Policy and Procedure gave an Adult Medicaid Services Navigation grant to the Bowen Center in April 2013. This funding was used in increasing follow-up of outpatient patients following a psychiatric hospitalization.

In-Hospital Services, Cancer Care Services, as well as ER Services' Contracts signed between the Bowen Center and St. Joseph Regional Medical Center commenced in July 2013. This was aimed at providing better primary care and behavioral health. The Bowen Center started using the new EMR (Electronic Medical Record) system in August 2013. Using the SOF Grant, Bowen Center purchased a building facility in Warsaw in November 2013 to offer inexpensive houses and eventually house possession for its clientele.

The corporate office relocated in June 2014 to 2621 East Jefferson Street from 850 North Harrison Street in Warsaw to provide outpatient services. To offer cheap housing as well as ultimate home ownership for clienteles in the Winona Lake community, the Bowen Center purchased a mobile home using the SOF Grant in February 2015. Two cluster homes belonging to the Bowen Center were shut down in Columbia City in March 2015. Using the SOF Grant, two lots and a mobile home, as well as a home in Huntington, were bought by Bowen Center in June 2015 with the aim of offering cheap housing and then ultimate home possession for it clienteles. Groundbreaking of a new inpatient unit was done in September 2015.

Bowen Center opened a Genoa Pharmacy in January 2016, which is located at the outpatient office in Fort Wayne. To offer spaces for RSP administrative duties and DCS visitations, Bowen Center leased a space in Kendallville in February 2016. The Center also leased a building in Columbia City in April 2016 to offer DCS visitations and group 
services. Housing units were bought by the Bowen Center in Warsaw (2109 East

Jefferson Avenue) in May 2016, which were used for Respite unit(s) for clienteles.

Clients and employees were relocated to the New Inpatient Unit in Pierceton, Indiana, in September 2016.

LabCorp's operation was opened at the Bowen's outpatient facility in Warsaw in October 2016 to serve the general public, workforce, and clients. The Indiana State Opioid Treatment Facility was licensed by Bowen Center in July 2017, and since then it has started offering clinical services. The Shady Rest facility was closed by Bowen Center in July 2017 and its ownership was transferred to the office of Marshall County Commissioners. 


\section{CHAPTER 3}

\section{METHODOLOGY}

This chapter describes the design, methods, and procedures utilized for this research study. It is organized by the following sections: type of study, population and sample, definition of variables, instrumentation, data collection, and data analysis schedule. The purpose of this exploratory study will be to investigate Community Mental Health Center (CMHC) employee's big five personality characteristics, demographic attributes and corresponding job satisfaction. These variables have been culled from a longer list of possibilities after a review of job satisfaction literature, psychological literature, and personal experiences. Parson's career theory of person-environment was selected because of its extensive research base, and it has been used in community mental health centers research before (Elkins, 2007; Pseekos, 2009). This study attempts to expand this body of existing research by including personality and job satisfaction in a manufacturing organization, a previously unexplored area.

\section{Type of Study}

This study will examine the relationship between CMHCs' demographic attributes, big five type indicators and their job satisfaction through a quantitive, nonexperimental, correlational, cross-sectional, survey research design. Quantitative research is utilized as it facilitates the development of "mathematical models, theories, and/or hypotheses pertaining to natural phenomena" (Thomas, 2003). 
Accordingly, the researcher did not implement a treatment, manipulate a variable, nor use random assignment procedures. Additionally, the data collected reflects the current atmosphere of the staff in the outpatient environment as perceived by the sample population within study. Therefore, the data analysis described staff's perceptions of their job satisfaction and its relationship to their personality traits.

This study best fits into the category described as a correlational field research study. This design provides for a high degree of external validity based on real-world setting and participants. Inferences about the relation between variables are discussed, but the causal inferences among variables cannot be determined as this is a correlational research project. Multiple independent variables were used, including the five personality factors, gender, age, education, marital status, ethnicity, years with the company, and years in occupation. The dependent variable is job satisfaction as presented by the general Job Satisfaction Survey.

\section{Population and Sample}

The population for this study are the employees of the Bowen Center in Warsaw, Indiana. This CMHC covers ten counties in northern Indiana. These include Marshall, Kosciusko, Whitley, Wabash, Huntington, Lagrange, Dekalb, Noble, and Allen Counties. The human resource department reported that they have 482 fulltime equivalent staff. They employee 257 Rehabilitation Service Providers, 29 Rehabilitation Coordinators, 15 WRAP Facilitators, 49 Behavioral Health Service Providers, 44 Licensed Outpatient Therapists, 8 Substance Use Therapists, 37 Client services staff and 43 non-clinical staff.

Of these employees $19.50 \%$ are male and $80.50 \%$ female. The reported employee race/ethnicity breakdown of the staff is African American 5.39\%, Asian or Pacific 
Islander $0.62 \%$, Hispanic of any race $2.49 \%$, other $4.98 \%$, and White $86.51 \%$. The HR department reported that the ages of their employees were 18-24, 15.56\%, 25-34, $42.74 \%, 35-44,16.39 \%, 45-54,14.32 \%, 55-64,9.54 \%$, and $65+, 1.45 \%$. Education for the population was $4.56 \%$ secondary education, $4.77 \%$ some college, $65.15 \% 4$ year college, $23.86 \%$ masters degree, and $1.66 \%$ doctorate degree.

Tenure of employees are 0-2 years, $68.46 \%, 3-4$ years, $15.77 \%$, 5-6 years, $3.11 \%$, 7-8 years, $4.36 \%$ and $9+, 8.30 \%$. Marital status of the employees are single, $58.71 \%$, married, $41.29 \%$, widowed, $0 \%$ (information not collected due to privacy), divorced, $0 \%$ (information not collected due to privacy), and separated, 0\% (information not collected due to privacy).

The demographics of the sample were as follows: A total of 180 surveys were returned. Surveys returned complete were 168. They represented 65 Rehabilitation Service Providers, 16 Rehabilitation Coordinators, 7 WRAP Facilitators, 19 Behavioral Health Service Providers, 23 Licensed Outpatient Therapists, 3 Substance Use Therapists, 11 Client services staff and 24 non-clinical staff outpatient staff.

Of these employees $18.24 \%$ are male and $81.76 \%$ female. This split is similar to industry standard and similar to our population. The reported employee race/ethnicity breakdown of the staff is African American 3.53\%, Asian or Pacific Islander 1.18\%, Hispanic of any race $1.18 \%$, other $2.94 \%$, and White $91.18 \%$. These splits are similar to similar to our population and the communities we serve. The reported ages of the sample employees were $18-24,17.16 \%, 25-34,42.01 \%, 35-44,17.16 \%, 45-54,11.24 \%, 55-64$, $8.88 \%$, and $65+, 3.55 \%$. Education for the population was $1.78 \%$ secondary education, $6.51 \%$ some college, $54.44 \% 4$ year college, $34.91 \%$ masters degree, and $2.37 \%$ doctorate degree. 
Tenure of employees are 0-2 years, $56.41 \%$, 3-4 years, $17.98 \%$, 5-6 years, $8.33 \%$, 7-8 years, $5.77 \%$ and $9+, 11.54 \%$. Marital status of the employees are single, $38.24 \%$, married, $46.06 \%$, widowed, $0 \%$, divorced, $12.35 \%$, and separated, $2.35 \%$.

\section{Hypotheses}

The null hypotheses which informed the study are as follows:

1. There is no significant effect of the Big Five traits on Total Job Satisfaction in CMHC employees of the Bowen Center.

2. There is no significant effect of the Big Five factors on Total Job

Satisfaction controlling for demographic characteristics in CMHC employees of the Bowen Center.

\section{Definition of Variables}

The primary explanatory variable for this study was the measure of personality. To measure this the five-factor model, or "Big Five" as it is often referred to, has been numbered and labeled as: (I) Extraversions; (II) Agreeableness; (III) Conscientiousness (or Will); (IV) Neuroticism (or Emotional Stability); and (V) Openness (or Intellect).

The trait "Extraversion" can be seen as a contrast between those who are outgoing versus those who are more reserved. High extraversion is often associated with individuals described as attention-seeking and domineering, whereas individuals with low extraversion can be described as reserved or reflective. Eight statements including "Is talkative" and "Is full of energy" are used where possible scores 8-40. 
Agreeableness can be seen as a contrast between compassionate/cooperative and those who are suspicious/individualistic. Agreeableness has 9 questions including "Is helpful and unselfish" and "Is generally trusting" where possible scores are 9-45.

Conscientiousness contrasts those who would be described as efficient/organized versus those who are laissez-faire/spontaneity. Conscientiousness has 9 questions including "Is a reliable worker" and "Does things efficiently." The scores can be between 9 and 45 .

Neuroticism can be seen as describing how susceptible a person is to psychological stress. This characteristic has 8 questions such as "Can be tense" and "Can be moody" and possible scores are from 8-40.

Finally, Openness seeks to describe a person's intellectual curiosity, level of creativity and level of stimulation. There are 10 statements and include "Values artistic, aesthetic experiences" and "likes to reflect, play with ideas." The scores range from 1050 (Pervin \& John, 1997, p. 260; see also Ijaz \& Khan, 2015; Judge, Heller, \& Mount, 2002; Kappagoda, 2012; Templer, 2012).

This study also utilized job satisfaction as the dependent variable. Armstrong (2010) stated that job satisfaction refers to the feelings and attitudes individuals or employees have about their jobs. For instance, a favorable and positive attitude towards the work indicates job satisfaction, whereas unfavorable and negative attitudes towards one's work or job shows job dissatisfaction (Armstrong, 2010). The dependent variable of total satisfaction is measured by the scoring of 36 items. These items include statements such as "I feel I am being paid a fair amount for the work I do," "I sometimes feel my job is meaningless," and "My job is enjoyable." (Spector, 1998). For the 36-item 
total where possible scores range from 36 to 216, the ranges are 36 to 108 for dissatisfaction, 144 to 216 for satisfaction, and between 108 and 144 for ambivalent.

\section{Instruments}

The population was asked to complete a demographics form, The Big Five Indicator (see appendix A) and the Job Satisfaction Survey: Version 44 (see appendix B).

\section{Demographics Form}

The participants were asked to identify personal characteristics including their age category, level of education, gender, ethnicity, and marital status. Occupational characteristics were also collected including years in current role, years in the company, job classification, and occupational area.

Big Five Indicator

The Big Five Inventory (BFI): Version 44 (V44) was created by John, Donahue, and Kentle (1991) from the University of California, Berkeley. It is a brief although complete measure of the five-factor model of personality. John, Naumann, and Soto (2008) touted the BFI as an instrument that "allows efficient and flexible assessment of the five dimensions when there is no need for more differentiated measure of individual facets." The psychometric features of the BFI have been thoroughly researched. Alpha reliabilities ranged from .75 to .90 with an average above .80 . Retest reliabilities ranged from .80 to .90 with a mean of .85 (John et al., 2008). The BFI was also tested for its validity through peer-ratings with scales correlated at .47 in a college sample and at .61 across family members in a community setting (John et al., 2008). 
The BFI is available from the Berkeley Personality Lab at the University of California, Berkeley. The authors indicate the BFI is "freely available for researchers to use for non-commercial research purposes."

\section{Job Satisfaction Survey}

The Job Satisfaction Survey (JSS) was selected because it is a multidimensional instrument that was originally used in the social services sector but has proven statistically sound in multiple areas (Spector, 2008). The instrument is comprised of 36 items. Each item has the same stem which is, "How satisfied are you with 'this aspect' of your job?" Respondents are asked to rate their degree of job satisfaction on a 5-point Likert scale. This scale ranges from "very dissatisfied" to "very satisfied." The JSS measures five work factors: personnel satisfaction, workload, professional support, salary, and prospects and training. Subfactors represented in the instrument include work content, communication, financial rewards, promotion, coworkers, meaningfulness, supervision, work load, work demands, and satisfaction "total." Internal consistency reliabilities (coefficient alpha), based on a sample of 2870. Subscales ranged from a low of .60 for coworkers to a high of .78 for nature of work. For the purposes of this dissertation the coefficient alpha for total satisfaction was .91 (Spector, 1985).

The data were collected over 1 month. A survey packet was sent to all clinical staff via email and paper copies were available in the work setting. Occupational groups were selected for study if at least 30 individuals responded.

The participants were instructed to print out the instruments and return them via anonymous interdepartmental envelopes to the Human Resource department. Reminder emails were sent out at 1-week and 1-month intervals with a deadline of 2 months. 
The data collection process consisted of three steps: initial distribution via email (BFI, JSS, and demographic profile sent as attachments), a general follow-up, and a reminder. The initial email was sent to the selected participants and was included as an attachment to a letter that briefly described the study, the demographics form, the JSS, and the BFI. The letter functioned as an introduction to the study, explained the importance of their participation, and included an implied-consent form, an assurance of confidentiality, and contact information if respondents had any questions, and an opt-out form. A copy of the letter is included in appendix C.

The general follow-up was emailed to all participants 1 week after the original distribution. Its purpose was to encourage those who had not completed the instruments to complete them and to thank those who had already returned the completed materials. A copy of the follow-up email is included in appendix D.

\section{Data Collection}

The sample in this study were employees of The Bowen Center a mid-sized CMHC, headquartered in Warsaw, Indiana. They are one of $23 \mathrm{CMHCs}$ in the state. The attempt was to find a representative sample that would be able to fill out enough instruments to complete the research. This CMHC was chosen because it was similar in size and makeup to the other rurally based CMHCs in the state which. The Center was also selected because of its availability and accessibility. The CEO of the Center was contacted by the researcher via email. After the presentation of the study, the CEO directed the researcher to the CSO committee to receive permission to conduct the study. This was granted to the researcher and permission was given to conduct the study at the Center. The CEO then prepared a letter to be sent to Andrews University Internal Review 
Board informing them that permission had been granted to conduct the study at the CMHC site.

The Andrews University Internal Review Board approved the study on May $5^{\text {th }}$, 2014. This research study was designed to be sensitive to both the ethical and moral issues concerning the involvement and protection of human subjects. As such, the researcher followed procedures agreed upon by the Institutional Review Board to gain permission to conduct the research study. The followed are outlined below. The Vice President of Human Resources shared the scope and procedure of the study at a meeting for the leadership of the organization. At this meeting directors of each county were given the opportunity to ask questions and clarify any misconceptions regarding the study. The directors were informed that an introductory email (see appendix C) was going to be sent to all staff inviting them to participate in the study. Informed consent was explained, and consent was implied if the staff completed the instruments and returned them completed. The introductory email was sent to all staff on May $2^{\text {nd }}, 2014$. Attached to the introductory email received a copy of the instruments which were to be printed, completed and returned to the Human Resource Department through company courier allowing anonymity. The completed surveys were to be sent via company interdepartmental envelopes without names or identifying information to maintain confidentiality.

Through this procedure the researcher, intends to minimize the amount of disruption to participants and clinical work. The estimated time to complete the instruments was approximately 10-15 minutes and the Center approved the staff could use worked time to complete the task. Moreover, while an invitation will be extended to 
all the staff, they reserved the right to decline participation or withdraw from the study at any time. One week later, a follow-up reminder (see appendix D) was sent.

The attached forms included a short demographics survey, the Job Satisfaction Survey, and The Big Five Type Indicator. Staff were also informed that only those who return completed instruments via described mailing procedures will be permitted to participate in the study. Staff indicated their agreement to participate in the study by completing the forms and following the mailing instructions. They were given an option to return the forms with "I do not wish to participate in this study" checked. The researcher then collected all the completed instruments from the Human Resource Department.

The introductory and reminder email included a statement that participation is voluntary, and participants have the right to withdraw at any time. Once the instruments were collected the researcher began the data process. The participants of the study were not asked to reveal any personal identification such as names or social security numbers on any of the research instruments. Only the aggregate results of the study will be available to the Center to ensure confidentiality and anonymity of the participants.

\section{Analysis of the Data}

The Statistical Program for the Social Sciences (SPSS 23.0) was used as the primary tool for data screening and analyses. The analyses utilized included descriptive, inferential, and multivariate statistical analyses. The research questions posed for the study also requires the use of linear regression analysis. This statistical technique is necessary for this study to "analyze variance in the outcome variables since the predictor variables are at various hierarchal levels" (Woltman, Feldstain, MacKay \& Rocchi, 2012). 
In essence, this statistical method takes into consideration that the "employees job satisfaction share variance according to their demographic and personality characteristics" (Woltman et al., 2012). This study seeks to examine the variance at these levels. Additionally, this study is exploratory in nature with a convenience sample. As such there was no manipulation of an independent variable and the terms explanatory and response variables, are used to describe the relationship between an independent and dependent variable.

\section{Treatment of Missing Data}

Of the sample collect there were only of few instances where missing data was found. Of the 180 packets returned, 10 indicated they did not wish to participate, and 2 packets were incomplete. Because the minimal number of missing cases, the 12 packets were removed. This process was completed using SPSS 23.0.

\section{Descriptive Analysis}

Descriptive statistics such a frequencies and means were computed for the criterion and predictor variables for demographic characteristics, Big Five Type Indicator and Job Satisfaction Survey.

\section{Correlation Analysis}

Additionally, a linear regression will be used establish significance between Big Five traits and Total Job Satisfaction. Each Big Five trait will be reviewed for its significance in correlational analysis will also be used to show the associations between Job satisfaction and demographic characteristics. Regression analysis was used to see 
which combination of dependent variables had a significant impact on job satisfaction and which combinations had the largest impact. An analysis of covariate was also utilized to examine job satisfaction with the demographic variables used as independent categorical variables and the big five traits included as covariates. This process was completed using SPSS 23.0.

\section{Summary}

In this chapter, the population and sample were described with the rationale for selection of the participants. The procedures were reviewed to show adherence to the Andrews University Internal Review Board. The instruments utilized were briefly described with reliability and validity information provided. These included the brief demographic survey, the Job Satisfaction Survey and the Big Five Type Indicator. Very briefly the statistical procedures and accompanying rationale for these were included. 


\section{CHAPTER 4}

\section{RESULTS, DATA ANALYSIS, AND DISCUSSION}

\section{Introduction}

The aim of this research dissertation was to examine job satisfaction as a function of personality among CMHC workers employed in occupations within the community mental health center (Bowen Center) and how this relationship varies when demographic and occupational characteristics are controlled in order to identify occupational characteristics that best fit an individual's personality characteristics, thus reaping the known benefits of the resulting job satisfaction (Jones, Hill, \& Henn, 2015). The purpose of this study was an in-depth examination of job satisfaction as a function of the fivefactor model of personality in the CMHC environment of Northern Indiana.

The dissertation was, therefore, conducted as a survey, with the aim of examining job satisfaction as a function of the five-factor model of personality in the CMHC environment of Northern Indiana. The study sample involved employees of the Bowen Center. The survey questionnaires from the field (filled questionnaires) were checked for accuracy and then the data were entered into an Excel spreadsheet for analysis. The other data were also imported into IBM SPSS version 23.0 for analysis and visualization. The analysis was based on 180 survey questionnaires administered and returned. The data collected from the 180 participants were analyzed and 168 were used. Descriptive statistics, correlation coefficients, and regression analysis were also conducted. 


\section{Results of Data Analysis}

Demographic Characteristics and Descriptive Statistics

Tables 1 and 2 summarize the study sample and the measures. Table 1 gives a simple frequency and percentage, forming the foundation of the quantitative analysis of the data.

Table 1

Demographic Characteristics

\begin{tabular}{|c|c|c|c|}
\hline & & Frequency & $\begin{array}{c}\text { Percent } \\
\%\end{array}$ \\
\hline \multicolumn{4}{|l|}{ Gender } \\
\hline & Male & 31 & $18.5 \%$ \\
\hline & Female & 137 & $81.5 \%$ \\
\hline \multicolumn{4}{|l|}{ Age } \\
\hline & $18-24$ & 29 & $17.3 \%$ \\
\hline & $25-34$ & 71 & $42.3 \%$ \\
\hline & $35-44$ & 29 & $16.1 \%$ \\
\hline & $45-54$ & 19 & $11.3 \%$ \\
\hline & $55-64$ & 15 & $8.9 \%$ \\
\hline & $65+$ & 6 & $3.6 \%$ \\
\hline & No Answer & 1 & $60.0 \%$ \\
\hline \multicolumn{4}{|c|}{ Education } \\
\hline & Secondary Education & 3 & $1.8 \%$ \\
\hline & Some College & 11 & $6.5 \%$ \\
\hline & 4 Year College & 91 & $54.2 \%$ \\
\hline & Masters & 58 & $34.5 \%$ \\
\hline & Doctorate & 4 & $2.4 \%$ \\
\hline & No Answer & 1 & $60.0 \%$ \\
\hline \multicolumn{4}{|c|}{ Marital Status } \\
\hline & Single & 65 & $38.7 \%$ \\
\hline & Married & 79 & $47.0 \%$ \\
\hline & Widowed & 0 & $0.0 \%$ \\
\hline & Divorced & 21 & $12.5 \%$ \\
\hline & Separated & 3 & $1.8 \%$ \\
\hline & No Answer & 0 & $0.0 \%$ \\
\hline
\end{tabular}


Table 1-Continued.

Ethnicity

\begin{tabular}{|c|c|c|c|}
\hline \multirow[t]{6}{*}{ 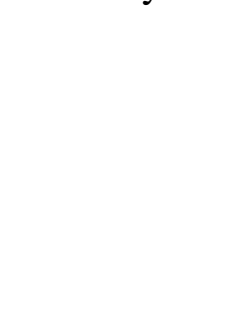 } & African American & 6 & $3.6 \%$ \\
\hline & Asian & 2 & $1.2 \%$ \\
\hline & Hispanic or Latino & 2 & $1.2 \%$ \\
\hline & Other & 5 & $3.0 \%$ \\
\hline & White & 153 & $91.1 \%$ \\
\hline & No Answer & 0 & $0.0 \%$ \\
\hline \multirow[t]{6}{*}{ Years in Job } & $0-2$ & 96 & $57.1 \%$ \\
\hline & $3-4$ & 27 & $16.1 \%$ \\
\hline & $5-6$ & 10 & $6.0 \%$ \\
\hline & $7-8$ & 10 & $6.0 \%$ \\
\hline & $9+$ & 21 & $12.5 \%$ \\
\hline & No Answer & 4 & $2.4 \%$ \\
\hline \multicolumn{4}{|c|}{ Years in Corporation } \\
\hline & $0-2$ & 88 & $52.4 \%$ \\
\hline & $3-4$ & 26 & $15.5 \%$ \\
\hline & $5-6$ & 13 & $7.7 \%$ \\
\hline & $7-8$ & 9 & $5.4 \%$ \\
\hline & $9+$ & 18 & $10.7 \%$ \\
\hline & No Answer & 14 & $8.3 \%$ \\
\hline \multicolumn{4}{|c|}{ Job Classification } \\
\hline & RSP & 64 & $38.1 \%$ \\
\hline & $\mathrm{RC}$ & 17 & $10.1 \%$ \\
\hline & WRAP & 7 & $4.2 \%$ \\
\hline & BHSP & 19 & $11.3 \%$ \\
\hline & Licensed OP & 22 & $13.1 \%$ \\
\hline & SA Therapist & 3 & $1.8 \%$ \\
\hline & Client Services & 11 & $6.5 \%$ \\
\hline & Other & 24 & $14.3 \%$ \\
\hline & No Answer & 1 & $0.6 \%$ \\
\hline \multicolumn{4}{|l|}{$\begin{array}{l}\text { Occupational } \\
\text { Program }\end{array}$} \\
\hline & Outpatient & 137 & $81.5 \%$ \\
\hline & Administrative & 20 & $11.9 \%$ \\
\hline & No Answer & 11 & $6.5 \%$ \\
\hline
\end{tabular}


Descriptive Statistics of the Big Five Type Indicator Participants' Characteristics

Table 2 shows the descriptive statistics in terms of mean and standard deviation in order to determine the factor closer to the gathered data (i.e., central tendency) and which factor is further from the average of the data (i.e., measure of dispersion). This will be used to identify which characters can apply to every participant. Possible responses were "Disagree strongly, Disagree a little, Neither agree nor disagree, Agree a little, or Agree strongly."

Table 2 reveals that participants with $M=3.71$ and $S D=1.448$ stated that they are people who are talkative, whereas participants with $M=2.10$ and $S D=1.104$ stated that they tend to find fault with others. Participants with $M=4.29$ and $S D=1.285$ stated that they do a thorough job, whereas participants with $M=1.77$ and $S D=1.109$ stated that they are depressed and blue, and participants with $M=3.57$ and $S D=1.295$ stated that they are original and come up with new ideas.

Participants with $M=2.71$ and $S D=1.424$ stated that they are reserved, whereas participants with $M=4.11$ and $S D=1.318$ are people who are helpful and unselfish with others, and participants with $M=2.02$ and $S D=1.217$ stated that they can be somewhat careless. Participants with $M=3.22$ and $S D=1.408$ stated that they are relaxed and handle stress well, whereas participants with $M=4.02$ and $S D=1.368$ stated that they are curious about many different things, and participants with a $M=3.29$ and $S D=1.315$ are full of energy.

The study participants who had a $M=1.08$ and $S D=0.53$ start quarrels with others, whereas participants with $M=4.53$ and $S D=1.262$ stated that they are reliable workers, and participants with the $M=2.87$ and $S D=1.378$ stated that they can be tense. 
Participants who had a $M=3.37$ and $S D=1.346$ are ingenious, deep thinkers, whereas participants with $M=3.42$ and $S D=1.320$ stated that they generate a lot of enthusiasm, and participants with $M=3.87$ and $S D=1.372$ stated that they have a forgiving nature. In addition, participants who had a $M=2.19$ and $S D=1.389$ tend to be disorganized, whereas participants with a $M=2.87$ and $S D=1.451$ worry a lot, and participants with a $M=3.44$ and $S D=1.367$ have an active imagination.

Moreover, participants with a $M=2.58$ and $S D=1.445$ tend to be quiet, whereas participants with a $M=3.90$ and $S D=1.403$ are generally trusting, and participants with a $M=1.69$ and $S D=1.032$ tend to be lazy. The study participants with a $M=3.64$ and $S D$ $=1.356$ are emotionally stable and not easily upset, whereas participants with $M=3.26$ and $S D=1.313$ are inventive, and participants with $M=3.30$ and $S D=1.437$ have an assertive personality. Participants with $M=1.78$ and $S D=1.151$ stated they can be cold and aloof, whereas participants with $M=4.01$ and $S D=1.324$ stated that they persevere until the task is finished, and participants with $M=2.47$ and $S D=1.261$ stated that they can be moody.

Participants with $M=3.65$ and $S D=1.428$ stated that they value artistic, aesthetic experiences, whereas the participants with $M=2.81$ and $S D=1.452$ stated that they are sometimes shy and inhibited, and participants with $M=4.22$ and $S D=1.327$ stated that they are considerate and kind to almost everyone. Participants with $M=3.97$ and $S D=$ 1.318 do things efficiently, whereas participants with $M=3.77$ and $S D=1.336$ remain calm in tense situations, and participants with $M=2.86$ and $S D=1.501$ prefer routine work. Participants with $M=3.67$ and $S D=1.472$ are outgoing and sociable, whereas participants with $M=1.73$ and $S D=1.096$ are sometimes rude to others. 
Table 2

Descriptive Statistics of the Big Five Type Indicator Participants' Characteristics

\begin{tabular}{|c|c|c|c|c|c|c|c|}
\hline & 1 & 2 & 3 & 4 & 5 & M & SD \\
\hline \multicolumn{8}{|l|}{ I am someone who.... } \\
\hline Is talkative & 6 & 13 & 27 & 56 & 66 & 3.71 & 1.448 \\
\hline Tends to find fault with others & 39 & 68 & 37 & 23 & 0 & 2.10 & 1.104 \\
\hline Does a thorough job & 0 & 1 & 6 & 53 & 108 & 4.29 & 1.284 \\
\hline Is depressed, blue & 79 & 43 & 27 & 18 & 0 & 1.77 & 1.109 \\
\hline Is original, comes up with new ideas & 3 & 9 & 41 & 77 & 38 & 3.57 & 1.295 \\
\hline Is reserved & 29 & 39 & 36 & 47 & 17 & 2.71 & 1.424 \\
\hline Is helpful and unselfish with others & 4 & 0 & 3 & 79 & 82 & 4.11 & 1.318 \\
\hline Can be somewhat careless & 58 & 58 & 23 & 25 & 4 & 2.02 & 1.217 \\
\hline Is relaxed, handles stress well & 12 & 24 & 38 & 64 & 30 & 3.22 & 1.408 \\
\hline Is curious about many different things & 2 & 4 & 22 & 53 & 87 & 4.02 & 1.368 \\
\hline Is full of energy & 3 & 26 & 48 & 62 & 29 & 3.29 & 1.315 \\
\hline Starts quarrels with others & 146 & 18 & 3 & 1 & 0 & 1.08 & 0.527 \\
\hline Is a reliable worker & 0 & 0 & 0 & 25 & 143 & 4.53 & 1.262 \\
\hline Can be tense & 17 & 41 & 41 & 50 & 19 & 2.87 & 1.378 \\
\hline Is ingenious, a deep thinker & 8 & 13 & 47 & 68 & 32 & 3.37 & 1.346 \\
\hline Generates a lot of enthusiasm & 3 & 19 & 43 & 69 & 34 & 3.42 & 1.320 \\
\hline Has a forgiving nature & 3 & 8 & 20 & 68 & 69 & 3.87 & 1.372 \\
\hline Tends to be disorganized & 62 & 38 & 25 & 34 & 9 & 2.19 & 1.389 \\
\hline Worries a lot & 22 & 40 & 34 & 48 & 24 & 2.87 & 1.451 \\
\hline Has an active imagination & 7 & 14 & 42 & 67 & 38 & 3.44 & 1.367 \\
\hline Tends to be quiet & 35 & 46 & 29 & 40 & 18 & 2.58 & 1.445 \\
\hline Is generally trusting & 3 & 6 & 20 & 63 & 75 & 3.90 & 1.403 \\
\hline Tends to be lazy & 80 & 54 & 22 & 10 & 2 & 1.69 & 1.032 \\
\hline Is emotionally stable, not easily upset & 2 & 16 & 28 & 72 & 50 & 3.64 & 1.356 \\
\hline Is inventive & 10 & 10 & 60 & 63 & 25 & 3.26 & 1.313 \\
\hline Has an assertive personality & 11 & 27 & 25 & 71 & 34 & 3.30 & 1.437 \\
\hline Can be cold and aloof & 83 & 40 & 25 & 18 & 2 & 1.78 & 1.151 \\
\hline Perseveres until the task is finished & 1 & 4 & 18 & 66 & 79 & 4.01 & 1.324 \\
\hline Can be moody & 30 & 48 & 48 & 36 & 6 & 2.47 & 1.261 \\
\hline Values artistic, aesthetic experiences & 3 & 13 & 38 & 51 & 62 & 3.65 & 1.428 \\
\hline Is sometimes shy, inhibited & 29 & 31 & 36 & 53 & 19 & 2.81 & 1.452 \\
\hline Is considerate and kind to almost everyone & 0 & 1 & 9 & 54 & 103 & 4.22 & 1.328 \\
\hline Does things efficiently & 1 & 7 & 11 & 78 & 71 & 3.97 & 0.318 \\
\hline Remains calm in tense situations & 2 & 10 & 23 & 77 & 56 & 3.77 & 1.336 \\
\hline Prefers work that is routine & 23 & 41 & 30 & 45 & 28 & 2.86 & 1.501 \\
\hline Is outgoing, sociable & 7 & 16 & 24 & 56 & 65 & 3.67 & 1.472 \\
\hline
\end{tabular}


Table 2-Continued.

Is sometimes rude to others

Makes plans and follows through with them

Gets nervous easily

Likes to reflect, play with ideas

Has few artistic interests

Likes to cooperate with others

Is easily distracted

Is sophisticated in art, music, or literature

$\begin{array}{rrrrrrr}81 & 49 & 21 & 15 & 2 & 1.73 & 1.096 \\ 0 & 6 & 11 & 85 & 66 & 3.97 & 1.279 \\ 34 & 39 & 38 & 45 & 12 & 2.59 & 1.389 \\ 5 & 12 & 38 & 61 & 52 & 3.59 & 1.389 \\ 46 & 45 & 43 & 22 & 12 & 2.29 & 1.332 \\ 1 & 1 & 9 & 68 & 89 & 4.15 & 1.292 \\ 30 & 45 & 32 & 39 & 22 & 2.68 & 1.460 \\ 27 & 34 & 39 & 44 & 23 & 2.79 & 1.471\end{array}$

Lastly, participants with $M=3.97$ and $S D=1.279$ stated that they make plans and follow through with them, whereas participants with $M=2.59$ and $S D=1.39$ get nervous easily, and participants with $M=3.594$ and $S D=1.39$ like to reflect and play with ideas. Participants with $M=2.29$ and $S D=1.332$ have few artistic interests, whereas participants with a $M=4.15$ and $S D=1.292$ stated that they like to cooperate with others. Participants with $M=2.68$ and $S D=1.460$ stated that they are easily distracted, whereas participants with $M=2.79$ and $S D=1.471$ stated that they are sophisticated in art, music, or literature as shown in Table 2.

\section{Descriptive Statistics of Participants' Opinion About Job Satisfaction}

Table 3 shows the descriptive statistics in terms of $M$ and $S D$ in order to determine the factor closer to the gathered data (i.e., central tendency) and which factor is further from the average of the data (i.e., measure of dispersion). This will help in identifying the participants' opinion about job satisfaction. Possible responses were "Disagree very much, Disagree moderately, Disagree slightly, Agree slightly, Agree moderately, Agree very much.” 
Table 3 reveals that participants with $M=2.58$ and $S D=1.637$ stated they feel they are being paid a fair amount for the work they do, whereas participants with the $M=$ 3.28 and $S D=1.756$ stated that there is really too little chance for promotion on their job, and participants with $M=4.75$ and $S D=1.707$ stated that their supervisor is quite competent in doing his/her job.

The study participants with $M=2.84$ and $S D=1.654$ stated that they are not satisfied with the benefits they receive, whereas participants with the $M=3.66$ and $S D=$ 1.721 stated that when they do a good job, they receive the recognition for it that they should receive, and participants with $M=3.33$ and $S D=1.623$ stated that many of their rules and procedures make doing a good job difficult. Participants with $M=5.08$ and $S D$ $=1.482$ stated that they like the people they work with, whereas participants with $M=$ 2.13 and $S D=1.422$ stated that they sometimes feel their job is meaningless, and participants with $M=3.04$ and $S D=1.590$ stated that communications seem good within their organization.

Participants with $M=4.74$ and $S D=1.791$ stated that raises are too few and far between, whereas participants with $M=3.52$ and $S D=1.709$ stated that those who do well on the job stand a fair chance of being promoted, and participants with $M=1.46$ and $S D=1.043$ stated that their supervisor is unfair to them. Furthermore, participants with $M$ $=3.81$ and $S D=1.658$ stated that the benefits they receive are as good as those that most other organizations offer, whereas participants with $M=2.71$ and $S D=1.626$ stated that they do not feel that the work they do is appreciated, and participants with $M=3.21$ and $S D=1.584$ stated that their efforts to do a good job are seldom blocked by red tape. 
Participants with $M=2.46$ and $S D=1.590$ stated that they find they have to work harder at their job because of the incompetence of people they work with, whereas participants with $M=4.67$ and $S D=1.502$ stated that they like doing the things they do at work, and participants with $M=2.17$ and $S D=1.445$ stated that the goals of the organization are not clear to them. Also, participants with $M=3.84$ and $S D=1.885$ stated that they feel unappreciated by the organization when they think about what they pay them, whereas participants with $M=3.47$ and $S D=1.663$ stated that people get ahead as fast there as they do in other places, and participants with $M=2.06$ and $S D=$ 1.471 stated that their supervisor shows too little interest in the feelings of subordinates. In addition, participants with $M=3.91$ and $S D=1.587$ stated that the benefit package they have is equitable, whereas participants with $M=3.52$ and $S D=1.725$ stated that there are few rewards for those who work here, and participants with $M=3.82$ and $S D=1.715$ stated that they have too much to do at work. Participants with $M=5.11$ and $S D=1.474$ stated that they enjoy their coworkers, whereas participants with $M=3.46$ and $S D=1.70$ stated that they often feel that they do not know what is going on with the organization, and participants with $M=4.73$ and $S D=1.542$ stated that they feel a sense of pride in doing their job. Participants with $M=2.44$ and $S D=1.583$ stated that they feel satisfied with their chances for salary increases, whereas participants with $M=3.24$ and $S D=1.612$ stated that there are benefits they do not have which they should have, and participants with $M=5.02$ and $S D=1.61$ stated that they like their supervisor. $=3.11$ and $S D=1.674$ stated that they are satisfied with their chances for promotion. Participants with $M=2.34$ and $S D=1.465$ stated that there is too much bickering and fighting at work, whereas participants with $M=4.44$ and $S D=1.551$ stated their job is 
enjoyable, and participants with $M=2.96$ and $S D=1.706$ stated work assignments are not fully explained (Table 3).

Table 3

Descriptive Statistics of Participants' Opinion About Job Satisfaction

\begin{tabular}{|c|c|c|c|c|c|c|c|c|c|}
\hline & & 1 & 2 & 3 & 4 & 5 & 6 & M & SD \\
\hline 1. & $\begin{array}{l}\text { I feel I am being paid a fair } \\
\text { amount for the work I do. }\end{array}$ & 44 & 48 & 27 & 18 & 20 & 11 & 2.58 & 1.637 \\
\hline 2. & There is really too little chance & 21 & 34 & 34 & 26 & 31 & 22 & 328 & 1756 \\
\hline 3. & My supervisor is quite competent & & & & & & & & \\
\hline & in doing his/her job. & 5 & 4 & 11 & 16 & 51 & 80 & 4.75 & 1.707 \\
\hline 4. & $\begin{array}{l}\text { I am not satisfied with the } \\
\text { benefits I receive. }\end{array}$ & 32 & 40 & 36 & 21 & 29 & 10 & 2.84 & 1.654 \\
\hline 5. & $\begin{array}{l}\text { When I do a good job, I receive } \\
\text { the recognition for it that I should }\end{array}$ & & & & & & & & \\
\hline & receive. & 15 & 18 & 33 & 33 & 43 & 26 & 3.66 & 1.721 \\
\hline 6. & $\begin{array}{l}\text { Many of our rules and procedures } \\
\text { make doing a good job difficult. }\end{array}$ & 19 & 26 & 27 & 54 & 27 & 15 & 3.33 & 1.623 \\
\hline 7. & I like the people I work with. & 0 & 0 & 4 & 13 & 62 & 88 & 5.08 & 1.482 \\
\hline 8. & $\begin{array}{l}\text { I sometimes feel my job is } \\
\text { meaningless. }\end{array}$ & 67 & 44 & 19 & 28 & 5 & 5 & 2.13 & 1.422 \\
\hline 9. & $\begin{array}{l}\text { Communications seem good } \\
\text { within this organization. }\end{array}$ & 23 & 37 & 37 & 35 & 26 & 10 & 3.04 & 1.590 \\
\hline 10. & $\begin{array}{l}\text { Raises are too few and far } \\
\text { between. }\end{array}$ & 6 & 6 & 13 & 15 & 35 & 92 & 4.74 & 1.791 \\
\hline 11. & $\begin{array}{l}\text { Those who do well on the job } \\
\text { stand a fair chance of being } \\
\text { promoted }\end{array}$ & 21 & 15 & 25 & 45 & 45 & 16 & 3.52 & 1.709 \\
\hline 12. & My supervisor is unfair to me. & 119 & 22 & 16 & 7 & 3 & 1 & 1.46 & 1.048 \\
\hline 13. & $\begin{array}{l}\text { The benefits we receive are as } \\
\text { good as most other organizations } \\
\text { offer. }\end{array}$ & 10 & 10 & 33 & 42 & 48 & 24 & 3.81 & 1.658 \\
\hline 14. & $\begin{array}{l}\text { I do not feel that the work I do is } \\
\text { appreciated. }\end{array}$ & 40 & 35 & 36 & 28 & 18 & 10 & 2.71 & 1.626 \\
\hline 15. & $\begin{array}{l}\text { My efforts to do good job are } \\
\text { seldom blocked by red tape. }\end{array}$ & 18 & 25 & 44 & 40 & 28 & 12 & 3.21 & 1.584 \\
\hline 16. & $\begin{array}{l}\text { I find I have to work harder at my } \\
\text { job because of the incompetence } \\
\text { of people I work with. }\end{array}$ & 57 & 33 & 21 & 37 & 14 & 6 & 2.46 & 1.590 \\
\hline 17. & $\begin{array}{l}\text { I like doing the things I do at } \\
\text { work. }\end{array}$ & 2 & 3 & 6 & 35 & 68 & 54 & 4.67 & 1.502 \\
\hline
\end{tabular}


Table 3-Continued.

18. The goals of this organization are not clear to me.

$\begin{array}{llllllll}62 & 49 & 24 & 19 & 8 & 6 & 2.17 & 1.445\end{array}$

19. I feel unappreciated by the organization when I think about what they pay me.

$\begin{array}{llllllll}23 & 10 & 22 & 32 & 39 & 42 & 3.84 & 1.885\end{array}$

20. People get ahead as fast here as they do in other places.

$\begin{array}{llllllll}11 & 19 & 38 & 39 & 43 & 14 & 3.45 & 1.663\end{array}$

21. My supervisor shows too little interest in the feelings of subordinates.

$\begin{array}{llllllll}79 & 37 & 17 & 20 & 11 & 4 & 2.06 & 1.471\end{array}$

22. The benefit package we have is equitable.

23. There are few rewards for those who work here.

$\begin{array}{llllllll}5 & 12 & 26 & 50 & 52 & 22 & 3.91 & 1.587\end{array}$

$\begin{array}{llllllll}13 & 30 & 27 & 40 & 32 & 25 & 3.52 & 1.725\end{array}$

24. I have too much to do at work.

25. I enjoy my coworkers.

$\begin{array}{llllllll}11 & 20 & 25 & 37 & 44 & 31 & 3.82 & 1.715\end{array}$

26. I often feel that I do not know what is going on with the organization.

$\begin{array}{llllllll}0 & 0 & 6 & 18 & 46 & 98 & 5.11 & 1.474\end{array}$

27. I feel a sense of pride in doing my job.

$\begin{array}{llllllll}19 & 26 & 22 & 49 & 32 & 20 & 3.46 & 1.700\end{array}$

28. I feel satisfied with my chances for salary increases.

29. There are benefits we do not have which we should have.

30. I like my supervisor.

31. I have too much paperwork.

32. I don't feel my efforts are rewarded the way they should be.

33. I am satisfied with my chances for promotion.

34. There is too much bickering and fighting at work.

35. My job is enjoyable.

36. Work assignments are not fully explained.

$\begin{array}{llllllll}1 & 5 & 9 & 27 & 62 & 64 & 4.73 & 1.542\end{array}$

$\begin{array}{llllllll}54 & 33 & 37 & 20 & 15 & 8 & 2.44 & 1.583\end{array}$

$\begin{array}{llllllll}16 & 26 & 49 & 37 & 22 & 18 & 3.24 & 1.612\end{array}$

$\begin{array}{llllllll}4 & 2 & 3 & 19 & 39 & 101 & 5.02 & 1.610\end{array}$

$\begin{array}{llllllll}9 & 12 & 16 & 40 & 40 & 51 & 4.19 & 1.744\end{array}$

$\begin{array}{llllllll}14 & 25 & 36 & 34 & 30 & 28 & 3.53 & 1.745\end{array}$

$\begin{array}{llllllll}31 & 22 & 34 & 37 & 34 & 10 & 3.11 & 1.674\end{array}$

$\begin{array}{llllllll}58 & 33 & 31 & 32 & 11 & 3 & 2.34 & 1.465\end{array}$

$\begin{array}{llllllll}2 & 6 & 9 & 45 & 61 & 44 & 4.44 & 1.551\end{array}$

$\begin{array}{llllllll}33 & 33 & 27 & 41 & 18 & 15 & 2.96 & 1.706\end{array}$

To conclude, participants with a $M=4.19$ and $S D=1.744$ stated that they have

too much paperwork, whereas participants with a $M=3.53$ and $S D=1.745$ stated that they don't feel their efforts are rewarded the way they should be, and participants with $M$ 


\section{Hypothesis Testing}

\section{Hypothesis 1}

To test Ho1, which states that there is no significant effect of the Big Five traits on Total Job Satisfaction in CMHC employees of the Bowen Center a linear regression analysis was used. From the ANOVA table it was found that the F-test and hence our model was statistically significant. Since there was a significant correlation between Total Job Satisfaction and the Big Five traits this rejected hypothesis Ho1, which states that workforces Big Five traits will not be a significant predictor of Total Job Satisfaction.

It is understood that R-Square is the proportion of variance in the dependent variable (Total Job Satisfaction) which can be predicted from the independent variables (Extraversion, Agreeableness, Conscientiousness, Neuroticism, and Openness). This value indicated that $16.9 \%$ of the variance in Total Job Satisfaction can be predicted from the variables Extraversion, Agreeableness, Conscientiousness, Neuroticism, and Openness. It needs to be stated that this is an overall measure of the strength of the association and does not reflect the extent to which any particular independent variable is associated with the dependent variable.

Table 4 shows that the t-test for Agreeableness equals 3.548, and is statistically significant, meaning that the regression coefficient for Agreeableness is significantly different from zero. Additionally, from the Standardized Coefficients Beta, a one standard deviation increase in Agreeableness leads to a 0.280 standard deviation increase in Total Job Satisfaction.

Table 4 
Correlations Between Big Five Traits and Total Job Satisfaction

\begin{tabular}{|l|r|r|r|r|r|}
\hline \multirow{2}{*}{ Model } & \multicolumn{2}{|c|}{ Unstandardized Coefficients } & \multicolumn{1}{c|}{$\begin{array}{c}\text { Standardized } \\
\text { Coefficients }\end{array}$} & \multicolumn{1}{c|}{$\mathrm{t}$} & \multicolumn{2}{c|}{ Sig. } \\
\cline { 2 - 4 } & \multicolumn{1}{|c|}{$\mathrm{B}$} & \multicolumn{1}{c|}{ Std. Error } & \multicolumn{1}{c|}{ Beta } & & \\
\hline (Constant) & 80.355 & 30.138 & & 2.666 & .008 \\
EXTRAVERSION & -.004 & .293 & -.001 & -.012 & .990 \\
AGREEABLENESS & 1.740 & .490 & .280 & 3.548 & .001 \\
CONCIENTIOUSNESS & -.109 & .421 & -.020 & -.258 & .797 \\
NEUROTICISM & -.832 & .352 & -.194 & -2.364 & .019 \\
OPENNESS & .426 & .297 & .104 & 1.435 & .153 \\
\hline
\end{tabular}

a. Dependent Variable: JSTOTAL

Hypothesis 2

Hypothesis 2 states there is no significant effect of the Big Five factors on Total Job Satisfaction controlling for demographic characteristics in CMHC employees of the Bowen Center. In order to test this hypothesis an ANCOVA was utilized to examine the association between job satisfaction with the demographic variables used as independent categorical variables and the big five traits included as covariates. Table 5, Tests of Within-Subjects Effects, presents the results for the main effect of our within-groups factor, Big Five traits and demographics, and their association regarding Total Job Satisfaction. The analysis revealed that the main effect for gender, marital status, ethnicity, program, age, education years in job and years in corporation were not significantly associated with Total Job Satisfaction failing to reject Ho2 which states Big Five factors are not significantly associated with Job Satisfaction after controlling demographic characteristics in CMHC employees of the Bowen Center. There was some evidence that job classification was associated with Total Job Satisfaction, $F(8,1072.765)$ $=1.948, \mathrm{p}<.1$, Partial Eta Squared $=.100$. Thus, there was a marginal significance overall difference between the 8 different job classifications and Total Job Satisfaction. 
The analysis found Agreeableness had a significant association with Total Job Satisfaction when controlling for demographics, $\mathrm{F}(1,4924.081)=8.941, \mathrm{p}<.05$, though this was only a medium effect (Partial Eta Square $=.060)$. Finally, Neuroticism was found to have a significant association with Total Job Satisfaction controlling for demographics, $\mathrm{F}(1,2298.416)=4.173, \mathrm{p}<.05$, though this was a weak effect (Partial Eta Squared $=.029)$. Partial eta squared is the variance explained by a given variable of the variance remaining after excluding variance explained by other predictors (Levine \& Hullett, 2002).

Table 5

Correlations Between Big Five Traits and Total Job Satisfaction Controlling for Demographics

\begin{tabular}{|c|c|c|c|c|c|c|c|c|}
\hline Source & $\begin{array}{c}\text { Type III Sum } \\
\text { of Squares }\end{array}$ & df & $\begin{array}{l}\text { Mean } \\
\text { Square }\end{array}$ & $\mathrm{F}$ & Sig. & $\begin{array}{c}\text { Partial Eta } \\
\text { Squared } \\
\end{array}$ & $\begin{array}{l}\text { Noncent. } \\
\text { Parameter }\end{array}$ & $\begin{array}{c}\text { Observed } \\
\text { Power }^{\mathrm{b}}\end{array}$ \\
\hline Model & $3422147.487^{\mathrm{a}}$ & 28 & 122219.553 & 221.919 & .000 & .978 & 6213.733 & 1.000 \\
\hline Gender & 1585.869 & 1 & 1585.869 & 2.880 & .092 & .020 & 2.880 & .392 \\
\hline MaritalSt & 1175.591 & 3 & 391.864 & .712 & .547 & .015 & 2.135 & .198 \\
\hline Ethnicity & 4613.038 & 4 & 1153.259 & 2.094 & .085 & .056 & 8.376 & .611 \\
\hline JobClass & 8582.119 & 8 & 1072.765 & 1.948 & .057 & .100 & 15.583 & .791 \\
\hline Program & 2582.946 & 2 & 1291.473 & 2.345 & .100 & .032 & 4.690 & .468 \\
\hline Age & 1288.145 & 1 & 1288.145 & 2.339 & .128 & .016 & 2.339 & .330 \\
\hline Education & 56.147 & 1 & 56.147 & .102 & .750 & .001 & .102 & .062 \\
\hline YrsinJob & 365.673 & 1 & 365.673 & .664 & .417 & .005 & .664 & .128 \\
\hline YrsinCorp & 353.969 & 1 & 353.969 & .643 & .424 & .005 & .643 & .125 \\
\hline EXTRAVERSION & 1060.225 & 1 & 1060.225 & 1.925 & .168 & .014 & 1.925 & .281 \\
\hline AGREEABLENESS & 4924.081 & 1 & 4924.081 & 8.941 & .003 & .060 & 8.941 & .844 \\
\hline CONSCIENTIOUSNESS & 19.194 & 1 & 19.194 & .035 & .852 & .000 & .035 & .054 \\
\hline NEUROTICISM & 2298.416 & 1 & 2298.416 & 4.173 & .043 & .029 & 4.173 & .527 \\
\hline OPENNESS & 1.350 & 1 & 1.350 & .002 & .961 & .000 & .002 & .050 \\
\hline
\end{tabular}




\section{Discussion of Study Findings}

Total Job Satisfaction as a Function of the Five-Factor Model of Personality

Getting a job and finding a work environment that is rewarding and enjoyable, as

well as meets individual requirements, is vital in boosting retention and increasing job satisfaction in the workplace (Cortese, Colombo, \& Ghislieri, 2010). The notion that personality plays an important role in finding job satisfaction in the CMHCs, and retaining the individual in the profession, has been supposed or hypothesized until today. This study's analysis suggested that employees at the CMHC with higher scores in job satisfaction could have a positive association with the Big Five personality traits of Extraversion, Agreeableness, Conscientiousness, Neuroticism, and Openness. However, an employee at CMHCs with higher scores in job satisfaction could have a negative association with the personality trait of neuroticism.

The study findings show that the personality domain of Agreeableness had a strong positive association with total job satisfaction, but the other positive Big Five traits including Extraversion, Conscientiousness, and Openness were not found to be significantly associated with Total Job Satisfaction. Neuroticism had a significant negative association with total job satisfaction. The study findings expand the understanding of how personality traits possibly influence retention and affect job satisfaction in the CMHCs. This rejected Hol which stated that Big Five traits are not significant predictors of Total Job Satisfaction in CMHC employees of the Bowen Center.

The findings also found that the Big Five traits of Agreeableness and Neuroticism (negative) had a significant association with total job satisfaction after controlling for 
demographic characteristics including gender, age, education level, marital status, ethnicity, years in job, years in corporation, job classification (type of job) and program. This rejected Ho2 which stated that Big Five traits would not have a significant association with Total Job Satisfaction after controlling demographic characteristics in CMHC employees of the Bowen Center. 


\section{CHAPTER 5}

\section{CONCLUSION, RECOMMENDATIONS, AND AREAS \\ FOR FUTURE STUDY}

\section{Conclusion}

It is pertinent to identify and understand which, if any of the Big Five personality traits predicts or have associations with job satisfaction in CMHCs. The study findings show that agreeableness was positively correlated with Total Job Satisfaction. However, neuroticism personality trait was negatively correlated with Total Job Satisfaction among employees in CMHCs. This implies that those who possess agreeableness as a personality trait to some degree will have higher level of job satisfaction compared to employees who possess the neuroticism personality trait since the neuroticism personality trait will have a negative effect on job satisfaction.

The study findings suggest that there is an association with workforces with agreeableness will have a higher level of job satisfaction. The study also found that agreeableness is positively related to job satisfaction, which is similar to the literature findings by researchers (Templer, 2012; Zhai et al., 2014) who also found a positive relationship between job satisfaction and agreeableness. Agreeableness is also positively associated with higher levels of job satisfaction and subjective well-being (Templer, 2012). Workforces who possess the agreeableness personality trait tend to be purpose driven, modest, trustworthy, tender-minded, and confident (Ongore, 2014). In addition, agreeable workforces are more engaged to their jobs and perform their work role effectively, ultimately leading to higher levels of job satisfaction. 
The study findings indicate that workforces with the neuroticism personality trait will have a negative effect or impact on job satisfaction. The study also found that neuroticism is negatively related to job satisfaction. This study finding is similar to Kappagoda's (2012) and Hlatywayo et al.'s (2013) study findings, which indicated that neuroticism is negatively correlated to job satisfaction. Employees who have a higher score in neuroticism tend to be less satisfied with their salary, the amount of work, and colleagues (Kappagoda, 2012).

Neuroticism is the primary source of negative affectivity (Judge, Heller, \& Mount, 2002; Kappagoda, 2012). Because of their essentially negative nature, neurotic employees experience more negative life situations than do other people, which could result in diminished job satisfaction levels depending on the degree to which such events occur or with respect to the work (Hlatywayo et al., 2013). Although employees who possess the neuroticism personality trait tend to have negative job satisfaction, workforces who score high in neuroticism are expected to have greater continuance to organization commitment (Judge, Heller, \& Mount, 2002).

Neurotic employees are more powerfully attracted to and motivated by hygiene factors, for example, work conditions (clean and comfortable), better pay, benefits (such as sick leave and good vacation), and job security (i.e., the job should be permanent and pensionable) (Furnham, Petrides, \& Tsaousis, 2005). Consequently, employees who possess the neuroticism personality trait will remain in the organization due to their investments made in the organization. In addition, neurotic individuals can develop fear of the costs related to exiting their current position, which means that if there is an occurrence of negative events in the organizations or work environment, neurotic 
employees can feel more anxious about facing new work environments, which may offer even tougher experiences (Erdheim, Wang, \& Zickar, 2006). Therefore, it can be concluded that workforces with the neuroticism personality trait tend to have negative job satisfaction levels in the community mental health center environment, and thus neuroticism is negatively related to job satisfaction.

Apart from the Big Five personality traits, the other key factors that impact the CMHC employees that play a critical role in employees' job satisfaction include inadequate compensation, recruitment, an aging workforce, shortage of staff, higher turnover rates, as well as distribution and retention of the staff (SAMHSA, 2010).

\section{Job Satisfaction as a Function of the Big Five Personality Traits}

The correlation analysis among the Big Five personality traits and job satisfaction was conducted. The correlation analysis suggests that workforces with the agreeableness $(r=0.057, p>0.05)$ personality trait will have a higher level of job satisfaction. This shows that agreeableness is positively related to job satisfaction, hence, rejecting the first study hypothesis.

However, a negative correlation was found between job satisfaction and neuroticism $(r=-0.57, p<0.01)$; this shows that workforces with the neuroticism personality trait will have negative impact on job satisfaction and thus rejecting the hypothesis.

\section{Demographics and Big Five Scores of Personality Traits That are Associated with Job Satisfaction}

Associations between the Big Five traits that are associated with total job satisfaction controlling for demographics were also conducted. The results of analysis 
between demographics and the Big Five personality traits that are associated with job satisfaction controlling for demographics show that there is a significant association between Big Five scores and Total Job Satisfaction controlling for demographics. The results show there are associations between the Big Five personality traits and Total Job Satisfaction while controlling for demographics. Job classification was the only demographic independent categorical variable that had a marginal association with Total Job Satisfaction. There was a significant association between agreeableness but there was a negative correlation between neuroticism and Total Job Satisfaction when controlling for demographic variables.

Based on the correlations between demographics and the Big Five scores of personality traits in this study, it can be concluded that there is an association between the Big Five scores of personality traits (such as agreeableness and neuroticism), demographics (job classification) and job satisfaction.

In this study, it was found that there was a positive relationship between agreeableness personality trait and Total Job Satisfaction, but neuroticism was found to be negatively associated with Total Job Satisfaction in CMHCs. Lastly, previous research has shown that job satisfaction has a greater influence on employees' turnover intentions (Masindi, 2015). Job satisfaction is also closely related to employee turnover intention and absenteeism (Saeed et al., 2014). Their study findings revealed a positive relationship for agreeableness, extroversion, and conscientiousness with job satisfaction in the CMHC environment of Northern Indiana. In addition, the study results indicated a negative association between neuroticism and job satisfaction. 


\section{Recommendations}

Job satisfaction is at the core of the Community Mental Health Centers because it will ensure higher quality service delivery. This study investigated job satisfaction as a function of the five-factor model of personality by examining the relationship of the Big Five personality traits with job satisfaction.

The research findings offer more understanding into the degree to which job satisfaction relate to the Big Five personality traits in the Community Mental Health Centers. The study suggests the following practical implications:

1. The study finding can be helpful to the managers of the Community Mental Health Centers to focus their attention on the personality trait of Agreeableness as it was found to have a positive association with job satisfaction and manage the workforce properly in order to provide higher quality service delivery to their clients, as well as achieve the mission and vision of the Community Mental Health Center.

2. The study finding can be helpful to the managers of the Community Mental Health Centers to focus their attention on the personality trait of Neuroticism as it was found to have a negative association with job satisfaction and work to screen out candidates with higher levels of neuroticism.

3. Personality traits which make people or employees successful in their jobs in the Community Mental Health Center are likely to aid the Community Mental Health Centers to be successful in their endeavors.

The study findings add a body of knowledge to existing literature in regard to the job satisfaction as a function of the five-factor model of personality, as well as the 
relationship between the Big Five personality traits and job satisfaction. The study has expounded on the relationship between the Big Five personality traits and job satisfaction; hence, the study findings can be used to precisely change the Community Mental Health Center environment work setting.

\section{Areas for Future Study}

1. Future longitudinal studies should be conducted to investigate the differential impact of the Big Five personality traits on work-related issues across time in the Community Mental Health Center environment.

2. Future studies should also be conducted to confirm the generalizability of the current results in the health-care industry context.

3. In the future, researchers studying the relationship between Job Satisfaction Survey sub scores to see if the Big Five personality traits impact the sub scores like they do Total Job Satisfaction.

4. Since a possible limitation of this study was a response bias related to a high proportion of the Agreeableness characteristic using a survey response method that limits this possible risk. Example could be to replicate the study but have survey responses mandatory. 
APPENDIX 
APPENDIX A

\section{DEMOGRAPHICS OF PARTICIPANTS}

\begin{tabular}{|c|c|c|c|c|c|c|}
\hline \multirow[t]{6}{*}{ Gender: } & $\ldots \mathrm{Ma}$ & Age: & \multicolumn{2}{|c|}{$\ldots 18-24$} & \multirow[t]{6}{*}{ Education: } & ___Secondary Education \\
\hline & \multicolumn{2}{|c|}{ __Female } & \multicolumn{2}{|c|}{ _24-34 } & & Some College \\
\hline & & & \multicolumn{2}{|c|}{ _ $35-44$} & & __ 4 Year College \\
\hline & & & \multicolumn{2}{|c|}{ _ $45-54$} & & ___Masters \\
\hline & & & \multicolumn{2}{|c|}{ _55-64 } & & ___Doctorate \\
\hline & & & \multicolumn{2}{|c|}{$\ldots 65+$} & & \\
\hline \multirow[t]{5}{*}{ Marital Status: } & $\ldots$ Sin & & \multicolumn{2}{|c|}{ Ethnicity: } & _White & \\
\hline & \multicolumn{4}{|c|}{ __ Married } & \multicolumn{2}{|c|}{ __Black or African American } \\
\hline & \multicolumn{4}{|c|}{ __ Widowed } & \multicolumn{2}{|l|}{ __Asian } \\
\hline & \multicolumn{4}{|c|}{ ___ Divorced } & \multicolumn{2}{|c|}{ __Hispanic or Latino } \\
\hline & \multicolumn{4}{|c|}{ __ Separated } & \multicolumn{2}{|l|}{ __ Other: } \\
\hline \multirow[t]{8}{*}{ Years in Job: } & _ $0-2$ & Years in Corpo & tion: & _ $0-2$ & Job Classification: & :__ RSP \\
\hline & _ $3-4$ & & & _3-4 & & RC \\
\hline & _5-6 & & & _5-6 & & $\ldots$ WRAP \\
\hline & _ $7-8$ & & & _ $7-8$ & & __ BHSP \\
\hline & ${ }^{9+}$ & & & ${ }^{9+}$ & & $\begin{array}{l}\text { Licensed OP } \\
\text { Therapist }\end{array}$ \\
\hline & & & & & & __SA Therapist \\
\hline & & & & & & __Client Service \\
\hline & & & & & & Other_ \\
\hline
\end{tabular}

Occupational Program: ___ Outpatient

__Administrative 


\begin{tabular}{|c|c|c|}
\hline & $\begin{array}{c}\text { JOB SATISFACTION SURVEY } \\
\text { Paul E. Spector } \\
\text { Department of Psychology } \\
\text { University of South Florida } \\
\text { Copyright Paul E. Spector 1994, All rights reserved. }\end{array}$ & \\
\hline & $\begin{array}{l}\text { PLEASE CIRCLE THE ONE NUMBER FOR } \\
\text { EACH QUESTION THAT COMES CLOSEST TO } \\
\text { REFLECTING YOUR OPINION } \\
\text { ABOUT IT. }\end{array}$ & 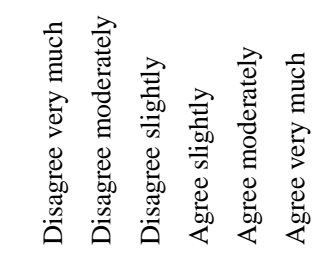 \\
\hline 1 & I feel I am being paid a fair amount for the work I do. & $\begin{array}{lllll}2 & 3 & 4 & 5 & 6\end{array}$ \\
\hline 2 & There is really too little chance for promotion on my job. & $\begin{array}{llllll}1 & 2 & 3 & 4 & 5 & 6\end{array}$ \\
\hline 3 & My supervisor is quite competent in doing his/her job. & $\begin{array}{lllll}1 & 2 & 3 & 4 & 5\end{array}$ \\
\hline 4 & I am not satisfied with the benefits I receive. & $\begin{array}{llllll}1 & 2 & 3 & 4 & 5 & 6\end{array}$ \\
\hline 5 & $\begin{array}{l}\text { When I do a good job, I receive the recognition for it that I should } \\
\text { receive. }\end{array}$ & $\begin{array}{llllll}1 & 2 & 3 & 4 & 5 & 6\end{array}$ \\
\hline 6 & $\begin{array}{l}\text { Many of our rules and procedures make doing a good job } \\
\text { difficult. }\end{array}$ & $\begin{array}{lllll}1 & 2 & 3 & 4 & 5\end{array}$ \\
\hline 7 & I like the people I work with. & $\begin{array}{lllll}1 & 2 & 3 & 4 & 5\end{array}$ \\
\hline 8 & I sometimes feel my job is meaningless. & $\begin{array}{llllll}1 & 2 & 3 & 4 & 5 & 6\end{array}$ \\
\hline 9 & Communications seem good within this organization. & $\begin{array}{llllll}1 & 2 & 3 & 4 & 5 & 6\end{array}$ \\
\hline 10 & Raises are too few and far between. & $\begin{array}{llllll}1 & 2 & 3 & 4 & 5 & 6\end{array}$ \\
\hline 11 & $\begin{array}{l}\text { Those who do well on the job stand a fair chance of being } \\
\text { promoted. }\end{array}$ & $\begin{array}{llllll}1 & 2 & 3 & 4 & 5 & 6\end{array}$ \\
\hline 12 & My supervisor is unfair to me. & $\begin{array}{llllll}1 & 2 & 3 & 4 & 5 & 6\end{array}$ \\
\hline 13 & $\begin{array}{l}\text { The benefits we receive are as good as most other organizations } \\
\text { offer. }\end{array}$ & $\begin{array}{llllll}1 & 2 & 3 & 4 & 5 & 6\end{array}$ \\
\hline 14 & I do not feel that the work I do is appreciated. & $\begin{array}{llllll}1 & 2 & 3 & 4 & 5 & 6\end{array}$ \\
\hline 15 & My efforts to do a good job are seldom blocked by red tape. & $\begin{array}{llllll}1 & 2 & 3 & 4 & 5 & 6\end{array}$ \\
\hline 16 & $\begin{array}{l}\text { I find I have to work harder at my job because of the } \\
\text { incompetence of people I work with. }\end{array}$ & $\begin{array}{llllll}1 & 2 & 3 & 4 & 5 & 6\end{array}$ \\
\hline 17 & I like doing the things I do at work. & $\begin{array}{llllll}1 & 2 & 3 & 4 & 5 & 6\end{array}$ \\
\hline 18 & The goals of this organization are not clear to me. & $\begin{array}{llllll}1 & 2 & 3 & 4 & 5 & 6\end{array}$ \\
\hline
\end{tabular}




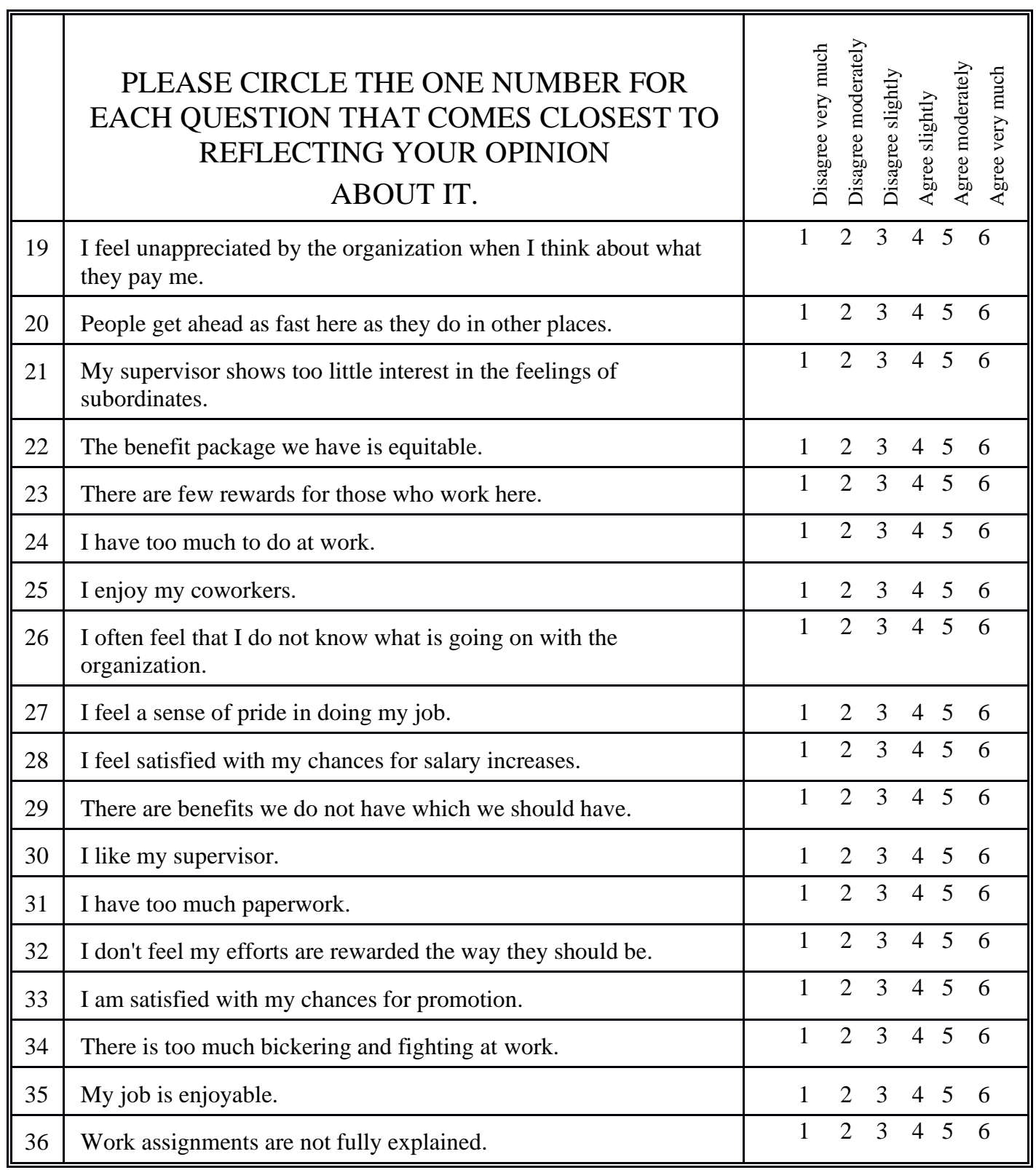




\section{APPENDIX B}

\section{HOW I AM IN GENERAL}

Here are a number of characteristics that may or may not apply to you. For example, do you agree that you are someone who likes to spend time with others? Please write a number next to each statement to indicate the extent to which you agree or disagree with that statement.

\begin{tabular}{|c|c|c|c|c|}
\hline $\mathbf{1}$ & $\mathbf{2}$ & $\mathbf{3}$ & $\mathbf{4}$ & $\mathbf{5}$ \\
$\begin{array}{c}\text { Disagree } \\
\text { Strongly }\end{array}$ & $\begin{array}{c}\text { Disagree } \\
\text { a little }\end{array}$ & $\begin{array}{c}\text { Neither agree } \\
\text { nor disagree }\end{array}$ & $\begin{array}{c}\text { Agree } \\
\text { a little }\end{array}$ & $\begin{array}{c}\text { Agree } \\
\text { strongly }\end{array}$ \\
\hline
\end{tabular}

\section{I am someone who...}

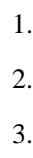

5 . new ideas

7. others$$
9 .
$$$$
10 .
$$$$
11 .
$$$$
12 .
$$$$
13 .
$$$$
14 .
$$$$
15 .
$$$$
\begin{aligned}
& 15 . \\
& 16 .
\end{aligned}
$$$$
17 .
$$$$
\begin{aligned}
& 17 . \\
& 18 .
\end{aligned}
$$$$
19 .
$$$$
20 .
$$$$
21 .
$$$$
22 .
$$$$
23 .
$$$$
24 .
$$

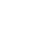

25.
Is talkative Tends to find fault with others Does a thorough job Is depressed, blue Is original, comes up with Is reserved Is helpful and unselfish with Can be somewhat careless Is relaxed, handles stress well Is curious about many different things

Is full of energy
Starts quarrels with others
Is a reliable worker
Can be tense
Is ingenious, a deep thinker
Generates a lot of enthusiasm
Has a forgiving nature
Tends to be disorganized
Worries a lot
Has an active imagination
Tends to be quiet
Is generally trusting
Tends to be lazy
Is emotionally stable, not
easily upset
Is inventive

26. Has an assertive personality

27. _ Can be cold and aloof

28. finished

29. _ Can be moody

30. __ Values artistic, aesthetic experiences

31. I _ Is sometimes shy, inhibited

32. almost everyone

33. __ Does things efficiently

34. situations

35. Prefers work that is routine

36. Is outgoing, sociable

37. Is sometimes rude to others

38. Makes plans and follows

through with them

39. __ Gets nervous easily

40. __ Likes to reflect, play with

ideas

41. ___ Has few artistic interests

42. L__ Likes to cooperate with others

43. __ Is easily distracted

44. Is sophisticated in art, music, or literature 
INTRODUCTORY E-MAIL

\section{Dear Bowen Center Clinician}

I am a Licensed Mental Health Counselor working on my Doctoral Dissertation in the School of education at Andrews University, Berrien Springs, Michigan. If you are over the age of 18 , I am inviting you to volunteer in a study that will improve our understanding of job satisfaction in the workplace. Unfortunately, if you're under the age of 18 you are not eligible for the study.

The purpose of this study will be to determine the personality type of individuals who are most satisfied in your particular work sector, adding to our understanding of John Holland's vocational theory concept of "congruence." Your responses will not be evaluated individually but instead combined with those of your peers to investigate the relationship among personality type, satisfaction, and personal demographics. This information will not necessarily be used by The Bowen Center to change their hiring process, internal promotion, or other decision-making processes but is being collected simply for the purpose of this study.

The attached forms should take about 10-15 minutes of your time. Please complete the materials as soon as possible and return via interdepartmental mail before May $16^{\text {th }}, 2014$. All information you provide will remain confidential. No identifying marks appear on the survey. Your responses will be combined with all of the returned responses so that only group scores will be analyzed. To maintain confidentiality please do not put your name on the instruments. Return the instruments via interdepartmental mail to "Robert Ryan, Warsaw" without your name or work area. 
While I encourage you to contribute to the better understanding of personality and job satisfaction, your participation is strictly voluntary. If you choose to return the completed instruments it will indicate you consent to your participation in the survey and you may keep this letter for informational purposes. If you have any questions you can call me directly at 574-527-2653. You may contact my advisor Dr. Dennis Waite, with questions at (269) 471-7771 or denniswaite@ phoenixconsultation.com. If you do not wish to participate, please mark the bottom of this form and return the materials to the sender. Thank-you for your time and consideration.

Sincerely,

Robert Ryan, Ed.S. LMHC

Doctoral Candidate

I do not wish to participate in this study 


\section{APPENDIX D}

\section{FOLLOW-UP REMINDER}

Dear *

I hope that you have received all the information for my study on personality and job satisfaction among you and your peers. If you have already completed and returned the instruments, thank-you. If you have not had the opportunity as of yet, please take a few minutes to complete it as soon as possible but before May $16^{\text {th }}, 2014$. If you have not received the above mentioned materials, please call me at (574) 527-2653, and I will get you another copy immediately. Thank-you again for your cooperation and contribution to research in this field.

Robert Ryan, Ed.S. LMHC

Andrews University

Doctoral Candidate 
APPENDIX E

RESEARCH PROTOCOL

\title{
JOB SATISFACTION AS A FUNCTION OF THE FIVE-FACTOR MODEL OF PERSONALITY
}

by

\author{
Robert Ryan, Counseling Psychology, Doctorial Candidate
}

This research proposal compliments previous research which has revealed a positive correlation between certain Big Five personality type indicators and job satisfaction in several sectors (Baysinger, 2004; Tanoff, 1999). The research population for this study consisted of bachelor, masters, and $\mathrm{Ph} . \mathrm{D}$. level clinicians and variously degreed administrative personnel. The Big Five Indicator (BFI), a 44-item instrument with five scales, and the Job Satisfaction Survey (JSS), a 36-item instrument with nine scales, will be used to measure the relationship between personality and job satisfaction while controlling for demographic variables.

\section{Objectives}

The purpose of this study was to examine the relationship between the Big Five personality type indicators and job satisfaction in a community mental health center. 


\section{Background and Rationale}

The focus of this study was to gain a better understanding of how not-for-profit community mental health centers can benefit from the use of a brief personality instrument in recruiting and promoting individuals with the highest probability of satisfaction. Additionally, the study will add to the understanding of the idea of “congruence" originally postulated by John Holland. Holland's theory focused on person/job fit which over the years has developed into matching personality to job type. This study will expand the literature by determining not just guiding individuals to occupations that have like personalities but occupations with like personalities with the highest job satisfaction. The study will be utilized to investigate the relationship among personality type, satisfaction, and personal demographics.

The information found will not necessarily be used by the respondent's corporation to change their hiring process, internal promotion, or other decision making processes but is being collected simply for the purpose of this study. The information will only be shared with the company after the data has been collected and analyzed. They will not receive a copy of the individual data sets.

\section{Procedures}

\section{Research Design}

\section{Population and Sample}

The Bowen Center is a community mental health center based in Warsaw Indiana. The Bowen Center employees over 482 fulltime equivalent staff working in the outpatient setting ranging from psychiatrists to administrative support staff. The Center

provides the full continuum of mental health services ranging from adult inpatient unit to 
outpatient therapy. The study will focus on the clinical and support staff in only the outpatient offices in all 10 counties. These offices are located in Marshall, Kosciusko, Wabash, Huntington, Whitley, Lagrange, Steuben, Dekalb, Noble, and Allen County. The population will include roughly 93 master's level clinicians, 257 bachelors level Homebased clinicians, and 37 client services staff.

\section{Measurement/Instrumentation}

The sample will be asked to complete a demographics form (attached), The Big Five Indicator (attached), and the Job Satisfaction Survey: Version 44 (attached). Demographics Form

The participants will be asked to identify personal characteristics including their age category, level of education, gender, ethnicity, and marital status. Occupational characteristics will also be collected including years in current role, years in the company, job classification, and occupational area.

Big Five Indicator

The Big Five Inventory (BFI): Version 44 (V44) was created by John, Donahue, and Kentle (1991) from the University of California, Berkeley. It is a brief although complete measure of the five-factor model of personality. John, Naumann, and Soto (2008) touted the BFI as an instrument that "allows efficient and flexible assessment of the five dimensions when there is no need for more differentiated measure of individual facets." The psychometric features of the BFI have been thoroughly researched. Alpha reliabilities ranged from .75 to .90 with an average above .80 . Retest reliabilities ranged from .80 to .90 with a mean of .85 (John et al., 2008). The BFI was also tested for its 
validity through peer-ratings with scales correlated at .47 in a college sample and at .61 across family members in a community setting (John et al., 2008).

The BFI is available from the Berkeley Personality Lab at the University of California, Berkeley. The authors indicate the BFI is "freely available for researchers to use for non-commercial research purposes."

\section{Job Satisfaction Survey}

The Job Satisfaction Survey (JSS) was selected because it is a multidimensional instrument that was originally used in the social services sector but proven statistically sound in multiple areas including manufacturing (Spector, 2008). The instrument is comprised of 38 items. Each item has the same stem which is "how satisfied are you with "this aspect" of your job?" Respondents are asked to rate their degree of job satisfaction on a 5-point Likert scale. This scale ranges from "very dissatisfied" to "very satisfied." The JSS measures five work factors: personnel satisfaction, workload, professional support, salary, and prospects and training. Subfactors represented in the instrument include work content, communication, financial rewards, promotion, coworkers, meaningfulness, supervision, work load, work demands, and satisfaction "total".

\section{Detailed Study Procedures}

The subjects will include all available clinicians and support staff from within The outpatient operations of The Bowen Center Corporation. Mary Gerard, the Vice President of Human Resources, will be sending the instruments to the potential subjects via interdepartmental mail. The instructions that will be provided are attached to the HR application. The subjects will be made clear within the in survey packet that their 
participation is voluntary and no compensation will be given for their participation beyond the satisfaction of contributing to the expanse of knowledge and a brief follow-up summary of the findings for those interested.

With regard to privacy, to assure the confidentiality for each respondent, the survey packet will be delivered to the respondent via interdepartmental mail, completed, and returned to myself via anonymous interdepartmental mail. These instructions will be clearly spelled out on the consent/instructions form (see attached document). No personal contact between the researcher and respondents will take place. The only contact will be if the respondent has questions, the researcher has provided his contact number (including the name of his Co-chair if needed).

\section{Internal Validity}

The researcher is employed as Vice President of Integrative Care at the Bowen Center. To avoid potential conflict of interest, I was asked to go through all of our normal internal policies and procedures with regard to completing research with the Center. I made a presentation to our Research Committee which is a subcommittee to our Clinical Staff Organizational Executive Committee. Internally all studies must meet the minimum standards put forth by The Joint Commission which accredits the Center.

The respondents will be protected by anonymity provided through the instrument package. Although the demographic sheet and instruments will be stapled together, no other matching of respondent will be made. 


\section{Data Analysis}

This study best fits into the category described as a correlational field research study. This design, presented in the attached document provides for a high degree of external validity based on real world setting and participants. Inferences about the relation between variables will be discussed, but the causal inferences among variables cannot be determined as this is a correlational research project. Multiple independent variables will used, including the five personality factors, gender, age, education, marital status, ethnicity, years with the company, years in occupation, pay, and whether there were recent or impending layoffs. The dependent variable is job satisfaction as presented by the general Job Satisfaction Survey (see attached).

The analysis of the data will focus on the relationship between job satisfaction and Big Five traits controlling for the above-mentioned demographic variables. The associations will be presented across and within the sub-groups as defined by occupational areas and job classifications and the Big Five type indicators. An ANCOVA analysis will then be utilized to examine the multivariate effects in the same sub-groups and the overall participant pool. There is little evidence that ordered variables would be necessary or beneficial based on previous research. 
REFERENCE LIST 


\section{REFERENCE LIST}

Adams, J. S. (1963). Toward an understanding of inequity. Journal of Abnormal and Social Psychology, 67(5), 422-436.

Ajila, C., \& Abiola, A. (2004). Influence of rewards on workers' performance in an organization. Journal of Social Science, 8(1), 7-12.

Al-Witri, F. Z. (2016). The dispositional theory of causation (Doctoral thesis). Columbia University. Retrieved from http://dx.doi.org/10.7916/D8Q240HG

Altmaier, E. M., \& Hansen, J.-I. C. (2012). The Oxford handbook of counseling psychology. Oxford: Oxford University Press.

Andrews, F.M., \& Withey, S.B. (1976). Social indicators of well-being: Americans' perceptions of life quality. New York: Plenum Press.

Armstrong, M. (2010). A handbook of human resource management practice (10th ed.). London: Kogan Page.

Ashton, M. C. (2013). Individual differences and personality (2nd ed.). New York: Academic Press.

Baker, W.K. (2011). Antecedents and consequences of job satisfaction: Testing a comprehensive model using integrated methodology. Journal of Applied Business Research, 20(3), 31-43.

Bakotić, D. (2016). Relationship between job satisfaction and organizational performance, Economic Research-Ekonomska Istraživanja, 29(1), 118-130.

Barak, A., Librowsky, I., \& Shiloh, S. (1989). Cognitive determinants of interests: An extension of a theoretical model and initial empirical examinations. Journal of Vocational Behavior, 34, 318-334.

Bashir, M., Jianqiao, L., Jun, Z., Ghazanfar, F., \& Khan, M. M. (2011). The role of demographic factors in the relationship between high performance work system and job satisfaction: A multidimensional approach. International Journal of Business and Social Science, 2(18), 207-218.

Baxamusa, B. N. (2016, August 5). Equity theory of motivation in a way no one ever put forth. Retrieved from http://www.buzzle.com/articles/equity-theory-ofmotivation.html 
Beeson, P. G., Johnson, D. R., \& Ortega, S. T. (1991). The farm crisis and mental health: A longitudinal (1981, 1986, 1989) and comparative study of the economy and mental health status. Unpublished manuscript.

Beheshtifar, M., Hoseinifar, H., \& Moghadam, M. (2011). Effect procrastination on work-related stress. European Journal of Economics, Finance and Administrative Sciences, 38, 59-64.

Bhattacharyya, D.K. (2009). Human resource research methods (2nd ed.). New Delhi: Excel Books.

Bloche, M.G., \& Cournos, F. (1990). Mental health policy for the 1990s: Tinkering in the interstices. Journal of Health Politics, Policy and Law, 15(2), 387-411.

Bookman, T., \& Carlson, B. (2013). State agrees to $\$ 30$ million settlement in mental health lawsuit. New Hampshire Public Radio. Available from https://www.nhpr.org/post/state-agrees-30-million-settlement-mental-healthlawsuit\#streatm/0

Bontis, N., Richards, D., \& Serenko, A. (2011). Improving service delivery: Investigating the role of information sharing, job characteristics, and employee satisfaction. The Learning Organization, 18(3), 239-250.

Bowen Center. (2018). History of the Bowen Center. Retrieved from http://www.bowencenter.org/about-bowen/history-of-bowen

Bowling, N. (2010, March). Effects of job satisfaction and conscientiousness on extrarole behavior. Journal of Business and Psychology, 25(1), 119-130.

Broadbridge, A., Maxwell, G., \& Ogden, S. (2007). Experiences, perceptions and expectations of retail employment for Generation Y. Career Development International, 12(6), 523-544.

Bryan, C., \& Sell, L. (2011). Job satisfaction, work environment, and rewards: Motivational theory revisited. Labour, 25(1), 1-23. http://dx.doi.org/10.1111/j.1467-9914.2010.00496.x

Buche, J., Beck, A., Page, C., Singer, P., \& Casemore, B. (2016). Behavioral health service delivery for vulnerable populations. Health Workforce Policy Brief. Available from http://www.behavioralhealthworkforce.org/wpcontent/uploads/2016/11/FA2P2_Vulnerable-Populations-Policy-Brief.pdf.

Buck, R. (1984). The communication of emotion. New York: Guilford Press. 
Cable, D.M., \& Judge, T.A. (1996). Person-organization fit, job choice decisions, and organizational entry. Organizational Behavior and Human Decision Process, 67, 294-311.

Carpenter, C., Bauer, T., \& Erdogan, B. (2010). Personality, attitudes, and work behaviors. Retrieved from http://courses.jonesinternational.edu/private/jiu/media/assets/978-1-4533-00909_Carpenter/978-1-4533-0090-9.carpenter.chapter.02.pdf

Cecil, H. F. (1988). Stress: Country Style: Illinois response to farm stress. Journal of Rural Community Psychology, 9(2), 51-60.

Celia, B. R. (2012). Impact of work-related demographic factors on job satisfaction of teaching staff in self-financing engineering colleges. International Journal of Exclusive Management Research, 2(3), 2249-2585.

Center for Substance Abuse Treatment. (2006). Substance abuse: Administrative issues in outpatient treatment. Rockville, MD: Substance Abuse and Mental Health Services Administration. Available from: https://www.ncbi.nlm.nih.gov/books/NBK64068/

Chartrand, J. M. (1991). The evolution of trait-and-factor career counseling: A person X environment fit approach. Journal of Counseling and Development, 69, 518-524.

Chris, A., \& Awonusi, A. (2004). Influence of rewards on workers' performance in an organization. Journal of Social Science, 8(1), 7-12.

Chu, F.D., \& Trotter, S. (1974). The madness establishment (Ralph Nader's study group report on the National Institute of Mental Health). New York: Grossman Publishers.

Cocker, F., Martin, A., Scott, J., Venn, A., \& Sanderson, K. (2013). Psychological distress, related work attendance, and productivity loss in small-to-medium enterprise owner/managers. International Journal of Environmental Research and Public Health, 10, 5062-5082. doi:10.3390/ijerph10105062

Cortese, C.G., Colombo, L., \& Ghislieri, C. (2010). Determinants of nurses' job satisfaction: The role of work-family conflict, job demand, emotional charge and social support. Journal of Nursing Management, 18(1), 35-43.

Cranny, C.J., Smith, P.C., \& Stone, E.F. (1992). Job satisfaction: How people feel about their jobs and how it affects their performance. New York: Lexington Books.

Crawford, E. R., LePine, J. A., \& Rich, B. L. (2010). Linking job demands and resources to employee engagement and burnout: A theoretical extension and meta-analytic test. Journal of Applied Psychology, 95(5), 834-848. 
Data Report: 2016 Indiana Mental Health Workforce Licensure Survey. (2017). The Bowen Center for Health Workforce Research and Policy. Indianapolis, IN: Indiana University School of Medicine. Available from http://hdl.handle.net/1805/13295

Deckert, J., \& Statz-Hill, J. (2016). Job satisfaction of peer providers employed in mental health centers: A systematic review. Social Work in Mental Health, 14(5), 564582 .

Denollet, J. (2013). Interpersonal sensitivity, social inhibition, and type D personality: how and when are they associated with health? Comment on Marin and Miller. Psychological Bulletin, 139(5), 991-997. doi:10.1037/a0033537

Diamond, P., Warner, D., \& Wong, P. (1998). Community mental health centers under managed care: Authority or provider? Lyndon B. Johnson School of Public Affairs, University of Texas at Austin.

Disley, P. (2009). Applying equity theory to staff working with individuals with intellectual disabilities. Intellectual and Developmental Disability, 34(1), 55-66.

Dorwart, R.A., \& Epstein, S.S. (1993). Privatization and mental health care: A fragile balance. Westport, CT: Auburn House.

Dowell, D.A., \& Ciarlo, J.A. (1983). Overview of the community mental health centers program from an evaluation perspective. Community Mental Health Journal, 19(2), 95-128.

Edwards, J. R. (2008). 4 Person-Environment Fit in organizations: An assessment of theoretical progress. The Academy of Management Annals, 2(1), 167-230.

Elkins, D. (2007). Empirically supported treatments: The deconstruction of a myth. Journal of Humanistic Psychology, 47, 474-500.

Erdheim, J., Wang, M., \& Zickar, M.J. (2006). Linking the Big Five personality constructs to organizational commitment. Personality and Individual Differences, 41, 959-970.

Eswaran, S., Islam, A., \& Yusuf, D. H. M. (2011). A study of the relationship between the Big Five personality dimensions and job involvement in a foreign-based financial institution in Penang. International Business Research, 4(4), 164-175. http://dx.doi.org/10.5539/ibr.v4n4p164

Farhadi, H., Fatimah, O., Nasir, R., \& Wan Shahrazad, W. S. (2012, July). Agreeableness and conscientiousness as antecedents of deviant behavior in workplace. Asian Social Science, 8(9), 2-7. 
Foley, H.A., \& Sharfstein, S.S. (1983). Madness and government: Who cares for the mentally ill? Washington, DC: American Psychiatric Press.

Friedman, R., Katz-Leavy, J., Manderscheid, R., \& Sondheimer, D. (1996). Prevalence of serious emotional disturbance in children and adolescents. In R. Manderscheid \& M Sonnenschein. Mental health, United States, 1996 (pp. 71-78). Rockville, MD: U.S. Department of Health and Human Services.

Furnham, A., Eracleous, A., \& Chamorro-Premuzic, T. (2009). Personality, motivation and job satisfaction: Hertzberg meets the Big Five. Journal of Managerial Psychology, 24(8), 765-779.

Furnham, A., Petrides, K.V., Tsaousis, I., Pappas, K., \& Garrod, D. (2005). A crosscultural investigation into the relationships between personality traits and work values. The Journal of Psychology, 139(1), 5-32.

Gangai, K.N., Agrawal, R., \& Gupta, M. (2015). Relationship between workplace motivation and absenteeism among employees in retail industry. Pezzottaite Journals, 4(3).

Ganu, D., \& Kogutu, C.N. (2014, December). Effect of the Big Five personality traits on job satisfaction and organizational commitment in the healthcare industry: The case of Kenya. American Journal of Health Sciences, 5(2), 145-154.

Ghinetti, P. (2007). The public-private job satisfaction differential in Italy. Labour, 21(2), 361-388. http://dx.doi.org/10.1111/j.1467-9914.2007.00375.x

Gogia, P. (2010, September 14). Equity theory of motivation. Retrieved from http://www.businessihub.com/equity-theory-of-motivation

Goldberg, L. R. (1993). The structure of phenotypic personality traits. American Psychologist, 48, 26-34.

Gottfredson, G. D., \& Holland, J. L. (1990). A longitudinal test of the influence of congruence: Job satisfaction, competency utilization, and counterproductive behavior. Journal of Counseling Psychology, 37, 389-398.

Grob, G.N. (1991). From hospital to community: Mental health policy in modern America. Psychiatric Quarterly, 62(3), 187-212.

Gronfein, W. (1985). Psychotropic drugs and the origins of deinstitutionalization. Social Problems, 32(5), 437-454. 
Gronholdt, L. (2001). Using employee satisfaction measurement to improve people management: An adaptation of Kano's quality types. Total Quality Management, 12(7), 949-958.

Halkos, G. (2008). The influence of stress and satisfaction on productivity. International Journal of Productivity and Performance Management, 59(5), 415-431.

Harpaz, I. (1990). The importance of work goals: An international perspective. Journal of International Business Studies, 21, 75-93. http://dx.doi.org/10.1057/palgrave.jibs.8490328

Hellerman, M., \& Kochanski, J. (2009, August 14). Beyond pay for performance: Countering the 'pay entitlement' mindset. Society for Human Resource Management. Retrieved from https://www.shrm.org/ResourcesAndTools/hrtopics/compensation/Pages/EntitlementPay.aspx

Herzberg, F. (1968, January). One more time: How do you motivate employees? Harvard Business Review, 81, 86-96.

Herzberg, F., Mausner, B., \& Snyderman, B.B. (1959). The motivation to work. New York: John Wiley \& Sons.

Hlatywayo, C.K., Mhlanga, T.S., \& Zingwe, T. (2013). Neuroticism as a determinant of job satisfaction among bank employees. Mediterranean Journal of Social Sciences, 4(13). doi: 10.5901/mjss.2013.v4n13p549

Hoboubi, N., Choobineh, A., Ghanavati, F.K., \& Keshavarzi, S. (2017, March). The impact of job stress and job satisfaction on workforce productivity in an Iranian petrochemical industry. Safety and Health at Work, 8(1), 67-71.

Hong, Y. (2009). The influence of perceived workplace spirituality on job satisfaction, intention to leave, and emotional exhaustion among community mental health center workers in the state of Kansas. Retrieved from:

https://kuscholarworks.ku.edu/bitstream/handle/1808/5712/Hong_ku_0099D_105 04_DATA_1.pdf?sequence=1

Hsieh, Y. H. (2011). Empirical study on personality traits, job satisfaction, and reward system preferences. African Journal of Business Management, 5(12), 4983-4992.

Hyde, P. (2013, January). Report to Congress on the nation's substance abuse and mental health workforce issues. Washington, DC: U.S. Department of Health and Human Services.

Ijaz, M., \& Khan, A. (2015). The relationship of Big Five personality traits with job satisfaction among banking employees (a case study of Askari Bank in District Peshawar). Journal of Applied Environmental and Biological Sciences, 5(5), 129 138. 
Jewell, L.N., \& Siegall, M. (1990). Contemporary industrial/organizational psychology. St. Paul, MN: West Publishing.

Jiang, J. (2000). Supervisor support and career anchor impact on the career satisfaction of the entry-level information systems professional. Journal of Management Information Services, 16(3), 219-241.

John, O. P., Donahue, E. M., \& Kentle, R. L. (1991). The Big Five Inventory--Versions $4 a$ and 54. Berkeley, CA: University of California, Berkeley, Institute of Personality and Social Research.

John, O. P., Naumann, L. P., \& Soto, C. J. (2008). Paradigm shift to the integrative bigfive trait taxonomy: History, measurement, and conceptual issues. In O. P. John, R. W. Robins, \& L. A. Pervin (Eds.), Handbook of personality: Theory and research (pp. 114-158). New York: Guilford Press.

John, O. P., \& Srivastava, S. (1999). The Big-Five trait taxonomy: History, measurement, and theoretical perspectives. In L. A. Pervin \& O. P. John (Eds.), Handbook of personality: Theory and research (Vol. 2, pp. 102-138). New York: Guilford Press.

Jones, N., Hill, C., \& Henn, C. (2015). Personality and job satisfaction: Their role in work-related psychological well-being. Journal of Psychology in Africa, 25(4), 297-304.

Judge, T., Bones, J., \& Illies, R. (2002). Personality and leadership: A qualitative and quantitative review. Applied Psychology, 87(1), 765-780.

Judge, T. A., Heller, D., \& Mount, M. K. (2002). Five-factor model of personality and job satisfaction: A meta-analysis. Journal of Applied Psychology, 87, 530-541.

Judge, T., Klinger, R., \& Heller, D. (2008). The dispositional sources of job satisfaction: A comparative test. Applied Psychology: An International Review, 57(3), 361372 .

Judge, T., Locke, E., Durham, C., \& Kluger, A. (1998). Dispositional effects on job and life satisfaction: The role of core evaluations. Journal of Applied Psychology, 83(1), 17-34.

Kahya, E. (2007). The effect of job characteristics and working conditions on job performance. International Journal of Industrial Ergonomics, 37, 515-523. http://dx.doi.org/10.1016/j.ergon.2007.02.006

Kappagoda, S. (2012). The impact of five-factor model of personality on job satisfaction of non-academic employees in Sri Lankan universities. South East Asian Journal of Contemporary Business, Economics and Law, 1, 1-7. 
Kermani, Z. Z. (2013). A study of the linking between job satisfaction and customer satisfaction: A case study of Iran Insurance; Kerman; Iran. Journal of Marketing Development and Competitiveness, 7(4), 104-109.

Kerr, B., \& McKay, R. (2013). Searching for tomorrow's innovators: Profiling creative adolescents. Creativity Research Journal, 25(1), 21-32. http://dx.doi.org/10.1080/10400419.2013.752180

Kumar, K., \& Bakhshi, A. (2010). The five-factor model of personality and organizational commitment: Is there any relationship? Humanity and Social Sciences Journal, 5(1), 25-34.

Kuranchie-Mensah, E.B., \& Amponsah-Tawiah, K. (2016). Employee motivation and work performance: A comparative study of mining companies in Ghana. Journal of Industrial Engineering and Management, 9(2), 255-309.

http://dx.doi.org/10.3926/jiem.1530

Lambert, D., Hartley, D., Bird, D., Ralph, R., \& Saucier, P. (1998). Medicaid mental health carveouts: Impact and issues in rural areas (Working Paper No. 9).

Portland, ME: Maine Rural Health Research Center.

Lambert, E., Hogan, N., \& Barton, S. (2001). The impact of job satisfaction on turnover intent: A test of structural measurement model using a national sample of workers. Social Science Journal, 38(2), 233-251.

Langer, C. L., \& Lietz, C. A. (2015). Applying theory to generalist social work practice: A case study approach. Hoboken, NJ: John Wiley \& Sons.

Leite, N., Rodrigues, A., \& Albuquerque, L. (2014, October/December). Organizational commitment and job satisfaction: What are the potential relationships? Brazilian Administration Review, 11(4). Retrieved from: http://www.scielo.br/scielo.php?script=sci_arttext\&pid=S180776922014000400476

Levine, T. \& Hullett, C. (2002). Eta squared, partial eta squared, and misreporting of effect size in communication research. Human Communication Research, 28(4), 612-625.

Levine, V. (1981). The role of outcomes in cost-benefit evaluation. New Directions for Evaluation, 9, 21-40.

Levy, J.J., \& Lounsbury, J.W. (2010, August). Big Five personality traits and performance anxiety in relation to marching arts satisfaction. Poster presentation at the annual convention of the American Psychological Association, San Diego, CA. 
Liu, C., Zhang, L., Ye, W., Zhu, J., Cao, J., Lu, X., \& Li, F. (2012). Job satisfaction and intention to leave: A questionnaire survey of hospital nurses in Shanghai of China. Journal of Clinical Nursing, 21(1-2), 255-263.

Lu, H., Barriball, K.L., Zhang, X., \& While, A. E. (2012). Job satisfaction among hospital nurses revisited: A systematic review. International Journal of Nursing Studies, 49(8), 1017-1038.

Masindi, T. (2015). The influence of job satisfaction and organizational commitment on turnover intention. Retrieved from:

http://digitalknowledge.cput.ac.za/jspui/bitstream/11189/3212/1/201018225_masi ndi_te_mtech_bus_admin_bus_2015.pdf

McCrae, R. R., \& Allik, J. (2012). The five-factor model of personality across cultures. New York: Springer Science \& Business Media.

McDougall, W. (2016). Character and the conduct of life: Practical psychology for everyman. New York: Routledge.

Mechanic, D. (1994). Integrating mental health into a general health care system. Psychiatric Services, 45(9), 896-897.

Mihalcea, A. (2013). The impact of leader's personality on employees' job satisfaction. Procedia-Social and Behavioral Sciences, 78(13), 90-94.

http://dx.doi.org/10.1016/j.sbspro.2013.04.257

Mohan, G., \& Mulla, Z.R, (2013, September). Openness to experience and work outcomes: Exploring the moderating effects of conscientiousness and job complexity. Tata Institute of Social Sciences, 7(2), 1-36. Retrieved from http://www.zubinmulla.com/gouri.pdf

Mursali, A., Basuki, E., \& Dharmono, S. (2009). Relationship between noise and job stress at a private thread spinning company. Universa Medicina, 28(1), 8-16.

Nabi, G.R. (2000). Motivational attributes and organizational experiences as predictors of career-enhancing strategies. Career Development International, 5(2), 91-98. http://dx.doi.org/10.1108/13620430010318963

Nielsena, M.B., Glasøc, L., \& Einarsenb, S. (2017, January). Exposure to workplace harassment and the Five Factor Model of personality: A meta-analysis. Personality and Individual Differences, 104, 195-206.

Ongore, O. (2014, August 25). A study of relationship between personality traits and job engagement. Procedia-Social and Behavioral Sciences, 141, 1315-1319. 
O'Toole, J. (1973). Work in America: Report of a special task force to the Secretary of Health, Education, and Welfare. Washington, DC: The MIT Press. Available from https://files.eric.ed.gov/fulltext/ED070738.pdf

Parsons, F. (1909). Choosing a vocation. Boston: Houghton Mifflin.

Peiser, C., \& Meir, E. (1978). Congruency, consistency, and differentiation of vocational interests as predictors of vocational satisfaction and preference stability. Journal of Vocational Behavior, 12, 270-278.

Pervin, L. A., \& John, O. P. (1997). Personality: Theory and research (7th ed.). New York: John Wiley \& Sons.

Platisa, C., Reklitisb, P., \& Zimerasc, S. (2015, February 12). Relation between job satisfaction and job performance in healthcare services. Procedia-Social and Behavioral Sciences, 175, 480-487.

Porter, L.W., Steers, R.M., Mowday, R.T., \& Boulian, P.V. (1974). Organizational commitment, job satisfaction, and turnover among psychiatric technicians. Journal of Applied Psychology, 59(5), 603-609.

Pseekos, A.C. (2009). The effect of Holland's person-environment fit on trait anger, interpersonal conflict at work, and workplace aggression. Unpublished doctoral dissertation, University of Southern Mississippi.

Redmond, B.F. (2013). Lesson 5: Equity theory: Is what I get for my work fair compared to others? Work attitudes and motivation. The Pennsylvania State University World Campus. Available from https://wikispaces.psu.edu/display/PSYCH484001SP17/5.+Equity+Theory

Reimers, B. (2001). Keep talent from taking flight. Network Computing, 12(16), 42-45.

Reio, G.T., \& Callahon, J.L. (2004). Affect, curiosity, and socialization-related learning: A path analysis of antecedents to job performance. Journal of Business and Psychology, 19, 3-22. http://dx.doi.org/10.1023/B:JOBU.0000040269.72795.ce

Ren, T. (2010). Value congruence as a source of intrinsic motivation. Kyklos, 63(1), 94109. http://dx.doi.org/10.1111/j.1467-6435.2010.00462.x

Richard, A. (2013). Job satisfaction from Herzberg's two-factor theory perspective. Munich: GRIN Verlag GmbH.

Robbins, S.P. (2005). Organizational behavior. Upper Saddle River, NJ: Pearson Prentice Hall. 
Rochefort, D. (1984). Origins of the "Third psychiatric revolution": The Community Mental Health Centers Act of 1963. Journal of Political Policy Law, 9(1) 1-30.

Saeed, I., Waseem, M., Sikander, S., \& Rizwan, M. (2014). The relationship of turnover intention with job satisfaction, job performance, leader member exchange, emotional intelligence and organizational commitment. International Journal of Learning \& Development, 4(2), 242-256.

Salyers, M.P., Rollins, A.L., Kelly, Y.-F., Lysaker, P.H., \& Williams, J.R. (2013, March). Job satisfaction and burnout among VA and community mental health workers. Administration and Policy in Mental Health Services Research, 40(2), 69-75. doi:10.1007/s10488-011-0375-7.

SAMSHA. (2012). Mental Health, United States, 2010 (NSDUH Series H-42, HHS Publication No. SMA 12-4681). Rockville, MD: Substance Abuse and Mental Health Services Administration. Available from https://www.samhsa.gov/data/sites/default/files/MHUS2010/MHUS2010/MHUS2010.pdf

Schmitt, N. (2012). The Oxford handbook of personnel assessment and selection. New York: Oxford University Press.

Schnapp, W. B., Bayles, S., Raffoul, P. R., \& Schnee, S. B. (1999). Privatization and the rise and fall of the public mental health safety net. Administration and Policy in Mental Health, 26(3), 221-225.

Scott, M., Swortzel, K. A., \& Taylor, W. N. (2005). The relationships between selected demographic factors and the level of job satisfaction of extension agents. Journal of Southern Agricultural Education Research, 55(1), 102-115. http://dx.doi.org/10.5032/jae.2005.03002

Sergiovanni, T. J. (1966). Investigation of factors which affect job satisfaction and job dissatisfaction of teachers. Journal of Management , 28, 23-25.

Shin, P., \& Mauery, D. (2013). The role of community health centers in providing behavioral health care. Journal of Behavioral Health Services \& Research. 40, 488-496. https://doi.org/10.1007/s11414-013-9353-z

Sibson Consulting. (2009). Insights into employee satisfaction, engagement and retention from Sibson's rewards of work study. 2009 Rewards of Work Study. Retrieved from http://www.sibson.com/media/1609/2009row.pdf

Silverman, W. H. (1980). Trainee-designed continuing education in community mental health. Professional Psychology, 11(1), 24-30. 
Spector, P. (1985). Measurement of human service staff satisfaction: Development of the Job Satisfaction Survey. American Journal of Community Psychology, 13, 693713.

Spector, P. (1998). Job satisfaction: Application, assessment, counseling, and consequences. Thousand Oaks, CA: Sage.

Spector, P. (2008). Introduction: On making a life in the organizational sciences. Journal of Organizational Behavior, 29(6), 731-732.

STATS Indiana. (2017). STATS Indiana labor force overview (SA). Retrieved from http://www.stats.indiana.edu/laus_sa/laus_view1.html

Tanoff, G. (1999). Job satisfaction and personality: The utility of the five-factor model of personality. Portland, OR: University of Oregon Press.

Templer, K.J. (2012, January). Five-factor model of personality and job satisfaction: The importance of agreeableness in a tight and collectivistic Asian society. International Association of Applied Psychology, 61(1), 114-129.

Tesdimir, Z.M., Asghar, M.Z., \& Saeed, S. (2016). Study of the relationship of personality traits and job satisfaction among professional sales representatives in the pharmaceutical industry in Turkey. In Proceedings of 2 nd International Conference on Business Management. Retrieved from https://www.google.com/url?sa=t\&rct=j\&q=\&esrc=s\&source=web\&cd=3\&cad=rj a\&uact=8\&ved=0ahUKEwjQ3NHEs6nVAhVRlxQKHZk2CGoQFgg2MAI\&url= http $\% 3 \mathrm{~A} \% 2 \mathrm{~F} \% 2 \mathrm{Fwww}$.umt.edu.pk\%2Ficobm2012\%2Fpdf\%2F2C100P.pdf\&usg=AFQjCNEpJ6L6lHrkLANYZfgMdz9mLz_VjQ

Thomas, A., \& Chess, S. (1977). Temperament and development. New York: Brunner/Mazel.

Tnay, E., Othman, A.E.A., Siong, H.C., \& Lim, S. (2013, November 6). The influences of job satisfaction and organizational commitment on turnover intention.

Procedia-Social and Behavioral Sciences, 97, 201-208.

Vaessen, T. (2010). Individual dispositions and job satisfaction. Retrieved from: https://www.google.com/url?sa=t\&rct=j\&q=\&esrc=s\&source=web\&cd=4\&cad=rj a\&uact=8\&ved=0ahUKEwjUqvGHtafV AhWEchQKHTkaDeIQFghEMAM\&url= http\%3A\%2F\%2Farno.uvt.nl\%2Fshow.cgi\%3Ffid\%3D121858\&usg=AFQjCNEY cdkC9cNcBC4BS5H6JLpyBq4jkg

Van der Doef, M., Mbazzi, F. B., \& Verhoeven, C. (2012). Job conditions, job satisfaction, somatic complaints and burnout among East African nurses. Journal of Clinical Nursing, 21(11-12), 1763-1775. 
Van Vuuren, M. (2017). Called to do meaningful work: A blessing or a curse? Christian Higher Education, 16(1-2), 47-54. Available from https://doi.org/10.1080/15363759.2017.1251245

Wagenfeld, M.O., Murray, J.D., Mohatt, D.F., \& DeBruyn, J.C. (Eds.). (1994). Mental health and rural America: 1980-1993 (NIH Publication No. 94-3500). Washington, DC: US Government Printing Office.

Whysall, P., Foster, C., \& Harris, L. (2009). Job dissatisfaction among retail employees: A study of three leading UK retailers. The International Review of Retail, Distribution and Consumer Research, 19(2), 179-198.

Wiener, Y., Vardi, Y., Muczyk, J. (1981). Antecedents of employees' mental health: The role of career and work satisfaction. Journal of Vocational Behavior, 19(1), 5060 .

Wiggins, J, D., Lederer, D. A., Salkowe, A., \& Rys, G. S. (1983). Job satisfaction related to tested congruence and differentiation. Journal of Vocational Behavior, 23, 112121.

Wilson, G. (2010). The effects of external rewards on intrinsic motivation. Retrieved from http://www.abcbodybuilding.com/rewards.pdf

Yahaya, A., Yahaya, N., Ismail, J., Sharif, Z., Saud, M.S., Mohd, K., . . Abbas, F. (2011, June 4). Effects of personality trait, motivation factors on performance of customer service personnel (CSP): A case of MPH bookstores. African Journal of Business Management, 5(11), 4519-4530.

Zhai, Q., Smyth, R., Nielsen, I., \& Luan, X. (2009, September 14-16). The role of positive and negative affectivity on job satisfaction and life satisfaction. In 2009 International Conference on Management Science \& Engineering. doi:10.1109/ICMSE.2009.5318066.

Zhai, Q., Willis, M., O'Shea, B., Zhai, Y., \& Yang, Y. (2014, February 5). Big Five personality traits, job satisfaction and subjective well-being in China. International Journal of Psychology, 48(6). doi:10.1080/00207594.2012.732700

Zitny, P., \& Halama, P. (2011). Self-esteem, locus of control and personality traits as predictors of sensitivity to injustice. Studia Psychologica, 53(1), 27-40.

Zunker, V.G. (2002). Career counseling: Applied concepts of life planning. Pacific Grove, CA: Brooks/Cole. 